Award Number: W81XWH-07-1-0330

TITLE: Estrogen and the Dietary Phytoestrogen Resveratrol as Regulators of the Rho GTPase Rac in Breast Cancer Metastasis

PRINCIPAL INVESTIGATOR: Suranganie Dharmawardhane, Ph.D.

CONTRACTING ORGANIZATION: University of Puerto Rico Medical Sciences Campus San Juan, PR 00936

REPORT DATE: September 2011

TYPE OF REPORT: Final

PREPARED FOR: U.S. Army Medical Research and Materiel Command Fort Detrick, Maryland 21702-5012

DISTRIBUTION STATEMENT: Approved for Public Release;

Distribution Unlimited

The views, opinions and/or findings contained in this report are those of the author(s) and should not be construed as an official Department of the Army position, policy or decision unless so designated by other documentation. 


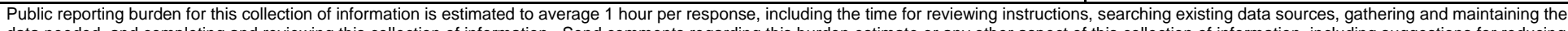

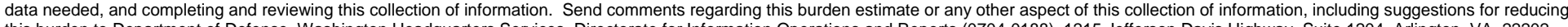

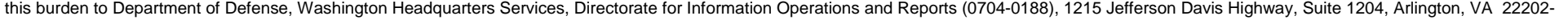

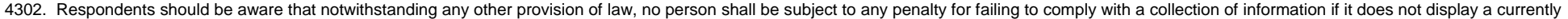
valid OMB control number. PLEASE DO NOT RETURN YOUR FORM TO THE ABOVE ADDRESS.

\begin{tabular}{l|l} 
1. REPORT DATE & 2. REPORT TYPE
\end{tabular}

September 2011 Final

4. TITLE AND SUBTITLE

3. DATES COVERED

1 June $2007-22$ August 2011

Estrogen and the Dietary Phytoestrogen Resveratrol as Regulators of the Rho GTPase Rac in Breast Cancer Metastasis

5a. CONTRACT NUMBER

5b. GRANT NUMBER

W81XWH-07-1-0330

5c. PROGRAM ELEMENT NUMBER

\section{AUTHOR(S)}

Suranganie Dharmawardhane, Ph.D.

5d. PROJECT NUMBER

5e. TASK NUMBER

5f. WORK UNIT NUMBER

E-Mail: su.d@upr.edu

7. PERFORMING ORGANIZATION NAME(S) AND ADDRESS(ES)

University of Puerto Rico Medical Sciences Campus

San Juan, PR 00936

8. PERFORMING ORGANIZATION REPORT NUMBER

9. SPONSORING I MONITORING AGENCY NAME(S) AND ADDRESS(ES)

10. SPONSOR/MONITOR'S ACRONYM(S)

U.S. Army Medical Research and Materiel Command

Fort Detrick, Maryland 21702-5012

11. SPONSOR/MONITOR'S REPORT NUMBER(S)

12. DISTRIBUTION I AVAILABILITY STATEMENT

Approved for Public Release; Distribution Unlimited

\section{SUPPLEMENTARY NOTES}

\section{ABSTRACT}

ABSTRACT: The hypothesis that estrogen and low concentrations of resveratrol promote breast cancer invasion and metastasis while high concentrations of resveratrol prevent breast cancer metastasis via regulation of Rac was tested. Results from Specific Aim 1 demonstrated that dependent on estrogen receptor (ER) status, E2 and resveratrol have differential effects on Rac activity, cell migration/invasion, and cell growth. Specific Aim 2, we tested the effect of resveratrol on mammary tumor growth and metastasis. At all concentrations tested, resveratrol increased mammary tumor growth and lung metastasis and enhanced Rac activity. Since the Rac activity of breast cancer cells could not be inhibited by a commercially available Rac inhibitor NSC-23766, we developed novel Rac inhibitors as anti breast cancer metastasis compounds (Hernandez, et al., 2010, Montalvo et al., in review). Resveratrol in combination with other grape polyphenols reduced breast cancer growth and metastasis to bone and liver by inhibition of PI3-K signaling (Castillo et al., 2009; Castillo et al., in review).

15. SUBJECT TERMS

Estrogen, resveratrol, breast cancer, metastasis, Rac

\begin{tabular}{|c|c|c|l|l|l|}
\hline \multicolumn{2}{|l|}{ 16. SECURITY CLASSIFICATION OF: } & $\begin{array}{l}\text { 17. LIMITATION } \\
\text { OF ABSTRACT }\end{array}$ & $\begin{array}{l}\text { 18. NUMBER } \\
\text { OF PAGES }\end{array}$ & $\begin{array}{l}\text { 19a. NAME OF RESPONSIBLE PERSON } \\
\text { USAMRMC }\end{array}$ \\
\cline { 1 - 2 } $\begin{array}{c}\text { a. REPORT } \\
\text { U }\end{array}$ & $\begin{array}{c}\text { b. ABSTRACT } \\
\text { U }\end{array}$ & c. THIS PAGE & UU & $\begin{array}{l}\text { 19b. TELEPHONE NUMBER (include area } \\
\text { code) }\end{array}$ \\
& & & \\
\end{tabular}




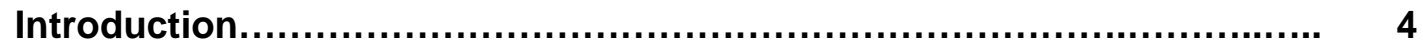

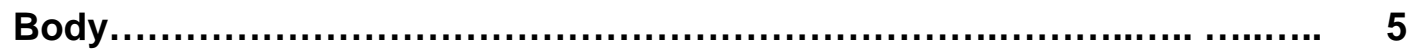

Key Research Accomplishments....................................... 12

Reportable Outcomes........................................................ $\quad 13$

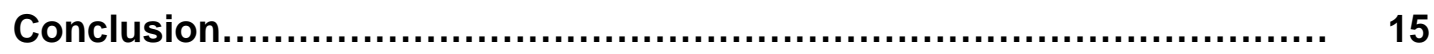

References.................................................................... 16

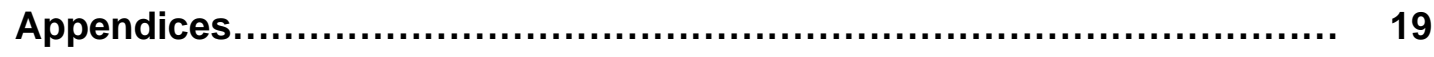




\section{INTRODUCTION}

The focus of this research project is the role of the hormone estrogen $\left(E_{2}\right)$ and the structurally similar natural compound resveratrol on breast cancer invasion and metastasis. $\mathrm{E}_{2}$ is important for initiation and progression of breast cancers [1;2;2]. Increased estrogen receptor (ER) $\alpha$ levels are associated with $50-80 \%$ of breast tumors and inhibition of ER $\alpha$ has become a major strategy for prevention and treatment of breast cancer [3-6]. During breast cancer progression, cancer cells become resistant to antiestrogen therapy because malignant breast cancers express only ER $\beta$ or no ER and overexpress EGFR isoforms EGFR1 or Her-2 [7]. Therefore, it is important to test alternative therapies that can be used effectively to treat ER (-) breast cancer.

Dietary consumption of grapes has for long been associated with a decrease in the incidence of cardiovascular diseases and cancer. The beneficial properties of grapes and its products are attributed to polyphenolic compounds, and ascribed to their antioxidant, cardioprotective, neuroprotective, anticancer, antiinflammation, antiaging, and antimicrobial properties [8;9]. Among grape and red wine polyphenols, resveratrol (3,4',5-trihydroxy-trans-stilbene) has received a great deal of attention due to a plethora of studies suggesting that resveratrol imparts cancer chemopreventive and therapeutic responses [10]. Resveratrol is structurally similar to $E_{2}$ and interacts with both $E R \alpha$ and $E R \beta$ but with 7,000-fold lower affinity than $E_{2}$ [11-14]. Resveratrol has proapoptotic, antigrowth, anti-inflammmatory, antiangiogenic, and anti-invasive properties that makes it an attractive anticancer compound [15-17].

Among the mediators of resveratrol's anticancer effects, the most widely studied are the mitogen activated protein kinase (MAPK), phosphoinositide 3-kinase (PI3-K)/Akt, and nuclear factor kappa B (NFkB) pathways [18;19]. It has been shown that resveratrol-mediated regulation of extracellular regulated kinase (ERK), c-Jun N-terminal kinase (JNK), and p38 MAPKs promotes apoptosis of breast cancer cells [20-22]. Resveratrol inhibited cell proliferation and ER $\alpha$ mRNA and protein levels in MCF-7 breast cancer cells through a mechanism dependent on p38 MAPK and p53 regulation [23]. In addition to inhibition of cancer initiation and progression, resveratrol has also been implicated in reduction of metastasis. Resveratrol has been shown to inhibit metastasis in colorectal cancer and melanoma [24;25]. Moreover, resveratrol is able to chemosensitize several types of cancers to chemotherapy. Its potential as a chemosensitization agent is due to the regulation of many signaling molecules including drug transporters, cell survival and cell proliferation regulators, and members of the NFkB and signal transducer and activator of transcription (STAT)3 signaling pathways [26]. However, most studies on the anti-cancer activities of resveratrol have focused on high, non-physiologically relevant, concentrations; whereas the effects of low dietary concentrations on cancer progression have been poorly studied.

Much of the data on potential anticancer properties of resveratrol are from in vitro studies using high concentrations of resveratrol ranging from 30-200 $\mu \mathrm{M}$ [27-33]. Because of its low bioavailability and since resveratrol's dual estrogenic/antiestrogenic role seems to be a concentration dependent feature, it is important to delineate its anticancer effects at a broad range of concentrations. We and others have shown that resveratrol at $50 \mu \mathrm{M}$ can inhibit cell migration and invasion [34-37]. Our group has shown that depending on the concentration, resveratrol can act as an estrogenic or anti-estrogenic compound. We demonstrated that $E_{2}$ and resveratrol regulate actin structures and focal adhesions, both relevant for breast cancer cell migration and invasion, and the related activation of the small GTPase Rac [34;38]. For these cell functions, we observed an inhibitory role for high concentrations of resveratrol and a promotional role for $\mathrm{E}_{2}$ and low concentrations of resveratrol [34;39]. Resveratrol is known to exert biphasic effects where low concentrations are estrogenic while high concentrations are antiestrogenic [28;30;40;41]. However, the effects of resveratrol in ERọ(-) or $\mathrm{ER} \alpha \beta(-)$ breast cancers are not well understood.

Therefore, the purpose of this study was to investigate the effects of resveratrol on breast cancer progression in metastatic breast cancers that have lost ER $\alpha$. We and others have demonstrated that activity of the Rho GTPase Rac is necessary for breast cancer invasion and metastasis [42;43]. Our preliminary data demonstrated that the effects of $\mathrm{E}_{2}$ and resveratrol on cell functions relevant for metastasis such as actin cytoskeletal rearrangement to form motile structures, cell migration, and invasion may be mediated by the action of Rac. Therefore, we tested the hypothesis that high concentrations of resveratrol prevent breast cancer invasion and metastasis while $\mathrm{E}_{2}$ and low concentrations of resveratrol promote breast cancer invasion and metastasis via Rac-regulated mechanisms. 


\section{BODY}

Since funding of this award, the origin of the MDA-MB-435 cell line has been called into question by studies that show expression of melanoma-associated genes in this cell line [44]. However, MDA-MB-435 cells are derived from a breast cancer patient, express breast differentiation-specific proteins, and secrete milk lipids [45]. Therefore, the simplest conclusion is that MDA-MB-435 is a very poorly differentiated breast carcinoma. A recent publication supports this idea by providing evidence that suggests the MDA-MB-435 cell line is indeed a poorly differentiated, aggressive breast cancer cell line that expresses both epithelial and melanocytic markers [46]. Since we proposed to use this cell line in the original proposal, and have $100 \%$ success with obtaining mammary fat pad tumors and metastases with this cell line, we continued to use both the established breast cancer cell line MDA-MB-231 and MDA-MB-435 cells for this investigation.

\section{Summary of Progress: Table 1: Determination of the effect of resveratrol on metastatic breast cancer cell lines in vitro (Specific Aim 1, presented in annual reports for 2007-2009) and in vivo (Specific Aim 2).}

Cell Function

Cell proliferation

Cell cycle progression

Cell migration/invasion

Mammary tumor growth

\begin{tabular}{|l}
\hline \\
\hline
\end{tabular}

Metastasis

Rac activity
MDA-MB-231

MDA-MB-435

Decreased by 5 (60\%) and $20 \mu \mathrm{M}$

(99\%) resveratrol

G2/S phase arrest by 5 and $20 \mu \mathrm{M}$

resveratrol

Increased by 0.5 (90\%) and 5

(50\%) $\mu \mathrm{M}$ resveratrol. Inhibited

$30 \%$ by $50 \mu \mathrm{M}$ resveratrol.

Mammary tumors increased 2.5-

fold by treatment with $5 \mathrm{mg} / \mathrm{kg}$

body weight (BW) resveratrol, and

only 1.25 -fold with $0.5 \mathrm{mg} / \mathrm{kg} \mathrm{BW}$

resveratrol, while $50 \mathrm{mg} / \mathrm{kg} \mathrm{BW}$

resveratrol had no effect.

Metastatic efficiency too low for

statistical analysis.

Increased in mammary tumors of mice treated with $5 \mathrm{mg} / \mathrm{kg} \mathrm{BW}$ resveratrol.
No effect with $5 \mu \mathrm{M}$ resveratrol.

Decreased $80 \%$ by $20 \mu \mathrm{M}$ resveratrol

No change in cell cycle stage

Increased $300 \%$ by 5 and $50 \%$ by

$25 \mu \mathrm{M}$ resveratrol. No effect with $50 \mu \mathrm{M}$ resveratrol.

Mammary tumors increased 2-3fold by treatment with $0.5,5,10$, and $50 \mathrm{mg} / \mathrm{kg}$ BW resveratrol.

\section{Lung and liver metastases} increased by 2.5 -3-fold with 0.5 , 5 , 10 , and $50 \mathrm{mg} / \mathrm{kg} \mathrm{BW}$ resveratrol

Increased 35-fold in mammary tumors of mice treated with 5 $\mathrm{mg} / \mathrm{kg}$ BW resveratrol and $\sim 10$-fold increase in mammary tumors of mice treated with 0.5 and $50 \mathrm{mg} / \mathrm{kg}$ BW resveratrol.

Progress on Specific Aim 2 (2009-2011): Effects of dietary grape polyphenol resveratrol on mammary tumor growth and metastasis in immunocompromised mice

(Castillo-Pichardo, et al., Manuscript in preparation for submission to the journal Clinical and Experimental Metastasis).

Many in vivo studies supporting the anti-cancer effects of resveratrol have used concentrations of resveratrol ranging from 50-800 mg/kg BW [12;47-49]. However, the effects of low concentrations of resveratrol, which are critical for a better understanding of the possible effect of dietary resveratrol in cancer and for dosing recommendations, have been poorly addressed at the in vivo scenario. Therefore low physiologically relevant concentrations of resveratrol $(0.5$ and $5 \mathrm{mg} / \mathrm{kg} \mathrm{BW})$ and a moderate concentration (50mg/kg BW) were used to test resveratrol's effect on progression of established breast cancer. 


\section{Methods}

\section{Animal model}

Hairless (severe combined immunodeficiency) SCID or athymic nu/nu (or nude) female mice, 5 to 6 wk old (Charles River Laboratories, Inc., Wilmington, MA) were maintained under pathogen-free conditions in Hepa-filtered cages under controlled light (12 h light and dark cycle), temperature $\left(22-24^{\circ} \mathrm{C}\right)$, and humidity (25\%). Throughout the experiment, the animals were provided with autoclaved AIN 76-A phytoestrogen-free diet (Tek Global, Harlan Teklad, Madison, WI) and water ad libitum.

\section{Tumor establishment}

Green fluorescent protein (GFP) tagged-MDA-MB-231 (ER $\alpha-)$, ER $\beta+$ )) or a bone metastatic variant of GFP-MDA-MB-435 (ER (-)) cells ( 1 x 10 ${ }^{6}$ ) in Matrigel (BD Biosciences, San Jose, CA) were injected into the fourth right mammary fat pad under isofluorane inhalation to produce orthotopic primary tumors as described in [50]. After tumor establishment (1 wk post-inoculation), the animals were randomly divided into experimental treatment groups ( $\mathrm{n}=10-12$ per group). The GFP-MDA-MB-231 cells were inoculated into SCID mice, while the GFP-MDA-MB-435 cells were inoculated into nude mice.

\section{Diet administration}

Hairless SCID or athymic nu/nu female mice were orally gavaged either with vehicle (90\% neobee oil, $10 \%$ ethanol), or 0.5 , 5 , or $50 \mathrm{mg} / \mathrm{kg}$ body weight (BW) resveratrol in a $100 \mu \mathrm{L}$ volume every (5 days/wk). Treatments continued until sacrifice at day 108 and 44 for the study performed on GFP-MDA-MB-231 and GFP-MDA-MB-435 breast cancer cells, respectively. The study performed with GFP-MDA-MB-435 cells had to be terminated earlier than anticipated due to the high tumor burden caused by resveratrol in this highly metastatic and aggressive breast cancer cell line.

\section{Whole body fluorescence image analysis}

Mammary tumor growth was quantified as changes in the integrated density of GFP fluorescence as per our previously described methods [50;51];[52]. Mice (under anesthesia) were imaged one week following breast cancer cell inoculation (on the first day of diet administration) and once a week thereafter. A 300 Watt power source with two optical delivery systems fitted with excitation filters $(470 / 40 \mathrm{~nm})$ was used for whole body imaging of GFP fluorescence (LT99D2, Lightools Research, Encinitas, CA). Images were captured with a Spot II charge-coupled device (CCD) camera (Diagnostic Instruments, Sterling Heights, MI) mounted with a 530/25 nm emission filter (Chroma Technology, Rockingham, VT).

Tumor fluorescence intensities were analyzed using Image J software (National Institutes of Health, Bethesda, MD). Relative tumor growth was calculated as the integrated density of fluorescence of each tumor on each imaging day relative to the integrated density of fluorescence of the same tumor on the first day of diet administration.

\section{Analysis of metastases}

Following sacrifice, lungs, kidneys, livers, and bones were excised and immediately stored in liquid $\mathrm{N}_{2}$. Stored organs were thawed and analyzed using an Olympus MV10 fluorescence macro zoom system microscope and images acquired with an Olympus DP71 digital camera as described in [50;51];[52]. Each organ was imaged on both sides. The fluorescent lesions (green component of RGB images) were quantified for integrated density of fluorescent pixels using Image $\mathrm{J}$ software.

\section{Rac activity assays}

Flash frozen mammary tumors were lysed using a homogenizer (Brinkmann Polytron, Mississauga, ONT, Canada) as previously described by us [52] and total protein was quantified using the Precision Red protein assay kit (Cytoskeleton, Inc. Denver, CO). Active Rac was pulled down using beads coupled to glutathione Stransferase (GST)-p21-activated kinase (PAK)-Cdc42/Rac interactive binding (CRIB) motif (GST-PAK-PBD beads) (Cytoskeleton, Denver, CO) as described in [38]. Proteins were resolved on 12\% SDS-PAGE gels and subjected to Western blot analysis using an anti-Rac antibody (Cell Signaling Technology, Inc., Danvers, MA). Positive bands were imaged using a VersaDoc system (Bio-Rad, Hercules, CA) and quantified using Image J software. Rac activity was determined as the Rac-GTP bound to the PAK-CRIB domain as a function of total Rac in a cell lysate.

\section{Statistical analysis}

Data are expressed as the mean \pm SEM. Statistical analyses were done using Microsoft Excel. Differences between means were determined using Student's t-Test. 
Results (Castillo-Pichardo, et al., manuscript in preparation, Clin. Exp. Metastasis)

\section{Resveratrol increases mammary tumor growth:}

Dietary resveratrol increased mammary tumor growth of tumors derived from the low metastatic ER $\alpha-$, ER $\beta+$

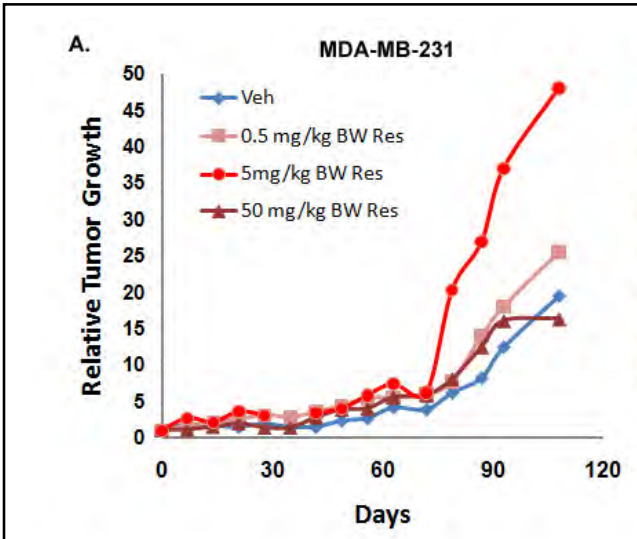

B.

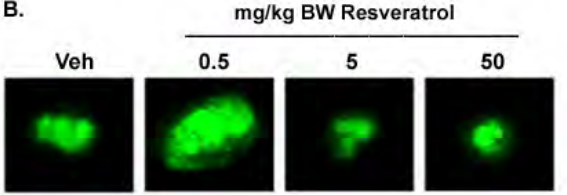

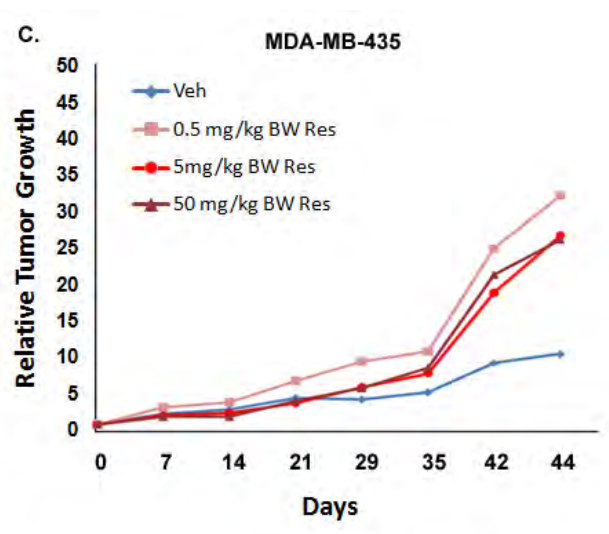

D.

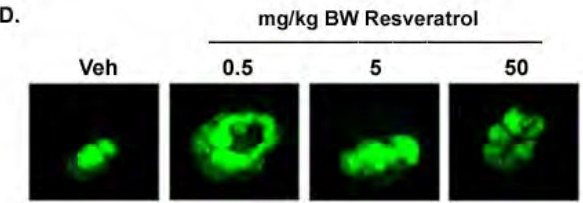

MDA-MB-231 and the highly metastatic ER- MDA-MB-435 breast cancer cell lines (Fig. 1). In SCID mice with MDA-MB231 mammary fat pad tumors, $5 \mathrm{mg} / \mathrm{kg}$ BW resveratrol treatment resulted in a dramatic increase in tumor growth, whereas 0.5 and $50 \mathrm{mg} / \mathrm{kg} \mathrm{BW}$ resveratrol treatments showed a growth pattern that was similar to vehicle control. Treatment with $50 \mathrm{mg} / \mathrm{kg}$ resveratrol resulted in a slight plateau following 90 days of administration, which may indicate inhibition of mammary

Figure 1. Effect of resveratrol on the growth of mammary fat pad tumors. 1 x $10^{6}$ GFP-tagged MDAMB-231 or MDA-MB-435 cells in Matrigel:Dulbecco's Modified Eagle’s Medium (DMEM) (1:1) were inoculated at the mammary fat pad of female SCID (MDA-MB-231) or athymic nude mice (MDA-MB435). One week following injection, mice were fed vehicle (Veh) or 0.5 , 5, or $50 \mathrm{mg} / \mathrm{kg}$ BW resveratrol (Res) 5 times a week by oral gavage. Whole body fluorescence images were acquired once a week. Relative tumor growth was calculated as the integrated density of fluorescence on each day of imaging as a function of the integrated density of fluorescence of the same tumor on day 1 of treatment administration. (A) Average relative GFP-MDA-MB-231 tumor growth as a function of days following inoculation. (B) Representative images of GFP-MDA-MB-231 tumors following vehicle or Res diets at day 108. (C) Average relative GFP-MDA-MB-435 tumor growth as a function of days following inoculation. (D) Representative images of GFP-MDA-MB-435 tumors following vehicle or Res diets at day 44.

tumor growth with long-term exposure. However, this study had to be ended at 115 days due to high tumor burden in the mice receiving $5 \mathrm{mg} / \mathrm{kg}$ BW resveratrol (Fig. 1A and B).

In mammary fat pad tumors established in nude mice from the more aggressive and highly metastatic breast cancer cell line MDA-MB-435, dietary resveratrol at all the concentrations tested demonstrated increased tumor growth, with the lowest $0.5 \mathrm{mg} / \mathrm{kg} \mathrm{BW}$ resveratrol being the concentration showing the greatest effect (Fig 1C and D). Again, this marked increase in tumor growth was not statistically significant at a $P \leq 0.05$. The heterogeneous tumor take and the high variability in both studies is most likely the cause of the non-statistically significant results.

The observed marked resveratrol-induced increase in tumor growth, especially by the lower concentrations, is indicative of a deleterious effect of resveratrol on established breast cancer. Therefore, our results highlight the importance of attaining a better understanding of resveratrol's effects at low concentrations. Also noteworthy is the fact that $50 \mathrm{mg} / \mathrm{kg}$ BW resveratrol, which in other studies has been shown to reduce tumor growth in ovarian cancer and hepatocarcinoma [47;49], induced tumor growth in MDA-MB-435 and not in MDA-MB-231 breast cancer cells. This suggests that resveratrol effects are not only concentration dependent but can also vary depending on ER isoform expression and cell type. In MDA-MB-231 derived tumors, only $5 \mathrm{mg} / \mathrm{kg}$ BW resveratrol promoted tumor growth, but such promotion did not start until approximately day 70 . The $50 \mathrm{mg} / \mathrm{kg}$ BW resveratrol diet may exert a growth inhibitory effect at long-term administration because the increase in growth plateaued after approximately 100 days. These observations suggest ER $\beta$ expression might 
have a protective role in the MDA-MB-231 cell line. Additionally, the estrogenic role of low concentrations of resveratrol previously reported by our group in the MDA-MB-231 breast cancer cell line was confirmed [38].

\section{Resveratrol increases metastasis:}

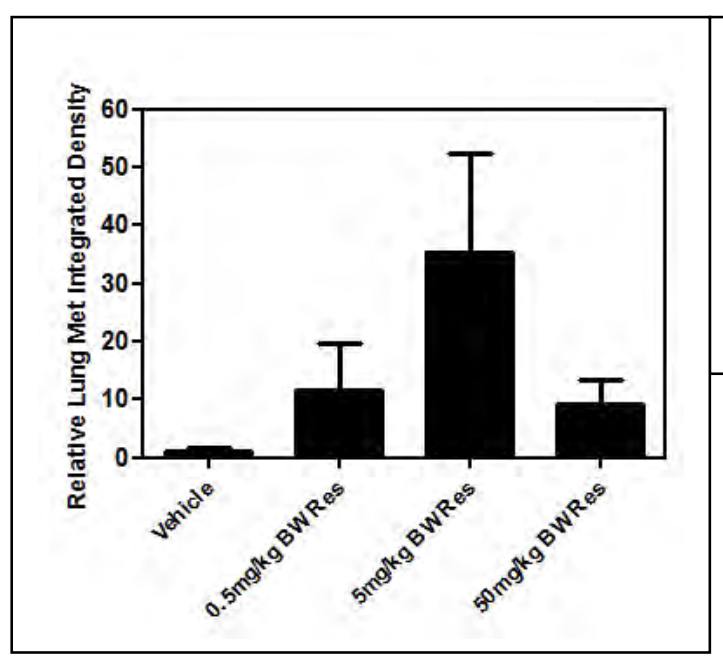

Figure 2. Effect of resveratrol on lung metastasis. Following necropsy, lungs were excised from mice with GFP-MDA-MB-435 mammary tumors that received vehicle or $0.5,5$, or $50 \mathrm{mg} / \mathrm{kg} \mathrm{BW}$ resveratrol (Res) diets and analyzed for metastases by fluorescence microscopy followed by quantitative image analysis. Relative integrated density $( \pm$ SEM) of fluorescent metastatic foci for vehicle or Res-treated mice (7-10 mice/group) is presented.

To investigate the role of resveratrol on breast cancer metastasis, following sacrifice, lungs, livers, kidneys, and bones from mice bearing MDA-MB-435 mammary tumors were harvested for detection of fluorescent metastatic foci. An association between tumor growth and lung metastasis was observed since resveratrol at 0.5, 5 and $50 \mathrm{mg} / \mathrm{kg}$ BW caused an 11-, 36-, and 9-fold increase in lung metastasis, respectively (Fig. 2). Concomitant with our findings on tumor growth in this cell line, resveratrol at $5 \mathrm{mg} / \mathrm{kg}$ BW showed the greater induction of lung metastasis. In the case of kidneys and bone, mice from the vehicle group did not present with metastasis while resveratrol-treated mice developed metastases (Table 2).

Table 2. Effects of resveratrol on metastasis of GFP-MDA-MB-435 mammary tumors

\begin{tabular}{|c|c|c|c|c|c|c|c|c|}
\hline & \multicolumn{4}{|c|}{ Percentage of mice with metastases } & \multicolumn{4}{|c|}{$\begin{array}{l}\text { Average integrated density of fluorescent } \\
\text { metastatic foci }\end{array}$} \\
\hline & \multirow[b]{2}{*}{ Vehicle } & \multicolumn{3}{|c|}{ Resveratrol (mg/kg BW) } & \multirow[b]{2}{*}{ Vehicle } & \multicolumn{3}{|c|}{ Resveratrol (mg/kg BW) } \\
\hline & & 0.5 & 5 & 50 & & 0.5 & 5 & 50 \\
\hline Kidneys & $0 \%$ & $14 \%$ & $10 \%$ & $22 \%$ & 0 & 0.21 & 0.12 & 0.29 \\
\hline Liver & $29 \%$ & $29 \%$ & $10 \%$ & $22 \%$ & 0.24 & 2.4 & 0.70 & 0.20 \\
\hline Bone & $0 \%$ & $0 \%$ & $20 \%$ & $22 \%$ & 0 & 0 & 0.038 & 0.02 \\
\hline
\end{tabular}

Metastasis to the kidneys was observed in $14 \%, 10 \%$, and $22 \%$ of mice in 0.5 , 5 , and $50 \mathrm{mg} / \mathrm{kg} \mathrm{BW}$ resveratrol treatment groups, respectively; whereas, metastasis to the bone was observed in $20 \%$ and $22 \%$ of mice treated with 5 and $50 \mathrm{mg} / \mathrm{kg}$ BW resveratrol, respectively. Finally, liver metastasis was identified in a similar percentage of mice from each treatment group, including vehicle control. However, the average integrated density was 10- and 2.9- fold higher in 0.5 and $5 \mathrm{mg} / \mathrm{kg} \mathrm{BW}$ resveratrol treated mice (Table 1), suggesting a higher number and/or bigger metastatic foci in mice treated with low concentrations of resveratrol when compared to vehicle treated mice. Overall, the percentage of mice presented with metastasis was low for statistical comparisons due to the short duration of the study which, because of high primary tumor burden, had to be terminated after only 44 days.

The metastatic efficiency of the MDA-MB_231 cells after 118 days was too low for statistical comparison, even though an increase in lung and lymph node metastasis were noted for the mice treated with 5 $\mathrm{mg} / \mathrm{kg}$ BW resveratrol, compared to vehicle controls. 


\section{Resveratrol increases Rac activity in mammary tumors:}

Since resveratrol regulation of breast cancer cell migration/invasion was previously shown by us to be dependent on signaling from the small GTPase Rac [38], Rac activity was measured in tumors from resveratrol

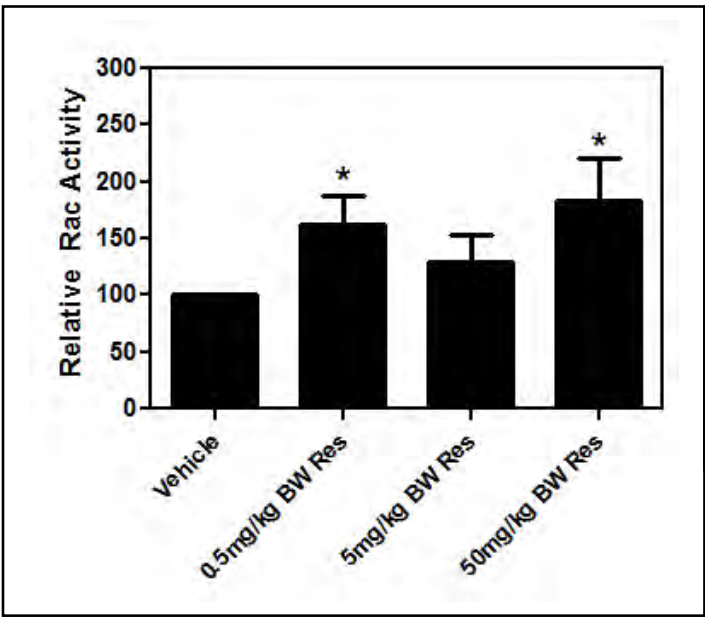

Figure 3. Rac activity of resveratrol treated tumors. GFP-MDAMB-435 mammary tumors from mice that received vehicle or 0.5 , 5 , or $50 \mathrm{mg} / \mathrm{kg}$ BW resveratrol (Res) diets were lysed. GST-PAK-PBD beads were used to pull down active GTP-bound Rac from tumor lysates. Active and total Rac levels were detected by Western blot analysis using anti-Rac antibody. Rac activity (active Rac/total Rac) relative to vehicle, as quantified from Image $\mathrm{J}$ analysis of integrated density of positive bands is presented. Error bars represent SEMs from at least three tumors per group. Asterisk denotes statistical significance at $p \leq 0.05$.

treated mice. Resveratrol at 0.5 and $50 \mathrm{mg} / \mathrm{kg}$ BW significantly increased Rac activity by 1.6- and 1.8-fold respectively. At $5 \mathrm{mg} / \mathrm{kg}$ BW resveratrol, Rac activity was increased by 1.3-fold, however, this increase was not statistically significant. In mice bearing MDA-MB-231 mammary tumors, 5 mg/kg BW resveratrol treatment resulted in a 25 -fold increase in Rac activity but this increase was not statistically significant (data not shown).

\section{Resvertarol has low bioavailability:}

Results generated from this study demonstrated that the concentration of resveratrol in the diet may be a factor for cancer progression and that circulating plasma levels of resveratrol could be used as a prognostic tool for cancer. Therefore, to determine the levels of dietary resveratrol in the plasma and urine, we developed a novel method of detection in collaboration with Dr. Jose Rodriguez-Orengo, (Professor, Department of Biochemistry, University of Puerto Rico-Medical Sciences Campus) (Castillo-Pichardo, et al., manuscript in preparation, Journal of Chromatography B). We developed a rapid ultra high-pressure liquid chromatography (UPLC)-tandem mass spectrometry (MS) method that requires minimal sample preparation and allows the quantification of resveratrol in mouse plasma at lower levels and shorter retention times than those previously reported by similar methodologies [53;54].

Sample preparation: A total of $2.5 \mu \mathrm{L}$ of Internal Standard (IS) (4 $\mathrm{gg} / \mathrm{mL}$ stock solution) were added to $100 \mu \mathrm{L}$ of plasma to obtain a final IS concentration of $100 \mathrm{ng} / \mathrm{mL}$. Then, $400 \mu \mathrm{L}$ of acetonitrile were added and the sample was vortex-mixed for $5 \mathrm{~s}$ and spun at $9,000 \mathrm{~g}\left(4^{\circ} \mathrm{C}\right)$ for $10 \mathrm{~min}$ to precipitate proteins. The supernatant was carefully transferred to a glass tube and the solvent was dried at room temperature using a speed vac. Once dry, samples were reconstituted in $100 \mu \mathrm{L}$ of $50 \%$ methanol, filtered through a $0.45 \mu \mathrm{m}$ nylon filter, and transferred for injection into the UPLC MS/MS system.

Ultra high pressure liquid chromatography: Chromatographic separation was achieved by injecting $5 \mu \mathrm{L}$ of sample onto a Zorbax Eclipse Plus $\mathrm{C}_{18}$ column $(2.1$ x $50 \mathrm{~mm}, 1.8 \mu \mathrm{m})$ from Agilent Technologies, Santa Clara, $\mathrm{CA}$. The column temperature was set to $40^{\circ} \mathrm{C}$. The mobile phase consisted of a gradient of $1 \mathrm{mM}$ ammonium fluoride in distilled water (solvent A) and 100\% methanol (solvent B) at a flow of $0.5 \mathrm{~mL} / \mathrm{min}$. The gradient elution was carried out as follows: $0 \mathrm{~min}, 0 \% \mathrm{~B}$; 2min, 30\% B; $2.5 \mathrm{~min}, 70 \% \mathrm{~B} ; 2.6 \mathrm{~min}, 95 \% \mathrm{~B} ; 3.5 \mathrm{~min}, 95 \%$ $\mathrm{B}$; and finally $3.6 \mathrm{~min}, 30 \% \mathrm{~B}$ for re-equilibrating.

Mass spectrometry: After chromatographic separation, samples were directly transferred to a triple quadrupole mass spectrometer, which performs MS/MS. The instrument employs electrospray ionization (ESI) with Agilent Jet Stream technology, which was used in the negative ionization mode for the method presented herein. The instrument settings were as follows: time filtering width 0.07 ; gas temperature $350^{\circ} \mathrm{C}$; gas flow $10 \mathrm{~L} / \mathrm{min}$, nebulizer 20 psi; sheath gas heater $400^{\circ} \mathrm{C}$; sheath gas flow $12 \mathrm{~L} / \mathrm{min}$; capillary $4000 \mathrm{~V}$; cell accelerator voltage (CAV) 7V; and collision energy (CE) 12V for resveratrol quantifier, 20V for resveratrol qualifier, and 24V for the IS. Retention time for both resveratrol the IS was $2.3 \mathrm{~min}$.

Resveratrol analysis and detection: Resveratrol was resolved by first running $70 \%$ of the aqueous solvent $\mathrm{A}$ through a $\mathrm{C}_{18}$ column set at $40^{\circ} \mathrm{C}$. These conditions retained resveratrol in the column, which was then eluted at 2.3 min with $70 \%$ percent of organic solvent B. For quantification, negative ESI was used with ammonium 
fluoride at $1 \mathrm{mM}$ as the aqueous solvent, which has been previously reported to substantially improve ionization in the negative ESI mode [55]. Only resveratrol and IS precursor ions with mass to charge (m/z) of 227 and 231, respectively, and at unit resolution were allowed to pass from MS1 to MS2. Product ions 185, 143, and 147 $\mathrm{m} / \mathrm{z}$ with unit resolution were detected and later used as resveratrol quantifier peak, resveratrol qualifier peak, and IS peak, respectively. The run time was only 5 min for each sample, representing a great improvement over previously described methodologies for quantification of resveratrol in plasma [54;56].

Linearity: Six calibration runs for resveratrol in mouse plasma were performed using standards of 100, 50, 10, 5,1 , and $0.5 \mathrm{ng} / \mathrm{mL}$ resveratrol, containing IS at $100 \mathrm{ng} / \mathrm{mL}$. All calibration curves were linear over the measured range, and are defined by the following equation $\mathrm{y}=(0.018289 \pm 0.000683) \mathrm{x}+(-0.0009212 \pm$ 0.0016098 ) (mean \pm SD for slope and y intercept); and presented a correlation coefficient $\left(\mathrm{R}^{2}\right)$ of $0.99916 \pm$ 0.00055 (mean \pm SD) (Fig. 4).

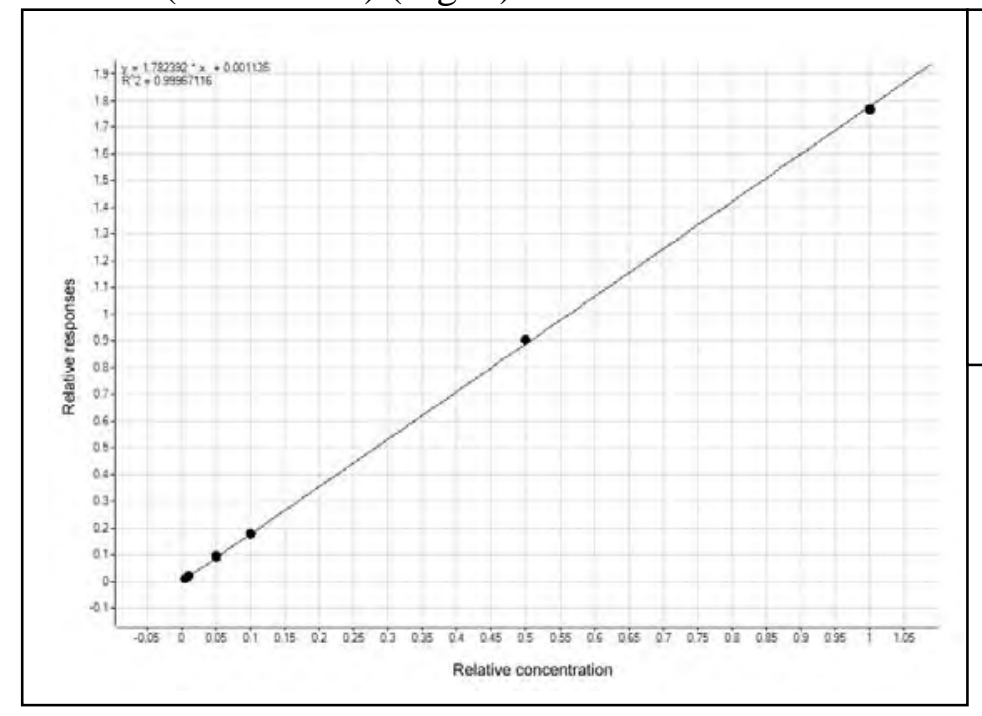

Figure 4. Calibration curve for resveratrol. One of the six calibration curves generated for resveratrol using Agilent software is presented. Linearity was achieved for $0.5-100 \mathrm{ng} / \mathrm{mL}$ resveratrol. Each standard contained $100 \mathrm{ng} / \mathrm{mL}$ of resveratrol- $\mathrm{d}_{4}$ (the IS).

Limit of detection and quantification, precision and accuracy: The limit of detection (LOD) and limit of quantification (LOQ) for resveratrol in plasma was $0.5 \mathrm{ng} / \mathrm{mL}$. Interday and intraday precision and accuracy showed a CV of 6 and 4\% (in average) and a relative error (RE) of 1.3 and $1.4 \%$ (in average), respectively.

Recovery: For determination of resveratrol's recovery in mouse plasma, neat and extracted resveratrol standards of low, intermediate, and high concentration $(5,50$, and $100 \mathrm{ng} / \mathrm{mL})$ of resveratrol were used. Five replicates of each standard were prepared and each one was injected twice; all standards were assayed in the same analytical run. The percent of recovery for resveratrol in mouse plasma was high, as shown by the reported values of 82, 76 , and $96 \%$ recovery for 5, 50, and $100 \mathrm{ng} / \mathrm{mL}$, respectively; average percent of recovery was $85 \pm 10 \%$.

Stability: Several tests were performed to evaluate the stability of resveratrol: benchtop and freeze/thaw stability in plasma, and post-preparative reinjection reproducibility in reconstitution solvent were determined. For the benchtop stability test, 1 and $100 \mathrm{ng} / \mathrm{mL}$ resveratrol standards (5 replicates; each injected once) were thawed and, after $6 \mathrm{~h}$ at room temperature, subjected to the sample preparation protocol (see methods). Our results show a CV of 14 and 4\% and a RE of 6 and $2 \%$ for the 1 and $100 \mathrm{ng} / \mathrm{mL}$ resveratrol standards, respectively. On the other hand, the freeze/thaw stability test used 25 and $100 \mathrm{ng} / \mathrm{mL}$ resveratrol standards (one replicate; each injected 5 times) that underwent 5 freeze/thaw cycles $\left(15 \mathrm{~min}\right.$ at $-80^{\circ} \mathrm{C} / 15 \mathrm{~min}$ at room temperature), followed by sample preparation. The CV was 3 and $2 \%$ and the RE was 11 and $1 \%$ for 25 and 100 $\mathrm{ng} / \mathrm{mL}$ resveratrol standards, respectively. Finally, the calculated concentration of 25 and $70 \mathrm{ng} / \mathrm{mL}$ resveratrol standards (two replicates; each injected twice) at $0 \mathrm{~h}$ and after $96 \mathrm{~h}$ at room temperature were compared for the determination of post-preparative reinjection reproducibility of resveratrol in reconstitution solvent. Recovery after 96 h was $99 \pm 7 \%$ (mean \pm SD) and $98 \pm 6 \%$ for 25 and $70 \mathrm{ng} / \mathrm{mL}$ resveratrol standards, respectively. These results suggest resveratrol is stable after $6 \mathrm{~h}$ in plasma and after $96 \mathrm{~h}$ in reconstitution solvent at room temperature. Additionally, resveratrol was proven to be stable after 5 freeze/thaw cycles. The robust stability of resveratrol greatly simplifies sample handling during preparation and allows for the preparation of multiple samples at the same time.

\section{Application of the method:}

The above described method allowed for the rapid quantification of low levels of resveratrol in mouse plasma that can detect as low as $0.5 \mathrm{ng} / \mathrm{mL}$ resveratrol. We are currently detecting the amount of resveratrol in the plasma of nude and SCID mice that received resveratrol diets and have been able to detect very low ng levels of resveratrol in the plasma. This result indicates that the bioavailability of resveratrol is low. However, 
the very low levels of resveratrol reaching the mammary tumors are sufficient to activate Rac and increase mammary tumor growth and metastasis.

The development of a reversed-phase UPLC method that uses tandem MS detection for the determination of resveratrol levels in mouse plasma demonstrated that we had the capacity to detect resveratrol in plasma and urine at a range from 0.5 to $100 \mathrm{ng} / \mathrm{mL}$. This method allows a rapid and very sensitive quantification of resveratrol in mouse plasma at concentrations as low as 500 ppt. By applying this methodology, a correlation between the plasma levels of resveratrol and its anti-cancer effects can be established. This in turn, will provide a better understanding of the concentration-dependency of resveratrol's health beneficial properties.

\section{Conclusions from Specific Aim 2:}

Taken together, our findings demonstrate a cancer promoting role for low dietary concentrations of resveratrol in breast cancer. Therefore, this study illuminates the importance of further delineating resveratrol's concentration dependent effects, particularly on breast cancer, before it can be tested in the clinic or used as a dietary supplement for breast cancer patients.

\section{Other Avenues of Research:}

Research from this award demonstrated that at physiological concentrations, resveratrol was not a viable candidate for prevention of breast cancer metastasis. The results of this study prompted us to pursue two major avenues of research that focus directly on novel therapies for breast cancer metastasis.

\section{Is resveratrol an effective breast cancer metastasis preventive agent in combination with other grape polyphenols?}

Even though our results conclusively demonstrated that dietary resveratrol promotes breast cancer metastasis, there is overwhelming evidence for a protective role for grape polyphenols. Therefore, we tested the hypothesis that combined grape polyphenols are more effective than individual compounds at inhibiting breast cancer progression. We investigated the effects of individual and combined resveratrol, quercetin and catechin, which constitute the major polyphenols in grapes and red wine, at low concentrations on two metastatic breast cancer cell lines. Our results show that treatment with combined grape polyphenols resveratrol, quercetin, and catechin (RQC) is more effective than individual treatments at inhibition of cell viability, cell cycle progression, and cell migration in ER $\alpha(-), E R \beta .+()$ low metastatic MDA-MB-231 and ER (-) highly metastatic MDA-MB-435 cancer cell lines. Moreover, in nude mice, dietary RQC treatment significantly decreased mammary tumor growth of both MDA-MB-231 and MDA-MB-435 cells [50;51]. A key finding is that RQC treatment at low dietary concentrations (5 mg/kg BW each) specifically prevented metastasis to bone and liver [50]. Please, see Appendix for manuscripts.

Additionally, we found that RQC induces apoptosis of breast cancer cells and have identified, by antibody array analysis, a myriad of RQC-regulated proteins in the apoptotic signaling cascade. We have also investigated other mechanisms by which RQC decreases breast cancer progression. Our findings demonstrate that individual and combined resveratrol, quercetin, and catechin reduce the activity of Akt, a major cell survival regulator. Moreover, RQC, but not individual polyphenols, activates AMP-activated protein kinase (AMPK) and inhibits mammalian target of rapamycin (mTOR) signaling. Therefore, our results implicate RQC in the regulation of the phosphoinositide 3-kinase (PI3-K)/Akt/mTOR pathway. Since this pathway is important for the development of resistance to the anti-epidermal growth factor receptor (EGFR) therapeutic gefitinib, we explored the potential of RQC as a chemosensitization agent for gefitinib. EGFR signaling is a key pathway that regulates cancer progression and metastasis. However, development of resistance to anti-EGFR therapeutics, such as gefitinib, greatly impairs their clinical effectiveness. We demonstrate that a combination of RQC and gefitinib decreases viability of gefitinib resistant MDA-MB-231 cells to a greater extent than RQC or gefitinib alone. Moreover, RQC is able to inhibit Akt and mTOR, and activate AMPK even in the presence of gefitinib. Finally, combined RQC and gefitinib is more effective than the individual treatments at inhibiting tumor growth and metastasis in SCID mice with mammary fat pad tumors established from MDA-MB-231 cells. Taken together, these results suggest that RQC treatment inhibits breast cancer progression and can potentiate antiEGFR therapy by inhibition of Akt/mTOR signaling (Castillo-Pichardo, et al., 2011, manuscript in review, Cancer Preven. Res., see Appendix).

Results of this study have been used as preliminary data for a R01 application to investigate the role of combined grape polyphenols in combination therapy with current breast cancer therapies. 


\section{Can Inhibition of Rac inhibit breast cancer metastasis?}

Since resveratrol increased metastasis with an associated increase in Rac activity of both breast cancer cells and mammary tumors, we formulated the hypothesis that specific inhibition of Rac activity impedes breast cancer metastasis. The commercially available Rac inhibitor NSC23766 that inhibits the interaction of Rac with its activators, guanine nucleotide exchange factors (GEFs), had only a modest inhibitory effect on Rac activity or cell migration of metastatic breast cancer cell lines. At the high concentrations required to inhibit Rac activity, NSC23766 was toxic to nude mice and resulted in death. Therefore, as a sub aim, we initiated the generation of more efficacious NSC23766 derivatives. A series of structural analogs of NSC23766 were developed in collaboration with medicinal chemists Drs. Cornelis Vlaar and Eliud Hernandez (Department of Pharmaceutical Sciences, University of Puerto Rico Medical Sciences Campus). New Rac inhibitors were developed by optimizing the lead structure, NSC23766. We recently reported the synthesis and testing of some of these inhibitors in breast cancer cells [57]. See Appendix for manuscript.

The most relevant finding is the recent identification of a Rac inhibitor EHop-016. Using MDA-MB-435 metastatic cancer cells that exhibit high endogenous Rac activity, we found that the new compound EHop-016, with an $\mathrm{IC}_{50}$ of $1.1 \mu \mathrm{M}$, is a 100-fold more efficient inhibitor of Rac activity than NSC23766. EHop-016 is specific for Rac and does not inhibit the other Rho GTPase family members Rho A and Cdc42. At effective concentrations $(<5 \mu \mathrm{M})$, EHop-016 does not affect the viability of transformed mammary epithelial cells (MCF10A) and reduces viability of MDA-MB-435 cells by 20\%. EHop-016 inhibits Rac-regulated cell functions by reducing lamellipodia formation and decreasing directed migration of metastatic cancer cells. Therefore, EHop016 holds promise as a targeted therapeutic agent for the treatment of metastatic cancers with high Rac activity (Montalvo et al., under revision following initial submission to Journ. Biochem., see Appendix for manuscript).

\section{KEY RESEARCH ACCOMPLISHMENTS}

1. Specific Aim 1: In vitro analysis of resveratrol effects on cell functions important for breast cancer metastasis have been completed (Table 1). We have shown that resveratrol can reduce cell proliferation and block cell cycle progression in ER $\beta$ (+) breast cancer cells but not ER (-) breast cancer cells. ER (-) breast cancer cell proliferation and cell cycle progression is not affected by low concentrations of resveratrol. Resveratrol at low concentrations, increased cell migration/invasion of both breast cancer cell lines.

2. Specific Aim 2: In vivo analysis of resveratrol and Rac inhibitor (NSC-23766) effects on breast cancer metastasis has been completed using the ER $\beta(+)$ and ER (-) MDA-MB-435 metastatic cancer cell lines. We report that at all concentration tested, resveratrol increased primary mammary tumor growth and metastasis to distant organs (Castillo-Pichardo, et al., manuscript in preparation for submission to Clin Exp Metastasis).

3. A highly sensitive UPLC/tandem MS method was developed to detect low levels of resveratrol in plasma and urine following resveratrol consumption (Castillo-Pichardo, et al, manuscript in preparation).

4. We found that resveratrol in combination with quercetin and catechin (major grape polyphenols) (RQC) at low physiologically relevant concentrations inhibited breast cancer cell proliferation, cell cycle progression, and migration, and induced apoptosis. Dietary administration of this combination of grape polyphenols resulted in inhibition of mammary tumor growth and metastasis to bone and liver [50;51].

5. We further elucidated the mechanisms by which RQC inhibits breast cancer progression and implicated RQC in inhibition of the phosphoinositide 3-kinase (PI3-K)/Akt/mammalian target of rapamycin (mTOR) signaling by both Akt inhibition and activation of AMP kinase. RQC treatment was shown to potentiate breast cancers to current anti epidermal growth factor receptor therapy gefitinib, in vitro and in vivo in SCID mice (Castillo-Pichardo, et al., submitted manuscript, Cancer Preven. Res).

6. Since the existing Rac inhibitor NSC-23766 did not inhibit breast cancer cell migration or mammary tumor growth we developed novel more efficient Rac inhibitors. We have characterized the inhibitory effects of potential candidates and isolated a promising Rac inhibitor EHop-016 ([57] and Montalvo, et al., submitted manuscript). 


\section{REPORTABLE OUTCOMES}

\section{A. Publications}

1. Castillo-Pichardo, L, Martinez-Montemayor, M, Martinez, J, Wall, K, Cubano L, and

Dharmawardhane S., 2009. Inhibition of mammary tumor growth and metastases to bone and liver by dietary grape polyphenols. Clin. Exp. Metastasis, 26: 505-16.

2. Hernandez, E, De La Mota-Peynado, A., Dharmawardhane, S., and Cornelis Vlaar, 2010. Novel inhibitors of Rac1 in metastatic breast cancer PRHealth Sc. J., 29 (4):348-356.

\section{B. Submitted Manuscripts}

1. Castillo-Pichardo, L, Dharmawardhane, S.. Grape polyphenols inhibit Akt/mTOR signaling and potentiate the effects of gefitinib in breast cancer, Submitted, Cancer Preven. Res., 07, 2011.

2. Montalvo-Ortiz, BL, Hernández, E, De La Mota-Peynado, A, Castillo-Pichardo, L, Humphries-Bickley, T, Vlaar, CP, and Dharmawardhane, S. Characterization of EHop-016, a novel small molecule inhibitor of Rac GTPase. Journ. Biol. Chem, in revision following review in 07, 2011.

\section{Manuscripts in Preparation}

1. Castillo-Pichardo, L, Perez, A, Dharmawardhane, S.. Dietary grape polyphenol resveratrol increases mammary tumor growth and metastasis in immunocompromised mice, to be submitted, Clin. Exp. Metastasis.

2. Castillo-Pichardo, L, Perez, A, Dharmawardhane, S., Rodriguez-Orengo, J, Rapid quantification of resveratrol in mouse plasma by ultra high pressure liquid chromatography (UPLC) coupled to tandem mass spectrometry, to be submitted, Journ. Chromatography B.

\section{Meeting Abstracts}

1. Dharmawardhane, S., De La Mota, A., Montalvo, B, Hernandez, J, Humphries-Bickley, T, Hernandez, E, Vlaar, C. Development of novel Rac inhibitors as anti breast cancer metastasis compounds. DoD/BCRP Era of Hope Conference, Orlando, FL, August 2-5, 2011.

2. Dharmawardhane, S., Castillo-Pichardo, L, Perez, A Resveratrol, a polyphenol from grapes, increases breast cancer metastasis but can prevent breast cancer progression in combination with other grape polyphenols. DoD/BCRP Era of Hope Conference, Orlando, FL, August 2-5, 2011.

3. Montalvo Ortiz, B, Hernandez Ofarrill, E, Hernandez, J, Vlaar, C, Dharmawardhane, S, Characterization of a novel Rac inhibitor as an anti cancer metastasis compound. $102^{\text {nd }}$ Annual Meeting of the American Association of Cancer Research. Orlando, FL, April 2-6, 2011.

4. Castillo-Pichardo, L, Dharmawardhane, S, Grape polyphenols in chemosensitization of the antiEGFR cancer therapeutic Gefitinib via regulation of Akt/mTOR signaling. $50^{\text {th }}$ Annual meeting of the American Society of Cell Biology, Philadelphia, PA, December 5-9, 2010.

5. Castillo-Pichardo, L, Santos, A, Flanagan, M, Dharmawardhane, S. Dietary resveratrol may promote cancer growth and metastasis via Rac activation. American Association of Cancer Research/Metastasis Research Society Annual Conference, Philadelphia, PA October 07-09, 2010.

6. Castillo-Pichardo, L., Otero-Franqui, E., and Dharmawardhane, S. Grape polyphenols inhibit breast cancer progression through regulation of the PI3K/Akt pathway. $49^{\text {th }}$ Annual meeting of the American Society of Cell Biology, San Diego, CA, December 5-9, 2009.

7. Castillo-Pichardo, L., De La Mota-Peynado, A., Maritnez-Montemayor, M., Otero-Franqui, E., and Dharmawardhane, S. Inhibitory mechanisms of breast cancer cell and tumor growth by red wine polyphenols. $100^{\text {th }}$ Annual Meeting of the American Association of Cancer Research. Denver, CO, April 18-22, 2009.

8. De La Mota-Peynado, A., Hernandez, E., Vlaar, C., and Dharmawardhane, S., Small molecule Rac inhibitors as anti-breast cancer invasive compounds. $48^{\text {th }}$ Annual meeting of the American Society of Cell Biology, San Francisco, CA, December 13-17, 2008. 
9. Castillo-Pichardo, L., and Dharmawardhane, S. Role of estrogen receptor isoform expression on inhibition of breast cancer progression by grape polyphenols. $48^{\text {th }}$ Annual meeting of the American Society of Cell Biology, San Francisco, CA, December 113-17, 2008.

10. Martinez-Montemayor, M. Castillo-Pichardo, L, De La Mota, A., Cubano, L., and Dharmawardhane, S. Natural therapeutics for breast cancer. $11^{\text {th }}$ RCMI International Symposium on Health Disparities, Honolulu, HI, December 1-4, 2008.

11. Dharmawardhane, S, Azios, NG, Castillo-Pichardo, L, and De La Mota-Peynado, A. Estrogen and resveratrol as regulators of the Rho GTPase Rac in breast cancer metastasis Era of Hope, Deaprtment of Defense Breast Cancer Research Program Meeting, Baltimore, MD, June 25-27, 2008.

12. Castillo, L, De la Mota, A, Martinez, M, Schlachterman, A, Valle, F, Wall, K, Martinez, J, Cubano, L, and Dharmawardhane, S. Role of red wine polyphenols in regulation of Rac activity, breast cancer cell proliferation, migration, and metastasis. American Association for Cancer Research Special Conference on signaling to the actin cytoskeleton, San Diego, CA, February 03-05, 2008.

13. Azios, N, Martinez, M, Schlachterman, A, Valle, F, Wall, K, Cubano, L, and Dharmawardhane, S. Role of soy isoflavones genistein and daidzein in regulation of cytoskeletal dynamics, migration, and metastasis of breast cancer cells in vitro and in vivo. American Association for Cancer Research Special Conference on signaling to the actin cytoskeleton, San Diego, CA, February 03-05, 2008.

14. Castillo-Pichardo, L., De La Mota-Peynado, A., Rivera, L., Cubano, L. A. Dharmawardhane, S., Role of grape polyphenols in metastatic breast cancer, $47^{\text {th }}$ Annual meeting of the American Society of Cell Biology, Washington DC, December 01-05, 2007.

15. Castillo-Pichardo, L, Martinez-Montemayor, M, Schlachterman, A, Valle, F, De La Mota, A, Cubano, L, Dharmawardhane, S. Combined grape polyphenols resveratrol, quercetin, and catechin exert synergistic inhibitory effects on metastatic breast cancer progression. American Association of Cancer Research special conference on Advances in Breast Cancer Research, San Diego, CA, October 17-20, 2007.

\section{E. List of Personnel}

Linette Castillo-Pichardo, Graduate student (no salary, recipient pre-doctoral award from US Army/BCRP) Brendaliz Montalvo, Postdoctoral fellow Angelica Santos, Postdoctoral fellow Alina De la Mota, Technician 


\section{CONCLUSIONS}

The proposed hypothesis that high concentrations of resveratrol prevent breast cancer invasion and metastasis while $\mathrm{E}_{2}$ and low concentrations of resveratrol promote breast cancer invasion and metastasis via Rac-regulated mechanisms was validated, but shown to be dependent on ER expression. Our results show that low concentrations of resveratrol act similar to estrogen and increases Rac activity and cell migration/invasion while high concentrations inhibit Rac activity, Rac/Rac.GEF association, and cell migration/invasion of ER $\beta$ (+) metastatic breast cancer cell line MDA-MB-231. However, in ER (-) MDA-MB-435 cells, estrogen had no effect and low concentrations of resveratrol increased and high concentrations of resveratrol inhibited cell proliferation and cell migration. In vivo studies with immunocompromised mice demonstrated that $5 \mathrm{mg} / \mathrm{kg}$ BW resveratrol increased and high concentrations of resveratrol had no effect on mammary tumor growth of MDAMB-231 cells. In mice with mammary tumors established with the ER (-) highly metastatic MDA-MB-435 cell line, all concentrations of dietary resveratrol increased mammary tumor growth and metastasis. This result may reflect the low bioavailability of dietary resveratrol where even high amounts of ingested resveratrol may result in very low levels in the circulation. Therefore, the conclusion from this study is that dietary resveratrol is available at low concentrations and at these physiologically relevant concentrations, resveratrol promotes breast cancer progression. Therefore, resveratrol is probably not a viable dietary anti breast cancer compound for women diagnosed with breast cancer, those at high risk, or survivors.

Interestingly, in both MDA-MB-231 and MDA-MB-435 metastatic cancer cells, a combination of resveratrol, quercetin, and catechin at 0.5 and $5 \mu \mathrm{M}$ significantly decreased cell proliferation and induced cell cycle arrest and apoptosis. We also reported that combined grape polyphenols reduced mammary tumor growth and metastasis [51;57]. The mechanism by which grape polyphenols inhibit breast cancer progression and act as a chemosensitizer for anti-EGFR therapy is via downregulation of mTOR signaling by Akt inhibition and AMPK activation (Castillo-Pichardo, et al., submitted). Therefore, resveratrol in combination with quercetin and catechin at equimolar concentrations has anti breast cancer metastasis and chemosensitization properties.

Our results show that the signaling protein Rac was activated in all mammary tumors that responded to resveratrol by increased growth and metastasis. We developed novel Rac inhibitors that were more efficient than the commercially available NSC-23766 Rac inhibitor that we planned to use in the original proposal. However, this inhibitor was not sufficient to inhibit all of the Rac activity of the metastatic cancer cell lines with high endogenous Rac activity. Therefore, we developed and identified NSC-23766 derivatives that has potential as Rac inhibitors and novel anti breast cancer metastasis compounds ([57], Montalvo et al., submitted). 


\section{REFERENCES}

1. Yager,J.D. and Davidson,N.E. (2006) Estrogen carcinogenesis in breast cancer. N.Engl.J.Med., 354, 270-282.

2. Fuqua,S.A. (2001) The role of estrogen receptors in breast cancer metastasis. J Mammary Gland Biol Neoplasia JID - 9601804, 6, 407-417.

3. Platet,N., Cathiard,A.M., Gleizes,M., and Garcia,M. (2004) Estrogens and their receptors in breast cancer progression: a dual role in cancer proliferation and invasion. Crit Rev.Oncol.Hematol., 51, 55-67.

4. Lewis,J.S. and Jordan,V.C. (2005) Selective estrogen receptor modulators (SERMs): Mechanisms of anticarcinogenesis and drug resistance. Mutat.Res., 591, 247-263.

5. Katzenellenbogen,B.S., Choi,I., Delage-Mourroux,R., Ediger,T.R., Martini,P.G., Montano,M., Sun,J., Weis,K., and Katzenellenbogen,J.A. (2000) Molecular mechanisms of estrogen action: selective ligands and receptor pharmacology. J Steroid Biochem Mol Biol JID - 9015483, 74, 279-285.

6. Park,W.C. and Jordan,V.C. (2002) Selective estrogen receptor modulators (SERMS) and their roles in breast cancer prevention. Trends Mol Med JID - 100966035, 8, 82-88.

7. Rastelli,F. and Crispino,S. (2008) Factors predictive of response to hormone therapy in breast cancer. Tumori, 94, 370-383.

8. Gomez-Serranillos,M.P., Martin,S., Ortega,T., Palomino,O.M., Prodanov,M., Vacas,V., Hernandez,T., Estrella,I., and Carretero,M.E. (2009) Study of red wine neuroprotection on astrocytes. Plant Foods Hum.Nutr., 64, 238-243.

9. Xia,E.Q., Deng,G.F., Guo,Y.J., and Li,H.B. (2010) Biological activities of polyphenols from grapes. Int.J.Mol.Sci., 11, 622-646.

10. Ndiaye,M., Kumar,R., and Ahmad,N. (2011) Resveratrol in cancer management: where are we and where we go from here? Ann.N.Y.Acad.Sci., 1215, 144-149.

11. Levenson,A.S., Gehm,B.D., Pearce,S.T., Horiguchi,J., Simons,L.A., Ward,J.E., III, Jameson,J.L., and Jordan,V.C. (2003) Resveratrol acts as an estrogen receptor (ER) agonist in breast cancer cells stably transfected with ER alpha. Int.J.Cancer, 104, 587-596.

12. Bhat,K.P., Lantvit,D., Christov,K., Mehta,R.G., Moon,R.C., and Pezzuto,J.M. (2001) Estrogenic and antiestrogenic properties of resveratrol in mammary tumor models. Cancer Res JID - 2984705R, 61, 7456-7463.

13. Harris,D.M., Besselink,E., Henning,S.M., Go,V.L., and Heber,D. (2005) Phytoestrogens induce differential estrogen receptor alpha- or Beta-mediated responses in transfected breast cancer cells. Exp.Biol.Med.(Maywood.), 230, 558-568.

14. Bowers,J.L., Tyulmenkov,V.V., Jernigan,S.C., and Klinge,C.M. (2000) Resveratrol acts as a mixed agonist/antagonist for estrogen receptors alpha and beta. Endocrinology, 141, 3657-3667.

15. Aggarwal,B.B. and Shishodia,S. (2006) Molecular targets of dietary agents for prevention and therapy of cancer. Biochem.Pharmacol., 71, 1397-1421. 
16. Signorelli,P. and Ghidoni,R. (2005) Resveratrol as an anticancer nutrient: molecular basis, open questions and promises. J.Nutr.Biochem., 16, 449-466.

17. Le Corre,L., Chalabi,N., Delort,L., Bignon,Y.J., and Bernard-Gallon,D.J. (2005) Resveratrol and breast cancer chemoprevention: molecular mechanisms. Mol.Nutr.Food Res., 49, 462-471.

18. Shukla,Y. and Singh,R. (2011) Resveratrol and cellular mechanisms of cancer prevention. Ann.N.Y.Acad.Sci., 1215, 1-8.

19. Fulda,S. and Debatin,K.M. (2006) Resveratrol modulation of signal transduction in apoptosis and cell survival: a mini-review. Cancer Detect.Prev., 30, 217-223.

20. Filomeni,G., Graziani,I., Rotilio,G., and Ciriolo,M.R. (2007) trans-Resveratrol induces apoptosis in human breast cancer cells MCF-7 by the activation of MAP kinases pathways. Genes Nutr., 2, 295-305.

21. Nguyen,T.H., Mustafa,F.B., Pervaiz,S., Ng,F.S., and Lim,L.H. (2008) ERK1/2 activation is required for resveratrol-induced apoptosis in MDA-MB-231 cells. Int.J.Oncol., 33, 81-92.

22. Alkhalaf,M. (2007) Resveratrol-induced growth inhibition in MDA-MB-231 breast cancer cells is associated with mitogen-activated protein kinase signaling and protein translation. Eur.J.Cancer Prev., 16, 334-341.

23. De,A.F., Giordano,F., Vivacqua,A., Pellegrino,M., Panno,M.L., Tramontano,D., Fuqua,S.A., and Ando,S. (2011) Resveratrol, through NF-Y/p53/Sin3/HDAC1 complex phosphorylation, inhibits estrogen receptor alpha\} gene expression via p38MAPK/CK2 signaling in human breast cancer cells. FASEB $J$.

24. Araujo,J.R., Goncalves,P., and Martel,F. (2011) Chemopreventive effect of dietary polyphenols in colorectal cancer cell lines. Nutr.Res., 31, 77-87.

25. Szekeres,T., Saiko,P., Fritzer-Szekeres,M., Djavan,B., and Jager,W. (2011) Chemopreventive effects of resveratrol and resveratrol derivatives. Ann.N.Y.Acad.Sci., 1215, 89-95.

26. Gupta,S.C., Kannappan,R., Reuter,S., Kim,J.H., and Aggarwal,B.B. (2011) Chemosensitization of tumors by resveratrol. Ann.N.Y.Acad.Sci., 1215, 150-160.

27. Waffo-Teguo,P., Hawthorne,M.E., Cuendet,M., Merillon,J.M., Kinghorn,A.D., Pezzuto,J.M., and Mehta,R.G. (1903) Potential cancer-chemopreventive activities of wine stilbenoids and flavans extracted from grape (Vitis vinifera) cell cultures. Nutr Cancer JID - 7905040, 40, 173-179.

28. Shih,A., Davis,F.B., Lin,H.Y., and Davis,P.J. (2002) Resveratrol induces apoptosis in thyroid cancer cell lines via a MAPK- and p53-dependent mechanism. J Clin Endocrinol Metab JID - 0375362, 87, 12231232.

29. She,Q.B., Huang,C., Zhang,Y., and Dong,Z. (2002) Involvement of c-jun NH(2)-terminal kinases in resveratrol-induced activation of p53 and apoptosis. Mol Carcinog JID - 8811105, 33, 244-250.

30. Miloso,M., Bertelli,A.A., Nicolini,G., and Tredici,G. (1999) Resveratrol-induced activation of the mitogen-activated protein kinases, ERK1 and ERK2, in human neuroblastoma SH-SY5Y cells. Neurosci.Lett., 264, 141-144.

31. Pozo-Guisado,E., Alvarez-Barrientos,A., Mulero-Navarro,S., Santiago-Josefat,B., and FernandezSalguero,P.M. (2002) The antiproliferative activity of resveratrol results in apoptosis in MCF-7 but not in MDA-MB-231 human breast cancer cells: cell-specific alteration of the cell cycle.

Biochem.Pharmacol., 64, 1375-1386. 
32. Soleas,G.J., Goldberg,D.M., Grass,L., Levesque,M., and Diamandis,E.P. (2001) Do wine polyphenols modulate p53 gene expression in human cancer cell lines? Clin.Biochem., 34, 415-420.

33. Niles,R.M., McFarland,M., Weimer,M.B., Redkar,A., Fu,Y.M., and Meadows,G.G. (2003) Resveratrol is a potent inducer of apoptosis in human melanoma cells. Cancer Lett., 190, 157-163.

34. Azios,N.G. and Dharmawardhane,S.F. (2005) Resveratrol and estradiol exert disparate effects on cell migration, cell surface actin structures, and focal adhesion assembly in MDA-MB-231 human breast cancer cells. Neoplasia, 7, 128-140.

35. Pozo-Guisado,E., Merino,J.M., Mulero-Navarro,S., Lorenzo-Benayas,M.J., Centeno,F., AlvarezBarrientos,A., and Salguero,P.M. (2005) Resveratrol-induced apoptosis in MCF-7 human breast cancer cells involves a caspase-independent mechanism with downregulation of Bcl-2 and NF-kappaB. Int.J Cancer, 115, 74-84.

36. Rodrigue,C.M., Porteu,F., Navarro,N., Bruyneel,E., Bracke,M., Romeo,P.H., Gespach,C., and Garel,M.C. (2005) The cancer chemopreventive agent resveratrol induces tensin, a cell-matrix adhesion protein with signaling and antitumor activities. Oncogene.

37. Woo,J.H., Lim,J.H., Kim,Y.H., Suh,S.I., Min,d.S., Chang,J.S., Lee,Y.H., Park,J.W., and Kwon,T.K. (2004) Resveratrol inhibits phorbol myristate acetate-induced matrix metalloproteinase-9 expression by inhibiting JNK and PKC delta signal transduction. Oncogene, 23, 1845-1853.

38. Azios,N.G., Krishnamoorthy,L., Harris,M., Cubano,L.A., Cammer,M., and Dharmawardhane,S.F. (2007) Estrogen and resveratrol regulate Rac and Cdc42 signaling to the actin cytoskeleton of metastatic breast cancer cells. Neoplasia, 9, 147-158.

39. Brownson,D.M., Azios,N.G., Fuqua,B.K., Dharmawardhane,S.F., and Mabry,T.J. (2002) Flavonoid effects relevant to cancer. J Nutr JID - 0404243, 132, 3482S-3489S.

40. Klinge,C.M., Blankenship,K.A., Risinger,K.E., Bhatnagar,S., Noisin,E.L., Sumanasekera,W.K., Zhao,L., Brey,D.M., and Keynton,R.S. (2005) Resveratrol and estradiol rapidly activate MAPK signaling through estrogen receptors alpha and beta in endothelial cells. J.Biol.Chem., 280, 7460-7468.

41. Pozo-Guisado,E., Lorenzo-Benayas,M.J., and Fernandez-Salguero,P.M. (2004) Resveratrol modulates the phosphoinositide 3-kinase pathway through an estrogen receptor alpha-dependent mechanism: relevance in cell proliferation. Int.J.Cancer, 109, 167-173.

42. Baugher,P.J., Krishnamoorthy,L., Price,J.E., and Dharmawardhane,S.F. (2005) Rac1 and Rac3 isoform activation is involved in the invasive and metastatic phenotype of human breast cancer cells. Breast Cancer Res., 7, R965-R974.

43. Chan,A.Y., Coniglio,S.J., Chuang,Y.Y., Michaelson,D., Knaus,U.G., Philips,M.R., and Symons,M. (2005) Roles of the Rac1 and Rac3 GTPases in human tumor cell invasion. Oncogene, 24, 7821-7829.

44. Lacroix,M. (2008) MDA-MB-435 cells are from melanoma, not from breast cancer. Cancer Chemother.Pharmacol..

45. Sellappan,S., Grijalva,R., Zhou,X., Yang,W., Eli,M.B., Mills,G.B., and Yu,D. (2004) Lineage infidelity of MDA-MB-435 cells: expression of melanocyte proteins in a breast cancer cell line. Cancer Res., 64, 3479-3485.

46. Chambers,A.F. (2009) MDA-MB-435 and M14 cell lines: identical but not M14 melanoma? Cancer Res., 69, 5292-5293. 
47. Lee,M.H., Choi,B.Y., Kundu,J.K., Shin,Y.K., Na,H.K., and Surh,Y.J. (2009) Resveratrol suppresses growth of human ovarian cancer cells in culture and in a murine xenograft model: eukaryotic elongation factor 1 A2 as a potential target. Cancer Res., 69, 7449-7458.

48. Chen,J., Dong,X.S., and Guo,X.G. (2009) [Inhibitory effect of resveratrol on the growth of human colon cancer ls174t cells and its subcutaneously transplanted tumor in nude mice and the mechanism of action]. Zhonghua Zhong.Liu Za Zhi., 31, 15-19.

49. Bishayee,A. and Dhir,N. (2009) Resveratrol-mediated chemoprevention of diethylnitrosamine-initiated hepatocarcinogenesis: inhibition of cell proliferation and induction of apoptosis. Chem.Biol.Interact., $179,131-144$.

50. Castillo-Pichardo,L., Martinez-Montemayor,M.M., Martinez,J.E., Wall,K.M., Cubano,L.A., and Dharmawardhane,S. (2009) Inhibition of mammary tumor growth and metastases to bone and liver by dietary grape polyphenols. Clin.Exp.Metastasis, 26, 505-516.

51. Schlachterman,A., Valle,F., Wall,K.M., Azios,N.G., Castillo,L., Morell,L., Washington,A.V., Cubano,L.A., and Dharmawardhane,S.F. (2008) Combined resveratrol, quercetin, and catechin treatment reduces breast tumor growth in a nude mouse model. Transl Oncol, 1, 19-27.

52. Martinez-Montemayor,M.M., Otero-Franqui,E., Martinez,J., De,L.M.-P., Cubano,L.A., and Dharmawardhane,S. (2010) Individual and combined soy isoflavones exert differential effects on metastatic cancer progression. Clin.Exp.Metastasis.

53. He,H., Chen,X., Wang,G., Wang,J., and Davey,A.K. (2006) High-performance liquid chromatography spectrometric analysis of trans-resveratrol in rat plasma. J.Chromatogr.B Analyt.Technol.Biomed.Life Sci., 832, 177-180.

54. Boocock,D.J., Patel,K.R., Faust,G.E., Normolle,D.P., Marczylo,T.H., Crowell,J.A., Brenner,D.E., Booth,T.D., Gescher,A., and Steward,W.P. (2007) Quantitation of trans-resveratrol and detection of its metabolites in human plasma and urine by high performance liquid chromatography. J.Chromatogr.B Analyt.Technol.Biomed.Life Sci., 848, 182-187.

55. Yanes,O., Tautenhahn,R., Patti,G.J., and Siuzdak,G. (2011) Expanding coverage of the metabolome for global metabolite profiling. Anal.Chem., 83, 2152-2161.

56. Lin,H.S. and Ho,P.C. (2009) A rapid HPLC method for the quantification of 3,5,4'-trimethoxy-transstilbene (TMS) in rat plasma and its application in pharmacokinetic study. J.Pharm.Biomed.Anal., 49, 387-392.

57. Hernandez,E., De,L.M.-P., Dharmawardhane,S., and Vlaar,C.P. (2010) Novel inhibitors of Rac1 in metastatic breast cancer. P.R.Health Sci.J., 29, 348-356. 


\title{
CHARACTERIZATION OF EHOP-016, A NOVEL SMALL MOLECULE INHIBITOR OF RAC GTPASE*
}

\author{
Brenda L. Montalvo-Ortiz ${ }^{1}$, Eliud Hernández ${ }^{2}$, Alina De La Mota-Peynado ${ }^{1}$, Linette \\ Castillo-Pichardo ${ }^{1}$, Tessa Humphries-Bickley ${ }^{1}$, Cornelis P. Vlaar ${ }^{2}$, and Suranganie \\ Dharmawardhane ${ }^{1}$ \\ From ${ }^{1}$ Department of Biochemistry, School of Medicine and ${ }^{2}$ Department of Pharmaceutical \\ Sciences, School of Pharmacy, \\ University of Puerto Rico, Medical Sciences Campus, San Juan, Puerto Rico 00936 \\ Running head: EHop-016, a novel Rac inhibitor
}

Address correspondence to:

Suranganie Dharmawardhane. Ph.D., PO Box 365067, San Juan, P.R. 00936-5067. Fax: 787274-8724; E-mail: su.d@upr.edu

Cornelis P. Vlaar, Ph.D., PO Box 365067, San Juan, P.R. 00936-5067. Fax: 787-767-2796; Email: cornelis.vlaar@upr.edu

The Rho GTPase family regulates cellular functions that promote cancer progression such as transcription, cell cycle progression, migration, invasion, and metastasis. Of the Rho GTPases, Rac is a central regulator of actin cytoskeleton reorganization to form cell surface extensions (lamellipodia and invadopodia) required for cell migration/invasion during cancer metastasis. Rac hyperactivation and overexpression is associated with aggressive cancers and thus, Rac is an attractive target to inhibit cancer malignancy. Interference of the interaction of Rac with its direct upstream activators, guanine nucleotide exchange factors (GEFs), is a viable strategy for inhibiting Rac activity. We report the synthesis and characterization of a novel inhibitor of Rac activity based on the structure of the established Rac/Rac-GEF inhibitor NSC23766. Using MDA-MB-435 metastatic cancer cells that exhibit high endogenous Rac activity, we show that the new compound EHop-016, with an $\mathrm{IC}_{50}$ of $1.1 \mu \mathrm{M}$, is a 100 -fold more efficient inhibitor of Rac activity than NSC23766. EHop-016 is specific for Rac and does not inhibit the other Rho GTPase family members Rho $A$ and Cdc42. At effective concentrations $(<5 \mu M)$, EHop-016 does not affect the viability of transformed mammary epithelial cells
(MCF-10A) and reduces viability of MDA-MB435 cells by $20 \%$. EHop-016 inhibits Racregulated cell functions by reducing lamellipodia formation and decreasing directed migration of metastatic cancer cells. Therefore, EHop-016 holds promise as a targeted therapeutic agent for the treatment of metastatic cancers with high Rac activity.

\section{INTRODUCTION}

Rho family GTPases (Rho, Rac, Cdc42) are important intracellular signaling proteins that control diverse cellular functions, including actin cytoskeletal organization, invasion and metastasis, transcriptional regulation, cell cycle progression, apoptosis, vesicle trafficking, and cell-to-cell and cell-to-extracellular matrix adhesions $(1,2)$. Consequently, Rho GTPases have been implicated in cancer, and the progression of other diseases by a large number of studies (3-9). Of the Rho family GTPases, Rac1 and Rac3, the isoforms expressed in non-hematopoietic cells, have been specifically implicated in rearrangement of the actin cytoskeleton into cell surface protrusions called lamellipodia or invadopodia that are specific for forward migration during invasion (10); and thus, have been implicated in promotion of metastasis (11-14). Racs have also been shown to be essential for Ras and other oncogene-mediated 
transformation $(15,16)$. We and others have implicated hyperactive Rac1 and Rac3 with increased survival, proliferation, and invasion of breast and brain cancers (13, 17-21). Recent reports have shown a role for Rac in mammalian target of rapamycin (mTOR)-mediated regulation of cancer malignancy $(22,23)$ and anti breast cancer therapy resistance (24). Moreover, Rac1 was shown to increase Estrogen receptor-alpha $(\mathrm{ER} \alpha)$-mediated transcriptional activity in breast cancer (25). Studies have also demonstrated a cancer promoting role for the constitutively active Rac1b splice variant that is overexpressed in breast and colorectal cancer (21, 26-29). Since the malignant phenotype of Rac is associated with activation of its direct downstream effectors p21activated kinases (PAKs) (30, 31), much effort has been focused on the development of PAK inhibitors as anti cancer therapeutics (32, 33). However, in addition to PAK, Racs have multiple downstream effectors such as WAVE and Mena/VASP that contribute to cancer $(34,35)$. Therefore, targeting Rac is a more viable approach for the development of anticancer drugs (36).

Unlike the related small GTPase Ras, Racs are not mutated in malignant cancers but rather overexpressed or hyperactivated (21). Racs are activated by GTP/GDP exchange catalyzed by guanine nucleotide exchange factors (GEF) that are regulated via a myriad of cell surface receptors (37). So far, over 60 potential Rac-GEFs have been identified (38-40). Of these, Dbl family GEFs such as T-cell invasion and metastasis gene product (Tiam-1) and Vav $(1,3)$ have been implicated in breast cancer progression (41-44). Tiam-1 expression has also been correlated with high breast cancer cell migration, indicating a specific role for Tiam-1 in breast cancer metastasis (45). Recent reports have also shown that $\mathrm{PIP}_{3}-$ dependent Rac exchanger 1 (p-Rex1) is upregulated in breast cancer cells and breast cancer patients with poor prognosis $(46,47)$. Thus, elevation of Rac.GEF expression and (or) activity appears to be a common phenomenon during cancer progression. Therefore, targeting the binding of Rac to GEFs is a rational strategy to inhibit Rac activity and thus, cancer invasion.

NSC23766 was identified as a small molecule that binds to a putative binding pocket in the surface groove of Rac1 that interacts with the Rac-specific GEFs Trio and Tiam1 (48-50).
NSC23766 has been shown to inhibit the anchorage-independent growth and invasion of human prostate cancer PC-3 cells, Rac activation and Rac-dependent aggregation of platelets stimulated by thrombin, Rac1 and Rac2 activities of hematopoietic stem/progenitor cells, and migration from mouse bone marrow to peripheral blood $(51,52)$. NSC23766 has also been shown to inhibit invasion of chronic myelogenous leukemia cells in vitro and in vivo in a mouse model (49). Thus, such structure-function based rational design appears to represent a new avenue for generating small molecule inhibitors of Rac and its functions. However, NSC23766 is a moderately active Rac inhibitor with a relatively high IC $_{50}$ of $50-100 \mu \mathrm{M}$ in fibroblasts, which limits its potential use as a therapeutic agent (48). In addition, we have found that in the highly metastatic cancer cell line MDAMB-435, NSC23766 inhibits Rac1 by only 20\% at a concentration of $50 \mu \mathrm{M}$, and that at this concentration there is no significant effect on lamellopodia formation. Therefore, there is a need for more effective inhibitors to reduce Rac activity in highly metastatic cancer cells.

The identification of novel inhibitors of Rac that function via different inhibitory mechanisms has been the subject of several studies. Thus, whereas NSC23766 inhibits the interaction of Rac1 with several of its GEFs, the Rac inhibitor EHT 1864 interferes with the interaction of Rac with its downstream effectors at concentrations of $10-50 \mu \mathrm{M}(53,54)$. A virtual screening of a selected subset of compounds from the ZINC database for binding affinity to Rac1 based on the crystal structure of Rac1 with NSC23766, identified several novel Rac1 inhibitors with experimental $\mathrm{IC}_{50}$ values ranging from 12.2-57 $\mu \mathrm{M}$ (55). In addition, a highthroughput flow-cytometry bead-based multiplex assay identified MLS000532223 as a compound that prevents GTP binding to Rac. However, other Rho GTPases, such as Cdc42, are also affected by this compound. Small molecule compounds have also been synthesized to specifically inhibit the Rac1b splice variant (56). Another report identified ITX3 as a GEF inhibitor that targeted Rac and RhoG interaction with Trio; however, this compound is effective at high 50-100 $\mu \mathrm{M}$ concentrations (57). In an endeavor to develop novel more potent Rac inhibitors with possible clinical applications, we demonstrated that 
NSC23766 could be utilized as a lead structure for the design of compounds with 2-3 times enhanced potency (58). Encouraged by these results, we now report the identification and characterization of the biological activity of EHop-016, a novel NSC23766 derivative that inhibits Rac1 100-fold more effectively than the parent compound.

\section{EXPERIMENTAL PROCEDURES}

Synthesis of EHop-016 - ${ }^{1} \mathrm{H}$ and ${ }^{13} \mathrm{C}$ NMR spectra were recorded on a Bruker $400 \mathrm{MHz}$ Spectrometer. Mass spectra were obtained on a Hewlett Packard 6890N GC/MS Spectrometer. All chemicals were purchased from Sigma Aldrich Chemical Company. The synthesis of EHop-016 (5) was performed in two steps according to the reaction scheme provided in Figure 1, and carried out analogous to the procedure described in (58). (2-Chloro-pyrimidin-4-yl)-(9-ethyl-9H-carbazol-3$y l$ )-amine 3 was obtained as a pure compound in a yield of $53 \%$. The product was identified with TLC, NMR and GC/MS. $\mathrm{R}_{f}=0.23$ (3:1, HexaneEthyl Acetate); ${ }^{1} \mathrm{H}$ NMR (DMSO-d 6 , $\left.400 \mathrm{MHz}\right) \delta$ 1.32 (t, $J=6.9 \mathrm{~Hz}, 3 \mathrm{H}), 4.45$ (q, $J=6.6 \mathrm{~Hz}, 2 \mathrm{H})$, $6.72(\mathrm{~s}, 1 \mathrm{H}), 7.20(\mathrm{t}, J=7.36 \mathrm{~Hz}, 1 \mathrm{H}), 7.47(\mathrm{t}, J=$ $7.30 \mathrm{~Hz}, 1 \mathrm{H}), 7.56(\mathrm{~s}, 1 \mathrm{H}), 7.62(\mathrm{t}, J=8.68 \mathrm{~Hz}$, 1H), 8.11 (t, J = 7.36 Hz, 1H), 8.27 (s, 1H), 10.1 (s, $1 \mathrm{H}) ;{ }^{13} \mathrm{C}\left(\right.$ DMSO$\left.-\mathrm{d}_{6}, 100 \mathrm{MHz}\right) \delta 13.7,37.0$, $109.2,109.4,115.0,118.7,120.3,121.3,121.9$, 122.3, 125.9, 129.9, 136.9, 140.0, 156.9, 159.6, 162.4; LRGC-MS m/z (rel\%):[M] 276 (100), [M$\mathrm{Cl}]^{+} 241$ (40), $\left[\mathrm{M}-\mathrm{C}_{5} \mathrm{H}_{5} \mathrm{~N}_{3} \mathrm{Cl}\right]^{+} 134$ (26). $\quad N^{4}-(9-$ Ethyl-9H-carbazol-3-yl)-N2-(3-morpholin-4-ylpropyl)-pyrimidine-2,4-diamine 5 (EHop-016) was obtained as a pure compound in a yield of $93 \%$. The product was identified to be essentially pure by TLC and NMR: $\mathrm{R}_{f}=0.34\left(9: 1, \mathrm{CH}_{2} \mathrm{Cl}_{2^{-}}\right.$ $\mathrm{MeOH}) ;{ }^{1} \mathrm{H}$ NMR (DMSO-d 6 , $\left.400 \mathrm{MHz}\right) \delta 1.31$ (t, $J=7.0 \mathrm{~Hz}, 3 \mathrm{H}), 1.73$ (m, 2H), $2.32(\mathrm{~m}, 2 \mathrm{H}), 2.34$ (t, $J=6.89 \mathrm{~Hz}, 8 \mathrm{H}), 3.52(\mathrm{~m}, 2 \mathrm{H}), 4.42$ (q, $J=7.0$ $\mathrm{Hz}, 2 \mathrm{H}), 5.98$ (d, $J=5.7 \mathrm{~Hz}, 1 \mathrm{H}), 6.69$ (t, $J=5.3$ $\mathrm{Hz}, 1 \mathrm{H}), 7.16$ (t, $J=7.4,1 \mathrm{H}), 7.43$ (t, $J=7.2 \mathrm{~Hz}$, $1 \mathrm{H}), 7.53$ (t, $J=9.0 \mathrm{~Hz}, 4 \mathrm{H}), 7.81(\mathrm{~d}, J=5.4 \mathrm{~Hz}$, $1 \mathrm{H}), 8.10$ (s, 1H), 8.66 (s, 1H), $9.1(\mathrm{~s}, 1 \mathrm{H}) ;{ }^{13} \mathrm{C}$ (DMSO-d $6,100 \mathrm{MHz}) \delta 13.7,26.2,36.9,53.4$, 56.3, 66.2, 108.9, 109.0, 118.2, 119.7, 120.2, 122.0, 122.2, 125.6, 132.5, 135.5, 139.9, 159.8, 160.9, 162.1 .
Docking of EHop-16 into the crystal structure of Rac1- For molecular docking, Autodock 4.0 with AutodockTools 1.5.4 as the graphical user interface were used $(59,60)$. The coordinates of the crystal structure from the Rac1NSC23766 complex were obtained from (61). EHop-016 was drawn using ChemDraw Ultra 7.0 and energy minimized with MOPAC AM1 in Chem3D Ultra 7.0. After removing NSC23766 from the crystal structure, AutodockTools was used to prepare the GEF-interacting region of Rac and EHop-016 for docking, and to create a grid of $60 \AA x 60 \AA x 60 \AA$ with a grid spacing of $0.375 \AA$ centered on the original position of NSC23766. A flexible docking of 100 GA-runs was performed with the number of individuals in population set to 200 and the maximum number of energy evaluations set to 25,000,000, with other parameters accepted as suggested by AutodockTools, which also was used for clustering $(\mathrm{RMS}=2 \AA$ ) of the results obtained.

Rac activity assays- Rac activity was determined from lysates of the MDA-MB-435 human metastatic cancer cell line (from ATCC) that we have previously shown to have high endogenous Rac activity (18). MDA-MB-435 cells in culture media were treated with vehicle $(0.1 \%$ DMSO), or varying concentrations of EHop-016 $(0-10 \mu \mathrm{M})$ for $24 \mathrm{~h}$. Rac1 activity was determined as previously described by us, using the G-LISA Rac1 Activation Assay kit (Cytoskeleton, Inc., Denver, CO) (58).

For generation of $\mathrm{IC}_{50}$ curves for each inhibitor (EHop-016 or NSC-23766) data from three independent duplicate experiments was pooled and four parameter dose-response curves were fitted using the non-linear regression function of GraphPad Prism ${ }^{\circledR}$.

Rho GTPase activity assays- Rho, Rac, and Cdc42 activities were analyzed from MDAMB-435 cell lysates by pulldown assays following treatment with EHop-016 for 24 h. GST-Rho binding domain from Rhotekin was used to isolate active GTP bound Rho, and a GST-p21 binding domain of PAK1 to isolate active Rac.GTP or Cdc42.GTP, as described in $(17,18)$. Active and total Rho GTPases were identified by western blotting with specific antibodies: anti RhoA, anti 
Rac (1,2,3), anti Rac3, or anti Cdc42 (Cell Signaling Technology, Inc., Danvers, MA).

Cell viability assays- As described in (58), MDA-MB-435 or MCF-10 mammary epithelial cells (from ATCC) were incubated in vehicle $(0.1 \%$ DMSO) or varying concentrations of EHop-016 $(0-10 \mu \mathrm{M})$ for $24 \mathrm{~h}$. Cell viability was measured using the MTT [3-(4,5dimethylthiazol-2-yl)-2,5-diphenyl tetrazolium bromide] cell survival and proliferation kit (Millipore, Inc., Billerica, MA) according to manufacturer's instructions.

Fluorescence microscopy- As described in (58), MDA-MB-435 cells (in DMEM with 10\% FBS) were treated with vehicle (0.1\% DMSO) or EHop-016 at 2 and $4 \mu \mathrm{M}$ for $24 \mathrm{~h}$. Cells were fixed, permeabilized, and stained with Rhodamine phalloidin to visualize F-actin. Fluorescence micrographs were acquired at $600 \mathrm{X}$ magnification in a Olympus BX40 fluorescence microscope using a Spot digital camera.

Cell migration assays- As described in (58), quiescent MDA-MB-435 cells were treated with vehicle or varying concentrations of EHop$016(0-5 \mu \mathrm{M})$ for $24 \mathrm{~h}$. Exactly $2 \times 10^{5}$ cells were placed on the top well of Transwell chambers (Corning Life Sciences, Lowell, MA) with media containing $10 \%$ FBS in the bottom well. The number of cells that migrated to the underside of the membrane following $4 \mathrm{~h}$ incubation was quantified for each treatment. Fixed cells were counted at 200X magnification in a Olympus CKX41 inverted fluorescence microscope following propidium iodide (PI) staining to visualize nuclei.

\section{RESULTS}

Synthesis of EHop-016- The inhibition of Rac1 activity has been proposed as a strategy for the prevention of cancer metastasis. However, the frequently utilized small molecule Rac1 inhibitor NSC23766 only has a moderate biological effect on the highly metastatic cancer cell line MDAMB-435, even at high concentrations; thus, illustrating the need for more potent and effective inhibitors. We recently reported the synthesis of novel NSC23766 derivatives that showed increased Rac1 inhibitory activity in MDA-MB435 cells with a considerable reduction of cell functions regulated by Rac (58). Further optimization of the NSC23766 lead structure lead to the identification of EHop-016, which was synthesized according to the procedure described in Figure 1.

Briefly, 2,4-dichloropyrimidine (1) was reacted with 3-amino-9-ethylcarbazole (2) by heating in iso-propanol in the presence of $N, N$ diisopropylethylamine. Separation of the regioisomers provided the pure 4-substituted pyrimidine derivative (3), which was reacted with 4-(3-Aminopropyl)morpholine (4) in sec-butanol under microwave heating in the presence of $N, N$ diisopropylethylamine to provide EHop-016 (5).

Molecular docking of EHop-016- NSC23766 was designed to prevent the activation of Rac1 by binding to the region where several GEFs interact with Rac1, thus inhibiting its activation. This mode of action was recently confirmed via analysis of the crystal structure of Rac1 with NSC23766. For the design of novel, more potent inhibitors, we wished to maintain the activity and selectivity profile of NSC23766. Therefore, in order to obtain a similar binding interaction for the new inhibitors, the core structural features of NSC23766 were maintained, including a central pyrimidine core, an aromatic 4-substituent and an amino-group containing 2-substituent, both connected to the pyrimidine core via nitrogen atoms. Thus far, EHop-016 is the most active Rac1 inhibitor based on NSC23766 that we have identified. Molecular docking, to study the binding interactions of EHop-016 with Rac1, demonstrated that EHop-016 can bind to Rac1 in different orientations into the cleft formed by amino acids Val36, Phe37, Asp38, Asn39, Trp56, Asp57, Thr58, Ala59, Tyr64, Leu67, Ag68, Leu70 and Ser71. Clustering of the docking results revealed that the largest cluster $($ size $=29)$ also had the docking conformation with the lowest energy ($7.91 \mathrm{kcal} / \mathrm{mol}$ ), and the most favorable conformation is illustrated in figure $1 \mathrm{~B}$, together with the position of NSC23766 in the crystal structure of the Rac1-NSC23766 complex. Whereas NSC23766 is stretched over the surface of Rac1, similar to the other novel Rac1 inhibitors that were recently identified (55), EHop-016 appears to favor a bent conformation that binds to 
a deeper binding pocket similar to the N,Ndiethylamino group of NSC23766. In its energetically most favorable conformation, the binding of EHop-016 is strengthened by two hydrogen bonding interactions with residues Asp38 and Asn39. Furthermore, EHop-016 has a close interaction with Trp56, which has been shown to be critical for binding of Rac to its GEFs (48-50). Two smaller clusters (sizes $=13$ and 21) with lowest energy conformations of -7.61 and $7.41 \mathrm{kcal} / \mathrm{mol}$ respectively, dock into the same cleft albeit in a somewhat different mode (supplemental data, figures S1A and S1B). Based on the above molecular docking results, structural similarity to NSC23766, and the biological activity profile described herein, it is reasonable to postulate that EHop-016 also interferes with binding of Rac1 with its GEFs via binding to the three-way junction site that contain the switch I, switch II, and $ß$ loops of the effector region of Rac that interacts with the dbl homology (DH) domain of Rac GEFs (62).

EHop-016 is a potent inhibitor of Rac1- The potential of EHop-016 to inhibit Rac activity was determined in the highly metastatic human cancer cell line MDA-MB-435 that was previously reported by us to contain high endogenous Rac activity (18). MDA-MB-435 cells were treated for $24 \mathrm{~h}$ with varying concentrations of EHop-016, and for comparison, NSC23766. Rac activity from cell lysates was measured using the G-LISA Rac1 activation assay. As shown in Figure 2, the $\mathrm{IC}_{50}$ of the parent compound, NSC23766 in MDA-MB435 cells was as high as $95 \mu \mathrm{M}$, which explains its moderate biological activity in this highly metastatic cancer cell line. Upon treatment of MDA-MB-435 cells with NSC23766 at a concentration of $50 \mu \mathrm{M}$, Rac activity is only inhibited by $\sim 30 \%$. The concentration curves in Figure 2 demonstrate that EHop-016 inhibits Rac1 activity in MDA-MB-435 cells with an $\mathrm{IC}_{50}$ of 1.1 $\mu \mathrm{M}$, while the $\mathrm{IC}_{50}$ for NSC23766 in the same cell line was $95 \mu \mathrm{M}$. Thus, EHop-016 is approximately 100 times more potent than NSC23766 and 10-50 times more potent than other currently available Rac inhibitors.

Activity of EHop-016 with other Rho family GTPases- In order to investigate the selectivity of EHop-016, we studied its effect on other Rho family GTPases. Similar to Rac1, the Rac isoform Rac3 that is also overexpressed in cancer cells was inhibited by $58 \%$ at a concentration of $1 \mu \mathrm{M}$ EHop-016. This is expected since Rac1 and Rac3 demonstrate significant structure similarity and are activated by the same GEFs (Fig. 3B). In accordance, Rac activity as detected by a pan Rac isoform antibody resulted in a 79\% inhibition at 2 $\mu \mathrm{M}$ EHop-016 (double the $\mathrm{IC}_{50}$ for Rac inhibition) and a $93 \%$ inhibition of Rac activity at $4 \mu \mathrm{M}$ EHop-016. However, EHop-016 did not affect the activity of the Rac homolog Cdc42 at 1, 2, or 4 $\mu \mathrm{M}$ EHop-016. Interestingly, the activity of the closely related Rho GTPase RhoA increased by 1.5-fold in response to $2 \mu \mathrm{M}$ but was closer to vehicle controls at $4 \mu \mathrm{M}$ EHop-016 (Fig. 3B). This increase may be a compensatory mechanism for Rac activation and is expected to increase Rhoregulated assembly of F-actin into stress fibers and further inhibit Rac-mediated lamellipodia formation and directed migration $(1,4,10)$.

Effect of EHop-016 on cell viability- Next, we tested the viability of MDA-MB-435 cancer cells and MCF10A transformed mammary epithelial cells in the presence of EHop-016. EHop-016 at the $\mathrm{IC}_{50}$ of $1 \mu \mathrm{M}$ or at a 2-fold higher concentration $(2 \mu \mathrm{M})$ did not significantly affect mammary epithelial or cancer cell viability (Fig. 4). At $10 \mu \mathrm{M}$, EHop-016 reduced viability of both cell lines by $50 \%$, indicating a potential toxicity at concentrations above $5 \mu \mathrm{M}$.

EHop-016 reduces Rac-regulated cell functions- Rac is a central regulator of lamellipodia and invadopodia that control directed mesenchymal migration and invasion of cancer cells (4). Therefore, we investigated the effect of EHop-016 on lamellipodia formation of MDAMB-435 cells. As shown in Figure 5, in cells stained with Rhodamine phalloidin to localize Factin, treatment for $24 \mathrm{~h}$ with EHop-016 at 2 and 4 $\mu \mathrm{M}$ inhibited lamellipodia formation in the MDAMB-435 metastatic cancer cell line that has high Rac expression and activity. Results show that $\sim 86 \%$ of control cells demonstrated lamellipodia and membrane ruffles. Following EHop-016 treatment at 2 and $4 \mu \mathrm{M}$, only $27 \%$ of the cells extended lamellipodia. Therefore, EHop-016 at concentrations that inhibited Rac activity by 70- 
$80 \%$ (Figs. 2, 3) significantly inhibited lamellipodia extension to a similar extent $(\sim 70 \%)$. However, EHop-016 did not affect the extension of filopodia that are regulated by Cdc42 (63). This data indicates a specific role for EHop-016 in inhibiting Rac-directed actin structures.

Next, we determined the effect of EHop-016 on directed cell migration, which is regulated by Rac-mediated lamellipodia formation (4). A transwell assay was used to determine the ability of quiescent MDA-MB-435 cells treated with EHop-016 at 0-5 $\mu \mathrm{M}$ to migrate towards culture media containing $10 \%$ serum, through a membrane containing $8 \mu \mathrm{M}$ diameter pores. Interestingly, control and cells treated with $\mathrm{IC}_{50}$ concentration of EHop-016 (1 $\mu \mathrm{M})$ showed larger nuclei and a spread morphology on the membrane, while the cells at higher concentrations demonstrated small nuclei at the pores of the membrane, without substantial spreading (Fig. 6A). Even though all PI-stained nuclei were quantified, it is possible that the cells treated with $>2 \mu \mathrm{M}$ EHop-016 do not have the same invasive capacity as the control cells or cells at lower EHop-016 concentrations, due to decreased lamellipodia and invadopodia. As shown in Figure $6 \mathrm{~B}$, treatment with 2 and $5 \mu \mathrm{M}$ EHop-016 reduced directed cell migration by $\sim 60 \%$ at concentrations that reduced Rac activity by $\sim 80 \%$ (Figs. 2, 3) without affecting cell viability (Fig. 4). Since equal cell numbers were placed on the top wells of the Transwell chambers and the migration assays were conducted for only four hours, we do not expect effects of reduced cell viability or cell death to affect data interpretation.

These experiments were conducted in culture media containing 10\% FBS to recapitulate the endogenous cellular environment. Since serum contains activators of Rac, Rho, and Cdc42, this experimental design does not allow for the analysis of Rac regulation in the absence of other cytoskeletal regulators. Experiments testing the effect of Rac-specific regulators such as epidermal growth factor (EGF) and platelet derived growth factor (PDGF) are in progress.

\section{DISCUSSION}

Herein, we describe the synthesis and characterization of a potent and specific small molecule inhibitor of Rac 1, a key signaling protein that regulates cancer progression. Recent studies have demonstrated that inhibition of Rac activity, and thus cancer cell invasion, is a viable strategy for the treatment of breast cancer metastasis (64, 65). Current small molecule inhibitors of Rac activity such as NSC23766 and EHT 1864 are effective at high concentrations, approximately 50-100 $\mu \mathrm{M}$ for NSC23766 and 10 $\mu \mathrm{M}$ for EHT 1864, and the inhibitory efficiency appears to be dependent on cell type. As we have previously shown, high metastatic variants of MDA-MB-435 demonstrate high endogenous Rac activity, without changes in Rac expression (18). Therefore high GEF activity may explain the moderate biological activity of NSC23766 in metastatic cancer cells.

Our objective was to utilize the structure of NSC23766 as a lead for the development of a novel, more potent inhibitor that similar to NSC23766, binds specifically into a surface groove of Rac1 known to be critical for Tiam 1 and Trio GEF interaction (66). Compared to NSC23766, EHop-016 was found to be a 100fold more potent inhibitor of Rac activity in the metastatic MDA-MB-435 cancer cell line. EHop016 is also a 10-50-fold more effective inhibitor of Rac1 than the recently reported NSC23766 derivatives (58). Our data demonstrate that EHop016 is specific for Rac isoforms Rac1 and Rac3, while Cdc42, a close homolog that is not activated by the Rac GEFs Tiam-1, Trio, Vav, or PRex $(46,62,67)$ is not inhibited by EHop-016. Because of its structural similarity to NSC23766, as well as its biological activity profile and molecular docking findings, it is proposed that EHop-016 also interacts with the effector region of Rac, where it inhibits the binding of GEFs $(48,62,68)$.

EHop-016 does not inhibit Rho activity indicating further specificity for blocking the Rac/Rac.GEF interaction. The increased Rho activity following a $24 \mathrm{~h}$ incubation of EHop-016 at double the $\mathrm{IC}_{50}$ concentrations may be due to a side effect of Rac inhibition. Studies have shown that Rac activation can inhibit Rho activity and Rho activation can inhibit Rac activity $(1,4,10)$. Therefore, this Rac-1/RhoA antagonism may explain the observed effect of Rho activity following Rac inhibition. Binding studies of Rho and EHop-016 will be conducted in future studies to rule out a role for EHop-016 in direct activation of Rho. 
We also show that cancer cell viability is not affected by EHop-016 at concentrations that inhibit Rac and actin cytoskeletal changes. Racs have been shown to affect cell survival via a number of signaling pathways including phosinositide 3-kinase (PI3-K), nuclear factor $\kappa \mathrm{B}$ (Nf-kB), and jun kinase (JNK)/p38 mitogen activated protein kinases (MAPK) (69). Recent reports have shown that the Rac GDP dissociation inhibitor Rho GDI is overexpressed in malignant cancers (70). Inhibition of RhoGDI was shown to reduce breast tumorigenesis by activation of Racinduced p38/JNK MAPK activities (71), while others have shown increased Rac-mediated breast cancer cell migration following Rho GDI inhibition (72). These discrepancies may be due to the multiple roles of Rho GDI in breast cancer $(70,73)$ and reports show that there are both positive and negative roles for p38/Jnk MAPK signaling in breast cancer progression (74-76). In fact, a recent report showed that NF- $\kappa \mathrm{B}$, but not cJun or p38 pathways, mediates the survival signals from Rac1 (20).

Our data demonstrating that EHop-016 does not affect the viability of mammary epithelial cells at effective concentrations, suggests its utility as a viable anti metastatic cancer therapeutic agent with only minor toxicity to normal cells. In preliminary studies, we have tested the effect of oral administration of EHop-016 to athymic nude mice at $1 \mathrm{mg} / \mathrm{kg}$ body weight once a week for 9 weeks and found no change in body weight or gross indications of toxicity (supplemental Fig. S2). Therefore, EHop-016 holds promise as a nontoxic Rac specific inhibitor for further development as an anti-cancer metastasis therapeutic.

Results show that EHop-016 reduced lamellipodia and directed cell migration by 60 $70 \%$ at concentrations that do not affect cell viability but inhibits Rac activity by $\sim 80 \%$. At a concentration of $2 \mu \mathrm{M}$, EHop-016 exerted a dramatic reduction in lamellipodia formation without affecting Cdc42-induced filopodia extension. The concentration at which EHop-016 inhibited lamellipodia extension and cell migration is approximately 10-50 fold less than the reported concentrations of NSC23766 and EHT1864 that are required to inhibit lamellipodia extension and cell migration $(48,58,77)$. This result is similar to our previous report of decreased MDA-MB-435 cell migration in the presence of other NSC23766 derivatives that inhibit Rac activity (58). Even though a single report demonstrated increased migration of MDA-MB-435 and MDA-MB-231 metastatic breast cancer cells following 50-100 $\mu \mathrm{M}$ NSC23766, in our hands, treatment with 100 $\mu \mathrm{M}$ NSC23766 for $24 \mathrm{~h}$ resulted in a $75 \%$ decrease in MDA-MB-435 cell migration (data not shown). Moreover, there are several reports of decreased cell migration in metastatic breast cancer cells following direct inhibition of Rac1 and Rac3 by expression of dominant negative Rac and siRNA knockdown of Rac expression, or by indirect inhibition of Rac by blocking upstream effector activity (13, 18, 72, 77-82). Therefore, given the volume of published data that supports our hypothesis, it is reasonable to conclude that Rac inhibition leads to decreased migration of metastatic cancer cells.

In conclusion, we have shown that EHop-016 is an effective Rac-specific inhibitor at micromolar concentrations, and substantially inhibits Racactivated lamellipodia formation and cell migration. Therefore, EHop-016 appears to be a promising candidate for further development as a pharmacological inhibitor of Rac activity in metastatic cancer cells. In addition, EHop-016 could prove to be a valuable, more potent probe for the study of Rac-regulated cellular processes.

Acknowledgements-We thank Dr. José RodríguezMedina for the use of the Olympus BX40 flurescence microscope and Dr. Luis Cubano for salary support of ADMP. 


\section{REFERENCES}

1. Ridley, A. J. (2006) Trends Cell Biol. 16, 522-529

2. Mack, N. A., Whalley, H. J., Castillo-Lluva, S., and Malliri, A. (2011) Cell Cycle 10, 1571-1581

3. Lazer, G. and Katzav, S. (2011) Cell Signal. 23, 969-979

4. Parri, M. and Chiarugi, P. (2010) Cell Commun. Signal. 8, 23

5. Mulloy, J. C., Cancelas, J. A., Filippi, M. D., Kalfa, T. A., Guo, F., and Zheng, Y. (2010) Blood 115, 936-947

6. Pai, S. Y., Kim, C., and Williams, D. A. (2010) Dis. Markers 29, 177-187

7. Vega, F. M. and Ridley, A. J. (2008) FEBS Lett. 582, 2093-2101

8. Tang, Y., Olufemi, L., Wang, M. T., and Nie, D. (2008) Front Biosci. 13, 759-776

9. Karlsson, R., Pedersen, E. D., Wang, Z., and Brakebusch, C. (2009) Biochim. Biophys. Acta 1796, 91-98

10. Hall, A. (2005) Biochem. Soc. Trans. 33, 891-895

11. Lin, M. and van Golen, K. L. (2004) Breast Cancer Res. Treat. 84, 49-60

12. Kleer, C. G., Griffith, K. A., Sabel, M. S., Gallagher, G., van Golen, K. L., Wu, Z. F., and Merajver, S. D. (2005) Breast Cancer Res. Treat. 93, 101-110

13. Chan, A. Y., Coniglio, S. J., Chuang, Y. Y., Michaelson, D., Knaus, U. G., Philips, M. R., and Symons, M. (2005) Oncogene 24, 7821-7829

14. Burbelo, P., Wellstein, A., and Pestell, R. G. (2004) Breast Cancer Res. Treat. 84, 43-48

15. Qiu, R. G., Chen, J., Kirn, D., McCormick, F., and Symons, M. (1995) Nature 374, 457-459

16. Renshaw, M. W., Lea-Chou, E., and Wang, J. Y. (1996) Curr Biol 6, 76-83

17. Azios, N. G., Krishnamoorthy, L., Harris, M., Cubano, L. A., Cammer, M., and Dharmawardhane, S. F. (2007) Neoplasia 9, 147-158

18. Baugher, P. J., Krishnamoorthy, L., Price, J. E., and Dharmawardhane, S. F. (2005) Breast Cancer Res. 7, R965-R974

19. Mira, J. P., Benard, V., Groffen, J., Sanders, L. C., and Knaus, U. G. (2000) Proc Natl Acad Sci U $S$ A 97, 185-189

20. Yoshida, T., Zhang, Y., Rivera Rosado, L. A., Chen, J., Khan, T., Moon, S. Y., and Zhang, B. (2010) Mol. Cancer Ther. 9, 1657-1668

21. Schnelzer, A., Prechtel, D., Knaus, U., Dehne, K., Gerhard, M., Graeff, H., Harbeck, N., Schmitt, M., and Lengyel, E. (2000) Oncogene 19, 3013-3020

22. Saci, A., Cantley, L. C., and Carpenter, C. L. (2011) Mol. Cell 42, 50-61

23. Gulhati, P., Bowen, K. A., Liu, J., Stevens, P. D., Rychahou, P. G., Chen, M., Lee, E. Y., Weiss, H. L., O'Connor, K. L., Gao, T., and Evers, B. M. (2011) Cancer Res. 71, 3246-3256

24. Dokmanovic, M., Hirsch, D. S., Shen, Y., and Wu, W. J. (2009) Mol. Cancer Ther. 8, 1557-1569

25. Rosenblatt, A. E., Garcia, M. I., Lyons, L., Xie, Y., Maiorino, C., Desire, L., Slingerland, J., and Burnstein, K. L. (2011) Endocr. Relat Cancer 18, 207-219

26. Singh, A., Karnoub, A. E., Palmby, T. R., Lengyel, E., Sondek, J., and Der, C. J. (2004) Oncogene 23, 9369-9380

27. Stallings-Mann, M. and Radisky, D. (2007) Cells Tissues. Organs 185, 104-110

28. Jordan, P., Brazao, R., Boavida, M. G., Gespach, C., and Chastre, E. (1999) Oncogene 18, 68356839

29. Matos, P. and Jordan, P. (2008) Mol. Cancer Res. 6, 1178-1184

30. Whale, A., Hashim, F. N., Fram, S., Jones, G. E., and Wells, C. M. (2011) Front Biosci. 16, 849864

31. Dummler, B., Ohshiro, K., Kumar, R., and Field, J. (2009) Cancer Metastasis Rev. 28, 51-63

32. Kichina, J. V., Goc, A., Al-Husein, B., Somanath, P. R., and Kandel, E. S. (2010) Expert. Opin. Ther. Targets. 14, 703-725

33. Yi, C., Maksimoska, J., Marmorstein, R., and Kissil, J. L. (2010) Biochem. Pharmacol. 80, 683689 
34. Bishop, A. L. and Hall, A. (2000) Biochem J 348 Pt 2, 241-255

35. Baranwal, S. and Alahari, S. K. (2011) Curr. Drug Targets.

36. Deacon, S. W. and Peterson, J. R. (2008) Handb. Exp. Pharmacol. 431-460

37. Jaffe, A. B. and Hall, A. (2005) Annu. Rev. Cell Dev. Biol. 21, 247-269

38. Rossman, K. L., Der, C. J., and Sondek, J. (2005) Nat. Rev. Mol. Cell Biol. 6, 167-180

39. Schmidt, A. and Hall, A. (2002) Genes Dev. 16, 1587-1609

40. Bernards, A. (2003) Biochim. Biophys. Acta 1603, 47-82

41. Palmby, T. R., Abe, K., Karnoub, A. E., and Der, C. J. (2004) Mol. Cancer Res. 2, 702-711

42. Miller, S. L., DeMaria, J. E., Freier, D. O., Riegel, A. M., and Clevenger, C. V. (2005) Mol. Endocrinol. 19, 939-949

43. Sastry, S. K., Rajfur, Z., Liu, B. P., Cote, J. F., Tremblay, M. L., and Burridge, K. (2006) J. Biol. Chem. 281, 11627-11636

44. Minard, M. E., Kim, L. S., Price, J. E., and Gallick, G. E. (2004) Breast Cancer Res. Treat. 84, 21-32

45. Adams, H. C., III, Chen, R., Liu, Z., and Whitehead, I. P. (2010) Breast Cancer Res. 12, R69

46. Sosa, M. S., Lopez-Haber, C., Yang, C., Wang, H., Lemmon, M. A., Busillo, J. M., Luo, J., Benovic, J. L., Klein-Szanto, A., Yagi, H., Gutkind, J. S., Parsons, R. E., and Kazanietz, M. G. (2010) Mol. Cell 40, 877-892

47. Montero, J. C., Seoane, S., Ocana, A., and Pandiella, A. (2010) Oncogene

48. Gao, Y., Dickerson, J. B., Guo, F., Zheng, J., and Zheng, Y. (2004) Proc. Natl. Acad. Sci. U. S. A 101, 7618-7623

49. Thomas, E. K., Cancelas, J. A., Chae, H. D., Cox, A. D., Keller, P. J., Perrotti, D., Neviani, P., Druker, B. J., Setchell, K. D., Zheng, Y., Harris, C. E., and Williams, D. A. (2007) Cancer Cell 12, 467-478

50. Binker, M. G., Binker-Cosen, A. A., Gaisano, H. Y., and Cosen-Binker, L. I. (2008) Exp. Physiol 93, 1091-1103

51. Akbar, H., Cancelas, J., Williams, D. A., Zheng, J., and Zheng, Y. (2006) Methods Enzymol. 406, 554-565

52. Nassar, N., Cancelas, J., Zheng, J., Williams, D. A., and Zheng, Y. (2006) Curr. Top. Med. Chem. 6, 1109-1116

53. Onesto, C., Shutes, A., Picard, V., Schweighoffer, F., and Der, C. J. (2008) Methods Enzymol. 439, 111-129

54. Shutes, A., Onesto, C., Picard, V., Leblond, B., Schweighoffer, F., and Der, C. J. (2007) J Biol. Chem. 282, 35666-35678

55. Ferri, N., Corsini, A., Bottino, P., Clerici, F., and Contini, A. (2009) J. Med. Chem. 52, 40874090

56. Beausoleil, E., Chauvignac, C., Taverne, T., Lacombe, S., Pognante, L., Leblond, B., Pallares, D., Oliveira, C. D., Bachelot, F., Carton, R., Peillon, H., Coutadeur, S., Picard, V., Lambeng, N., Desire, L., and Schweighoffer, F. (2009) Bioorg. Med. Chem. Lett. 19, 5594-5598

57. Bouquier, N., Vignal, E., Charrasse, S., Weill, M., Schmidt, S., Leonetti, J. P., Blangy, A., and Fort, P. (2009) Chem. Biol. 16, 657-666

58. Hernandez, E., De La Mota-Peynado, A., and Dharmawardhane, S. and Vlaar, C. P. (2010) P. R. Health Sci. J 29, 348-356

59. Morris, G. M., Goodsell, D. S., Halliday, R. S., Huey, R., Hart, W. E., Belew, R. K., and Olson, A. J. (1998) J. Comp. Chem. 19, 1639-1662

60. Huey, R., Morris, G. M., Olsen, A. J., and Goodsell, D. S. (2007) J. Comp. Chem. 28, 1145-1152

61. Zheng, Y., Nassar, N., and Skowronek, K. R. (2010) U. S. Patent No. 17,826,982.

62. Worthylake, D. K., Rossman, K. L., and Sondek, J. (2000) Nature 408, 682-688

63. Fukata, M., Nakagawa, M., and Kaibuchi, K. (2003) Curr. Opin. Cell Biol. 15, 590-597

64. Sun, D., Xu, D., and Zhang, B. (2006) Drug Resist. Updat. 9, 274-287

65. Yamazaki, D., Kurisu, S., and Takenawa, T. (2005) Cancer Sci. 96, 379-386 
66. Gao, Y., Xing, J., Streuli, M., Leto, T. L., and Zheng, Y. (2001) J. Biol. Chem. 276, 47530-47541

67. Zugaza, J. L., Lopez-Lago, M. A., Caloca, M. J., Dosil, M., Movilla, N., and Bustelo, X. R. (2002) J. Biol. Chem. 277, 45377-45392

68. Karnoub, A. E., Worthylake, D. K., Rossman, K. L., Pruitt, W. M., Campbell, S. L., Sondek, J., and Der, C. J. (2001) Nat. Struct. Biol. 8, 1037-1041

69. Murga, C., Zohar, M., Teramoto, H., and Gutkind, J. S. (2002) Oncogene 21, 207-216

70. Harding, M. A. and Theodorescu, D. (2010) Eur. J. Cancer 46, 1252-1259

71. Zhang, Y., Rivera Rosado, L. A., Moon, S. Y., and Zhang, B. (2009) J. Biol. Chem. 284, 1295612965

72. Schunke, D., Span, P., Ronneburg, H., Dittmer, A., Vetter, M., Holzhausen, H. J., Kantelhardt, E., Krenkel, S., Muller, V., Sweep, F. C., Thomssen, C., and Dittmer, J. (2007) Cancer Res. 67, 10694-10702

73. Barone, I., Brusco, L., Gu, G., Selever, J., Beyer, A., Covington, K. R., Tsimelzon, A., Wang, T., Hilsenbeck, S. G., Chamness, G. C., Ando, S., and Fuqua, S. A. (2011) J. Natl. Cancer Inst. 103, 538-552

74. Han, J. S. and Crowe, D. L. (2010) Anticancer Res. 30, 3407-3412

75. Ostrander, J. H., Daniel, A. R., Lofgren, K., Kleer, C. G., and Lange, C. A. (2007) Cancer Res. 67, 4199-4209

76. Brosseau, C. M., Pirianov, G., and Colston, K. W. (2010) Steroids 75, 1082-1088

77. Nethe, M., Anthony, E. C., Fernandez-Borja, M., Dee, R., Geerts, D., Hensbergen, P. J., Deelder, A. M., Schmidt, G., and Hordijk, P. L. (2010) J. Cell Sci. 123, 1948-1958

78. Chan, A., Akhtar, M., Brenner, M., Zheng, Y., Gulko, P. S., and Symons, M. (2007) Mol. Med. 13, 297-304

79. Kirui, J. K., Xie, Y., Wolff, D. W., Jiang, H., Abel, P. W., and Tu, Y. (2010) J. Pharmacol. Exp. Ther. 333, 393-403

80. Han, G., Fan, B., Zhang, Y., Zhou, X., Wang, Y., Dong, H., Wei, Y., Sun, S., Hu, M., Zhang, J., and Wei, L. (2008) Oncol. Rep. 20, 929-939

81. Shi, H. Y., Stafford, L. J., Liu, Z., Liu, M., and Zhang, M. (2007) Cell Motil. Cytoskeleton 64, 338-346

82. Sala, G., Dituri, F., Raimondi, C., Previdi, S., Maffucci, T., Mazzoletti, M., Rossi, C., Iezzi, M., Lattanzio, R., Piantelli, M., Iacobelli, S., Broggini, M., and Falasca, M. (2008) Cancer Res. 68, 10187-10196

\section{FOOTNOTES}

*This research was supported by DoD/US Army BCRP W81XWH-07-1-0330 and 3SC3GM08482402S1 (to SD), RCMI Grant \#G12RR035051 to UPR MSC (to CPV and EH), 5U54CA096297 to UPR MSC (to TH-B) and RCMI G12RR03035 to Universidad Central del Caribe, Bayamon, PR. 


\section{FIGURE LEGENDS}

FIGURE 1. Synthesis and docking of EHop-016 into the putative GEF binding pocket of Rac1. A, Synthetic scheme for the preparation of EHop-016. The synthesis was performed by a two step approach as described in (58). B, Compound EHop-016 docked into GEF binding pocket of Rac1, and its comparison with the position of NSC23766 in the crystal structure of the Rac1-NSC23766 complex.

FIGURE 2. Effect of EHop-016 and NSC-23766 on Rac activity. MDA-MB-435 cells were treated with vehicle (0.1\% DMSO), or varying concentrations of EHop-016 $(0-10 \mu \mathrm{M})$ or NSC23766 $(0-100 \mu \mathrm{M})$ for 24 h. Cell lysates were subjected to the G-LISA Rac1 Activation Assay (Cytoskeleton, Inc., Denver, CO), as per manufacturer's instructions. IC $_{50}$ curves for percentage Rac activity are relative to vehicle from 3 biological replicates each with 2 technical replicates. Error bars are represented as \pm S.D. Four-parameter dose-response curves generated using GraphPad Prism ${ }^{\circledR}$ are shown.

FIGURE 3. Effect of EHop-016 on Rho GTPase activity. MDA-MB-435 cells were treated with vehicle or EHop-016 at the indicated concentrations $(1,2$, or $4 \mu \mathrm{M})$ for $24 \mathrm{~h}$. Cell lysates were subjected to a pulldown assay using a GST-CRIB domain of PAK and western blotted for Rac3, Rac $(1,2,3)$ or Cdc42. A GST-RBD domain of Rhotekin was used to pulldown Rho.GTP and detected by western blotting with anti RhoA antibody. The average percentage of Rho GTPase activity was calculated from the integrated density of positive bands of RhoGTPase.GTP from a pulldown/total Rho GTPase in cell lysate for each treatment and each Rho GTPase (Rac3, Rac, Cdc42, or RhoA) relative to vehicle controls. A, Representative western blot of pulldowns immunostained for Rac3.GTP (top row) or total Rac3 in cell lysate (bottom row), $\mathrm{N}=3 . . B$, Representative western blots of pulldowns immunostained for Rac, Cdc42, or RhoA.GTP (top row) or total Rac, Cdc42, or RhoA in cell lysate (bottom row), N=2.

FIGURE 4. Effect of EHop-016 on cell viability. Cell viability of MDA-MB-435 or MCF-10 cells was measured using the MTT cell survival and proliferation kit (Millipore, Inc). The mean values \pm SEM $(\mathrm{N}=3)$ are presented relative to vehicle $(100 \%)$. An asterisk indicates statistical significance compared to vehicle controls $(p \leq 0.05)$.

FIGURE 5. Effect of EHop-016 on the actin cytoskeleton. A, Effect of EHop-016 on the actin cytoskeleton. Quiescent MDA-MB-435 metastatic breast cancer cells (in 10\% FBS) were treated with vehicle or EHop-016 at 2 or $4 \mu \mathrm{M}$ for $24 \mathrm{~h}$. Cells were fixed, permeabilized, and stained with Rhodamine phalloidin to visualize F-actin. Representative micrographs are shown at $600 \mathrm{X}$ magnification. Arrows indicate lamellipodia, arrowheads, filopodia. $B$. The percentage of cells that demonstrated lamellipodia was quantified for each treatment from 10 representative microscopic fields. An asterisk indicates statistical significance compared to vehicle controls $(p \leq 0.001)$.

FIGURE 6. Effect of EHop-016 on directed cell migration. MDA-MB-435 cells treated with vehicle or EHop-016 (0-5 $\mu \mathrm{M})$ for $24 \mathrm{~h}$ were subjected to a Transwell migration assay. The number of cells that migrated to the underside of the top well in response to serum in the bottom well was quantified for each treatment. A, Representative micrographs of PI stained cells for each treatment at 200X magnification. $B$. Percentage of cells that migrated to the underside of a membrane with $8 \mu \mathrm{m}$ diameter pores, relative to vehicle (100\%). Results are shown for 3 biological replicates with 2 technical replicates per experiment \pm S.D. An asterisk indicates statistical significance compared to vehicle controls $(p \leq 0.05)$. 
Figure 1, Montalvo, et al.

A.
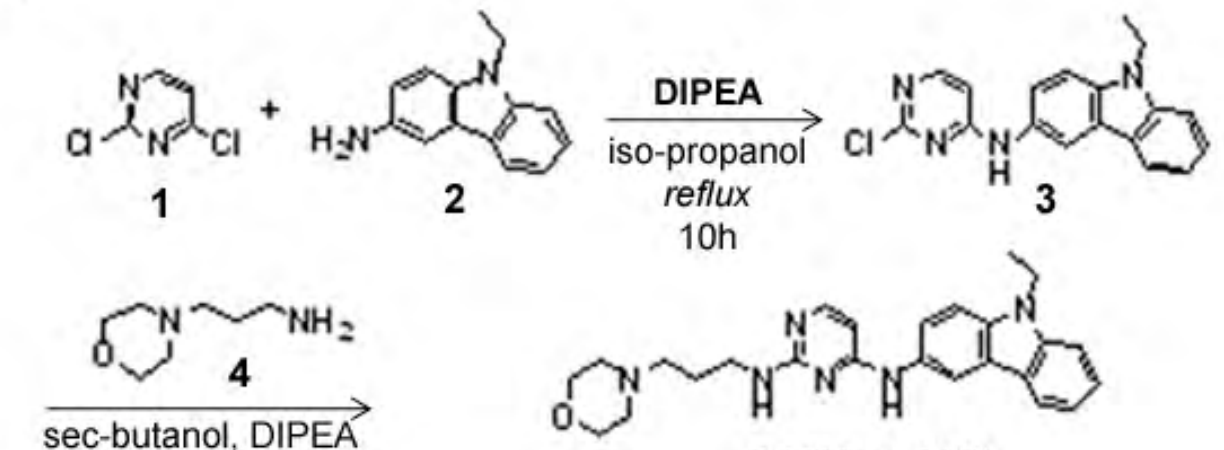

Microwave $120^{\circ} \mathrm{C}, 30 \mathrm{~min}$

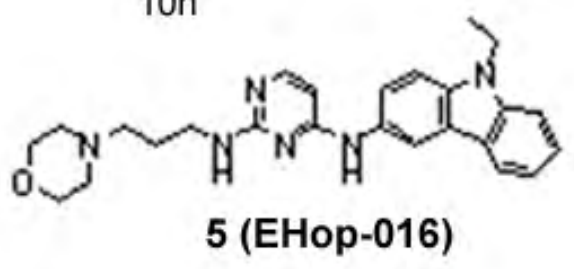

B.

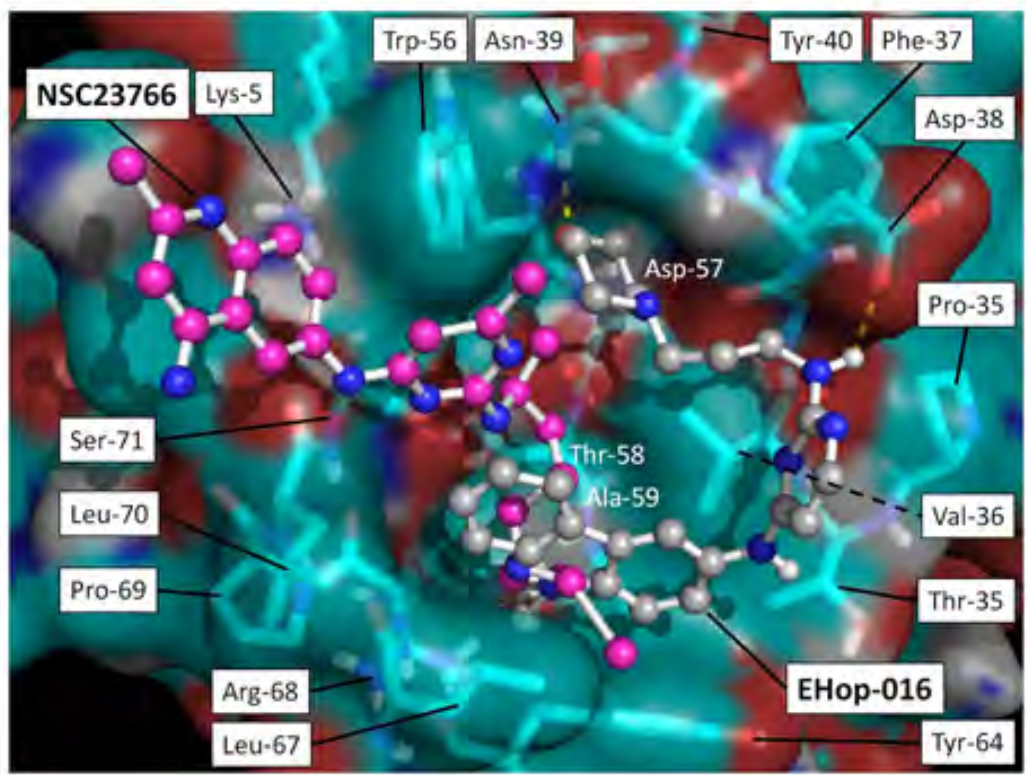


Figure 2, Montalvo et al.

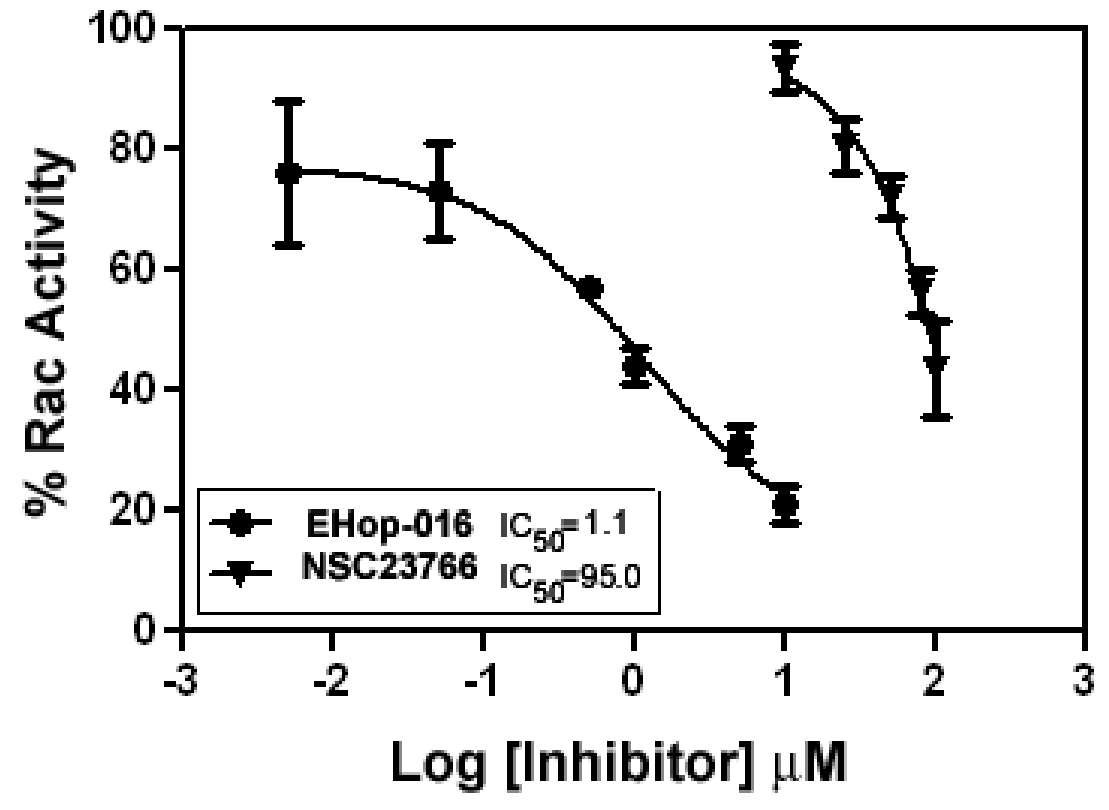


Figure 3, Montalvo et al.

A.

EHop-016 $\mu \mathrm{M}$

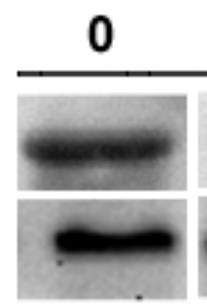

1

100

42

Rac3.GTP

Total Rac3

$\%$ Average Activity

B.

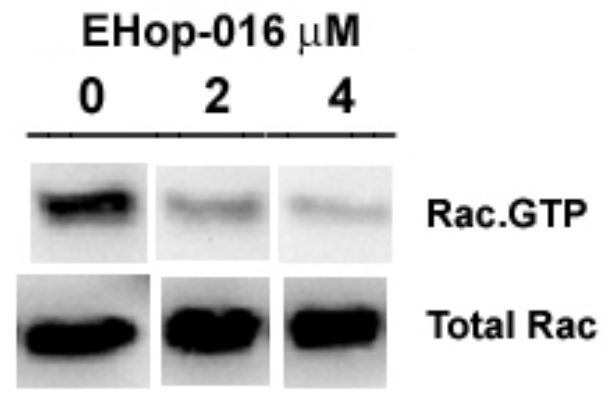

$\begin{array}{lll}100 & 19 & 07\end{array} \%$ Average Activity

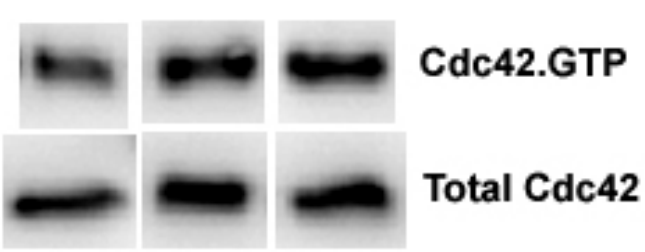

$\begin{array}{llll}100 & 116 \quad 92 \quad \% \text { Average Activity }\end{array}$

$\leadsto \Leftrightarrow$ Rho A.GTP

Total Rho A

$\begin{array}{llll}100 & 155 \quad 108 \quad \% \text { Average Activity }\end{array}$ 


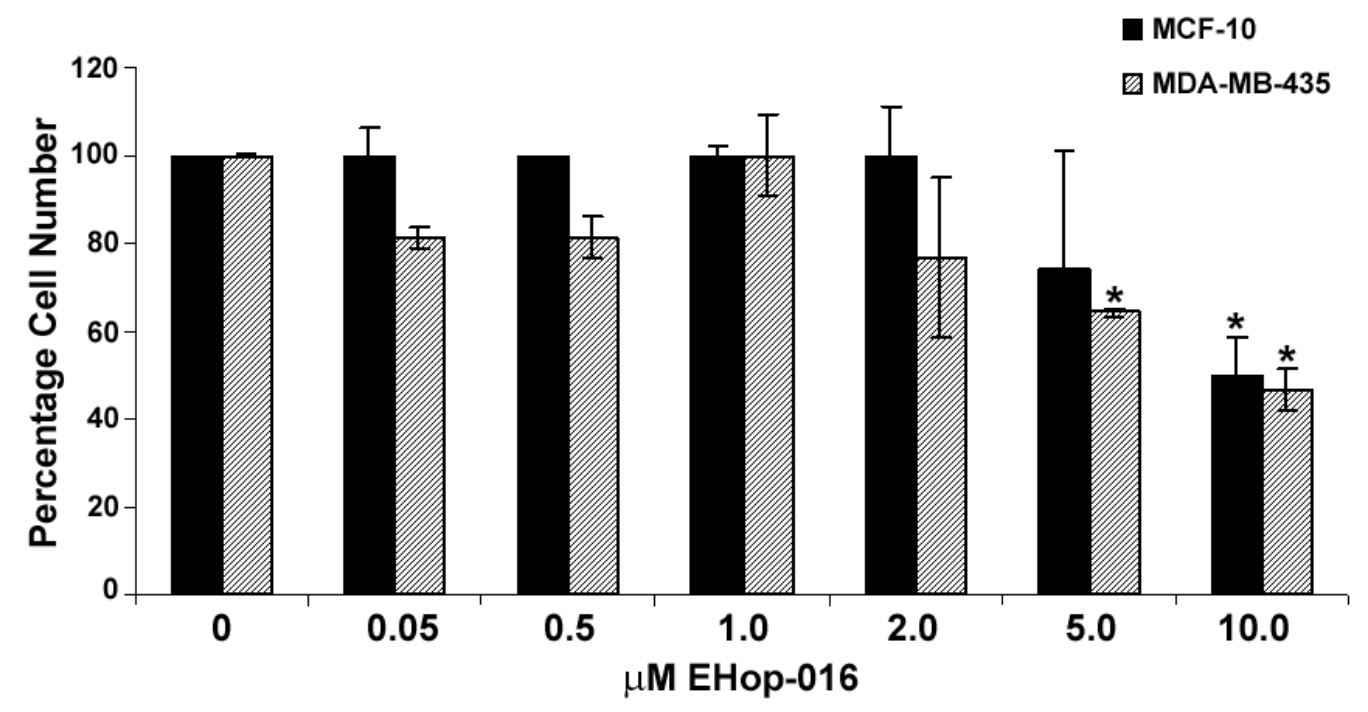


Figure 5, Montalvo, et al.

A.

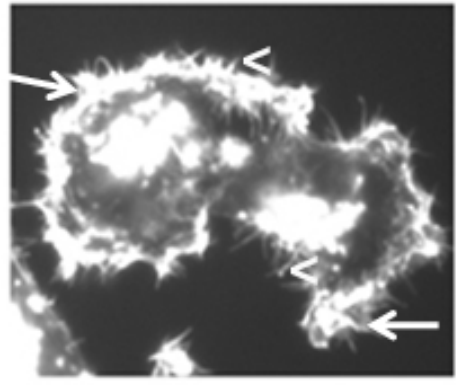

Vehicle

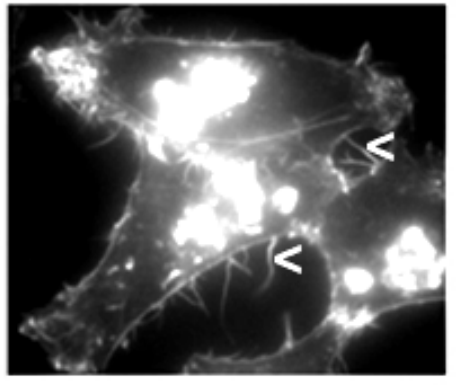

$2 \mu \mathrm{M}$ EHop-016

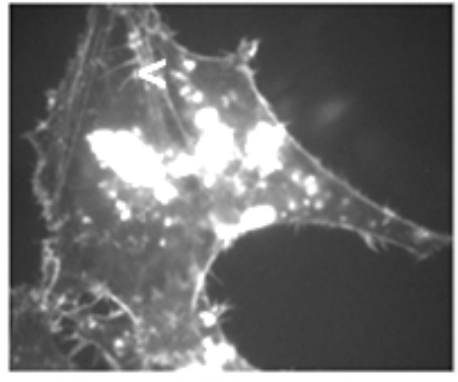

$4 \mu \mathrm{M}$ EHop-016

B.

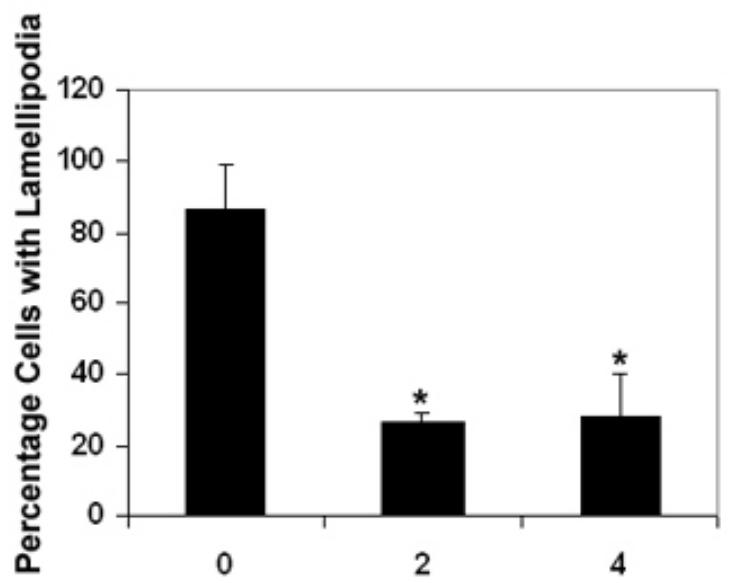


A.
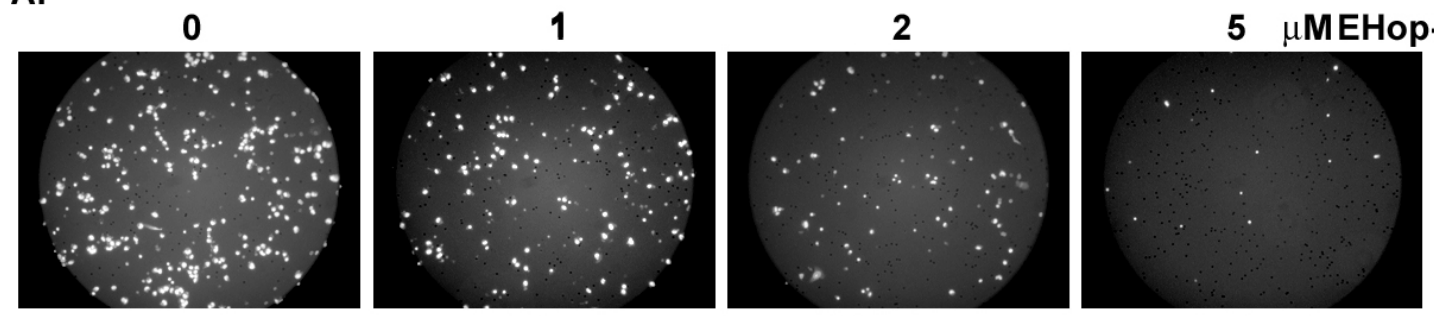

B.

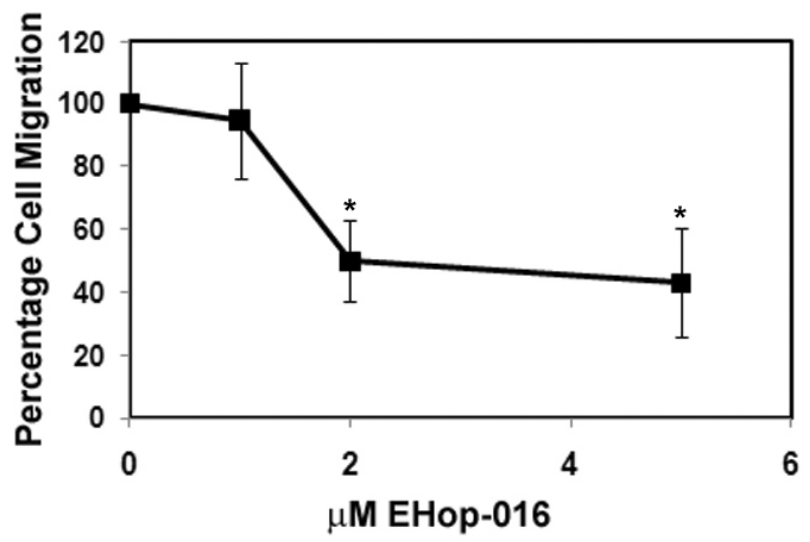


Grape polyphenols inhibit Akt/mTOR signaling and potentiate the effects of gefitinib in breast cancer

\author{
Linette Castillo-Pichardo and Suranganie Dharmawardhane* \\ Department of Biochemistry, School of Medicine, University of Puerto Rico, Medical Sciences Campus, \\ San Juan, PR
}

Running Title: Grape polyphenols chemosensitize breast cancers to gefitinib

Key Words: breast cancer, resistance, gefitinib, grape polyphenols, chemosensitization

Financial Support: This research was supported by grant numbers DoD/BCRP W81XWH-07-1-0330 to SD; DoD/BCRP W81XWH-08-01-0258 to LCP; NIH/NCRR 2G12RR003035 to UCC; NIH/NCRR G12-RR03051 to UPR MSC.

"To whom correspondence should be addressed:

Suranganie Dharmawardhane

Department of Biochemistry, School of Medicine,

University of Puerto Rico, Medical Sciences Campus

PO Box 365067

San Juan, P.R. 00936-5067.

E-mail: su.d@upr.edu

Word count: 4,989

Number of figures and tables: 6 


\section{Abstract}

Grape and red wine polyphenols are known to have cancer preventive properties. We recently reported that combined grape polyphenols resveratrol, quercetin, and catechin (RQC), at low concentrations, are effective at inhibiting metastatic cancer progression. Herein, we investigate the mechanisms by which RQC decreases breast cancer progression and explore the potential of RQC as a chemosensitization agent for the anti-epidermal growth factor receptor (EGFR) therapeutic gefitinib. EGFR signaling is a key pathway that regulates cancer progression and metastasis. However, development of drug resistance constitutes a major problem with current anti-EGFR therapeutics. We found that RQC induces apoptosis in gefitinib insensitive MDA-MB-231 breast cancer cells via regulation of a myriad of proteins in the apoptotic signaling cascade. Individual resveratrol, quercetin, or catechin, or combined RQC reduces the activity of Akt, a major cell survival regulator that contributes to the development of anti-EGFR therapy resistance. RQC, but not individual polyphenols, activates AMPactivated protein kinase (AMPK) and inhibits mammalian target of rapamycin (mTOR) signaling. Moreover, we demonstrate that a combination of RQC and gefitinib decreases proliferation of MDA-MB231 cells to a greater extent than RQC or gefitinib alone. RQC also inhibits Akt and mTOR, and activates AMPK even in the presence of gefitinib. Finally, combined RQC and gefitinib is more effective than the individual treatments at inhibiting tumor growth and metastasis in SCID mice with mammary fat pad tumors established from MDA-MB-231 cells. These results suggest that RQC treatment inhibits breast cancer progression and can potentiate anti-EGFR therapy by inhibition of Akt/mTOR signaling. 


\section{Introduction}

Breast cancer is the most commonly diagnosed form of cancer in women 40-55 years of age and is the second major cause of cancer deaths (1). Recent clinical advances have increased the survival rates from primary breast cancer; however, de novo and acquired resistance to therapy is a common phenomenon that contributes to disease relapse (2) Combination therapies that target several pathways are effective but can have devastating side effects $(3 ; 4)$. Therefore, developing new strategies for prevention of breast cancer progression and overcoming drug resistance represents a major challenge.

Individual grape polyphenols at high concentrations act as cancer preventives and have antiproliferative, antioxidant, antiangiogenic, antiinvasive, and pro-apoptotic properties (5;6). Grape polyphenols specifically inhibit the growth of breast cancer cells with low cytotoxicity towards normal mammary epithelial cells (7). These compounds have also been shown to act as selective estrogen receptor (ER) modulators and induce differential gene expression via ERa and ERß (8). Grape juice constituents and grape seed extract (GSE) inhibited breast cancer initiation and reduced cancer in rodent models (9-11). GSE treatment was also shown to block Akt activity and inhibit angiogenic signaling in breast cancer and gliomas (12), and be more effective in combination with resveratrol, quercetin, and catechin $(13 ; 14)$. In humans, grape consumption has been significantly inversely associated with breast cancer risk (15). However, the molecular mechanisms of grape polyphenols, or their effects on metastasis, are not fully understood.

We have shown that a combination of the major polyphenols in grape and red wine, resveratrol, quercetin, and catechin (RQC), at low concentrations, can inhibit proliferation, cell cycle progression, migration, and survival in breast cancer cells. Additionally, we reported that RQC is capable of reducing tumor growth and site-specific metastasis $(16 ; 17)$. Grape polyphenols are desirable cancer therapeutics due to easy availability, rapid absorption and metabolism, and low toxicity (18). Such advantages make grape polyphenols attractive not only as cancer preventives/therapeutics but also as chemosensitization agents for current chemotherapy. 
Grape polyphenols can individually inhibit EGFR and Her2 activities (19;20) and decrease Her2 expression (21). EGFR activation triggers multiple signaling pathways associated with tumor progression and metastasis. Overexpression of EGFR family members contributes to tumor malignancy and poor prognosis in many types of cancers, including breast cancer where $45 \%$ of patients have been shown to be EGFR positive (22). Clinical trials have shown that gefitinib, an EGFR-specific tyrosine kinase inhibitor, is well tolerated and posses antitumor activity of many cancers, including breast cancer (23). However, de novo and acquired resistance to gefitinib treatment is a recurrent problem (24). Therefore, multiple studies have investigated the potential of combination therapies to overcome gefitinib resistance $(25 ; 26)$.

In breast cancer, the EGFR target phosphoinositide 3 kinase (PI3-K)/Akt and mammalian target of rapamycin (mTOR) pathways have been shown to be central for breast cancer malignancy and evasion to gefitinib treatment $(27 ; 28)$. Akt activates mTORC1 complex (mTOR and raptor) by inhibition of tuberous sclerosis complex (TSC2), a GTPase activating protein and thus, a negative regulator of Rheb GTPase that activates mTOR (29). mTOR is negatively regulated by adenosine monophosphate (AMP)-regulated kinase (AMPK), a key metabolic sensor of low nutrients and stress. AMPK acts disparate to Akt to inhibit mTORC1 via an activating phosphorylation of TSC2 as well as by direct inhibition of raptor (30). Activation of AMPK and downstream inhibition of mTOR is associated with chemosensitization to anti-cancer agents. Therefore, dual PI3-K/mTOR inhibitors that may inhibit Akt as well as AMPK have potential in aggressive cancer therapy $(31 ; 32)$. Since combination therapy can have devastating side effects, a safer alternative is the use of common dietary compounds with low toxicity that can inhibit therapy resistance pathways (33). Herein, we show that combined grape polyphenols induce apoptosis and reduce mTOR signaling via inhibition of Akt and activation of AMPK in breast cancer. The capacity of the RQC formulation in combination with gefitinib to reduce cell proliferation, tumor growth, and metastasis of a gefitinib resistant breast cancer cell line demonstrates the potential of grape polyphenols to act as chemosensitizers of anti-EGFR therapy. 


\section{Methods}

\section{Cell culture}

The human low metastatic breast cancer cell line MDA-MB-231 (ER $\alpha-$, ER $\beta+)$ expressing green fluorescent protein (GFP) was used (kind gift of Dr. Danny Welch, The University of Alabama at Birmingham, AL, 2009) (34). Cells were cultured in DMEM with $10 \%$ heat-inactivated (HI) FBS as described in (16).

\section{Caspase 3 activity assay}

Apoptosis was determined by analyzing the caspase 3 activity of MDA-MB-231 cell lysates following vehicle $(0.2 \% \mathrm{DMSO})$ or a combination of resveratrol, quercetin, and catechin (RQC) at $5 \mu \mathrm{M}$ each for $48 \mathrm{~h}$ or $96 \mathrm{~h}$ using a Caspase-3 Colorimetric Assay Kit as per manufacturer's instructions (Sigma-Aldrich, St. Louis, MO). Briefly, the p-nitroaniline (pNA) moiety resulting from hydrolysis of acetyl-Asp-Glu-Val-Asp p-nitroanilide (Ac-DEVD-pNA) by caspase 3 activity was detected at $405 \mathrm{~nm}$ $\left(\varepsilon_{\mathrm{mM}}=10.5\right)$ after incubating the reaction mixture at $37^{\circ} \mathrm{C}$ for $22 \mathrm{~h}$. The concentration of pNA released from the substrate was calculated from the absorbance values at $405 \mathrm{~nm}$ using a calibration curve prepared with pNA standards. Concentration of pNA was further converted to caspase 3 activity in $\mu$ mol of $\mathrm{pNA} / \mathrm{min} / \mathrm{mL}$.

\section{Antibody arrays}

Total protein extracts from MDA-MB-231 cells treated for $48 \mathrm{~h}$ or $96 \mathrm{~h}$ with vehicle, or $5 \mu \mathrm{M} \mathrm{RQC}$ were incubated overnight with a human apoptosis antibody array (R\&D Systems, MN), as per manufacturer's instructions. Unbound proteins were washed away and the array incubated with a cocktail of biotinylated detection antibodies. Finally, detection was achieved through the use of streptavidin-HRP chemiluminescent reagents.

For array data analysis, average integrated density signal (calculated using Image $\mathrm{J}$ software) for the two replicates of each antibody was calculated. Then, the two sets of data were normalized using a normalization factor calculated as the average signal for positive controls in one data set vs. the other. Finally, fold changes were calculated to express the effect of RQC on protein expression compared to vehicle control. 


\section{Western blotting}

Quiescent MDA-MB-231 cells were treated for $15 \mathrm{~min}$ with vehicle, or $5 \mu \mathrm{M}$ resveratrol (Res), quercetin (Quer), or catechin (Cat), or a combination of Res, Quer, and Cat (RQC) at $5 \mu \mathrm{M}$ each. In another set of experiments, MDA-MB-231 cells were treated for 15 or 30 min with vehicle, $5 \mu \mathrm{M} R \mathrm{R}$, $30 \mu \mathrm{M}$ gefitinib, or a combination of $5 \mu \mathrm{M} R Q C$ and $30 \mu \mathrm{M}$ gefitinib. Cells were then lysed as in (20) and total protein was quantified using the Precision Red protein assay kit (Cytoskeleton, Inc. Denver, CO). Equal total protein amounts were resolved on SDS-PAGE gels and Western blotted using anti-Akt, antiphospho $\mathrm{Akt}^{\mathrm{S} 473}$, anti-AMPKa, anti-phospho $\mathrm{AMPK \alpha}^{\text {Thr172 }}$, anti-p70S6K, or anti-phospho p70S6K ${ }^{\text {Thr389 }}$ (Cell Signaling Technology, Inc., Danvers, MA) antibodies. The integrated density of positive bands was quantified using Image J software.

\section{Cell viability}

MDA-MB-231 $\left(5 \times 10^{4}\right)$ cells were seeded in 6 well plates and $24 \mathrm{~h}$ later treated for $48 \mathrm{~h}$ (in culture media with $5 \%$ HI FBS) with vehicle, or RQC at $0.167,0.5,1.67,5$, or $15 \mu \mathrm{M}$ for the generation of RQC dose response curve. For the generation of gefitinib dose response curve, MDA-MB-231 cells were treated for $48 \mathrm{~h}$ with vehicle, or $0.1,1,10,20,30,40$, or $50 \mu \mathrm{M}$ gefitinib. Finally, for the determination of combined $\mathrm{RQC}$ and gefitinib effects, $0.5,1.67$, or $5 \mu \mathrm{M} \mathrm{RQC}$ was combined with 10,20 or $30 \mu \mathrm{M}$ gefitinib. Cells were fixed, nuclei stained with propidium iodide (PI) and cell viability was quantified as the number of cells with intact nuclei.

For the generation of dose response curves and the determination of $\mathrm{IC}_{50}$ values, data from three independent experiments was pooled and four parameter dose-response curves were fitted using the non-linear regression function of GraphPad Prism®.

\section{Animals}

Hairless (severe combined immunodeficiency) SCID female mice, 5 to 6 wk old (Charles River Laboratories, Inc., Wilmington, MA) were maintained under pathogen-free conditions in Hepa-filtered cages under controlled light (12 h light and dark cycle), temperature $\left(22-24^{\circ} \mathrm{C}\right)$, and humidity $(25 \%)$. Throughout the experiment, the animals were provided with autoclaved AIN 76-A phytoestrogen-free diet (Tek Global, Harlan Teklad, Madison, WI) and water ad libitum. 


\section{Tumor establishment}

GFP-MDA-MB-231 cells $\left(\sim 1 \times 10^{6}\right)$ in Matrigel (BD Biosciences, San Jose, CA) were injected into the fourth right mammary fat pad under isofluorane inhalation to produce orthotopic primary tumors as described in (17). After tumor establishment (1wk post-inoculation), the animals were randomly divided into experimental treatment groups ( $n=10-12$ per treatment group).

\section{Diet administration}

Hairless SCID female mice were orally gavaged either with vehicle for RQC treatment $(90 \%$ neobee oil, $10 \%$ ethanol), vehicle for gefitinib (1\% Tween-80 in 1X PBS, pH 7.4), a combination of $5 \mathrm{mg} / \mathrm{kg}$ body weight (BW) Res, $5 \mathrm{mg} / \mathrm{kg}$ BW Quer, and $5 \mathrm{mg} / \mathrm{kg} \mathrm{BW}$ Cat (RQC), or $200 \mathrm{mg} / \mathrm{kg} \mathrm{BW}$ gefitinib, in a $100 \mu \mathrm{L}$ volume every other day, 7 days a week. The group receiving both treatments was gavaged one day with $5 \mathrm{mg} / \mathrm{kg} \mathrm{BW} \mathrm{RQC}$, and the next day with $200 \mathrm{mg} / \mathrm{kg} \mathrm{BW}$ gefitinib in a $100 \mu \mathrm{L}$ volume, 7 days a week. Treatments continued until sacrifice at day 84 .

\section{Whole body fluorescence image analysis}

Mammary tumor growth was quantified as changes in integrated density of GFP fluorescence as per our previously described methods $(16 ; 17)$. Anesthetized mice were imaged one week following breast cancer cell inoculation (on day 1 of diet administration) and once a week thereafter. A 300 Watt power source with two optical delivery systems fitted with excitation filters $(470 / 40 \mathrm{~nm})$ was used for whole body imaging of GFP fluorescence (LT99D2, Lightools Research, Encinitas, CA). Images were captured with a Spot II charge-coupled device (CCD) camera (Diagnostic Instruments, Sterling Heights, MI) mounted with a 530/25 nm emission filter (Chroma Technology, Rockingham, VT).

Tumor fluorescence intensities were analyzed using Image J software (National Institutes of Health, Bethesda, MD). The final images were acquired on day 84. Relative tumor growth was calculated as the integrated density of fluorescence of each tumor on each day of imaging relative to the integrated density of fluorescence of the same tumor on day 1 of diet administration. Tumor growth in vehicle for RQC group was not statistically different than vehicle for gefitinib. Therefore, the average of both groups was used for data analysis. 


\section{Analysis of metastases}

Following sacrifice, lungs, kidneys, and livers were excised and immediately stored in liquid N2. Stored organs were thawed and analyzed using an Olympus MV10 fluorescence macro zoom system microscope and images acquired with an Olympus DP71 digital camera as described in (17). Each organ was imaged on both sides. The fluorescent lesions (green component of RGB images) were quantified for integrated density of fluorescent pixels using Image $\mathrm{J}$ software.

\section{Statistical analysis}

Data are expressed as the mean \pm SEM. Statistical analyses were done using Microsoft Excel and GraphPad Prism®. Differences between means were determined using Student's t-Test. 


\section{Results}

\section{Effects of combined grape polyphenols on apoptosis and apoptotic signaling proteins}

We previously reported that combined grape polyphenols resveratrol, quercetin, and catechin (RQC) was more effective than individual compounds at inhibiting biological functions relevant for breast cancer progression, such as cell proliferation, cell cycle progression and cell migration using $\mathrm{ERa}(-), \mathrm{ER} \beta(+) \mathrm{MDA}-\mathrm{MB}-231$ low metastatic breast cancer cells and ER(-) MDA-MB-435 highly metastatic cancer cells $(16 ; 17)$. In addition, combined grape polyphenols were effective at inducing apoptosis in the MDA-MB-435 cell line (17). Since RQC treatment at $5 \mu \mathrm{M}$ each decreased MDA-MB231 cell viability by $\sim 80 \%$ compared to vehicle controls and caused S phase cell cycle arrest (16), the effect of $5 \mu \mathrm{M}$ RQC treatment on apoptosis of MDA-MB-231 cells was determined. Caspase 3 was selected to assess the effect of RQC on both receptor-regulated and mitochondrial apoptotic pathways. Treatment with combined grape polyphenols at $5 \mu \mathrm{M}$ for $48 \mathrm{~h}$ did not affect caspase 3 activity, while 5 $\mu \mathrm{M} R Q \mathrm{C}$ for $96 \mathrm{~h}$ increased caspase 3 activity by three fold with a $p \leq 0.05$ thus, implicating $\mathrm{RQC}$ treatment in apoptosis induction (Fig. 1A).

Next, the molecular mechanisms of RQC-induced apoptosis were studied using human apoptotic antibody arrays (R\&D Systems, Inc., MN). Treatment of MDA-MB-231 cells with combined grape polyphenols at $5 \mu \mathrm{M}$ for $48 \mathrm{~h}$ and $96 \mathrm{~h}$ resulted in the regulation of a myriad of proteins in the apoptotic signaling cascade (Fig. 1B). Table 1 summarizes apoptotic signaling proteins that were significantly regulated by RQC treatment for $48 \mathrm{~h}$ and $96 \mathrm{~h}$ in three independent experiments. At $48 \mathrm{~h}$, a number of death receptor pathway proteins including inhibitors of apoptosis such as cellular inhibitor of apoptosis protein 1 (clAP-1) and survivin were decreased; however, we did not observe a change in caspase 3 activity at this time point. At $96 \mathrm{~h}$, when $5 \mu \mathrm{M} R Q \mathrm{R}$ treatment increases caspase 3 activity, there is a correlative significant increase in cleaved caspase 3 expression and FAS ligand and its receptor (Fig. 1, Table 1). This result indicates a potential death receptor-mediated regulation of apoptosis by RQC; however, further studies are required to confirm this observation.

Similar to our previous report for the MDA-MB-435 metastatic cancer cell line (17), RQC treatment of MDA-MB-231 cells induced apoptosis suggesting that the inhibitory effect of RQC on cell proliferation 
may be due to cell cycle arrest and subsequent apoptosis. RQC-mediated induction of apoptosis in MDA-MB-231 cells was delayed when compared to MDA-MB-435 cells, in which RQC induced apoptosis after $48 \mathrm{~h}$. However, in the MDA-MB-231 cell line, RQC treatment for $96 \mathrm{~h}$ caused a significant $S / G_{2}$ phase arrest, whereas in the MDA-MB-435 cell line RQC only caused a moderate $S$ phase arrest $(16 ; 17)$. These results suggest the main mechanism of RQC-induced cell death is apoptosis in the case of the MDA-MB-435 cell line; while in the MDA-MB-231 cell line, both cell cycle arrest and apoptosis may contribute to RQC-induced cell death.

\section{Effects of RQC on regulation of the mTOR pathway}

To further investigate the molecular mechanisms by which RQC reduces breast cancer cell survival, we determined the effect of RQC on PI3-K/Akt signaling. Activation of the PI3-K pathway upon RQC treatment was measured by determining the activation status, i.e. phosphorylation levels, of Akt. The Ser/Thr kinase Akt is phosphorylated and activated by phosphoinositide-dependent kinase when phosphatidylinositol 3,4,5-trisphosphate levels are increased due to PI3-K activity. Activated Akt signals to cell survival and proliferation via a multitude of signaling cascades including the mTOR pathway. In MDA-MB-231 cells, we found that $5 \mu \mathrm{M}$ treatment with resveratrol, quercetin, catechin, or RQC for 15 min significantly decreased Akt activity when compared to vehicle, as measured by western blot analysis of total and phosphorylated $\mathrm{Akt}^{\text {(Ser473) }}$ (Fig. 2A, upper panel). Individual and combined RQC treatment resulted in a statistically significant $50-70 \%$ inhibition of Akt activity (Fig. 2A, lower panel). Treatment with $5 \mu \mathrm{M} R Q C$ for $15 \mathrm{~min}$ also decreased Akt activity significantly in MDA-MB-435 cells (data not shown).

We have previously shown that combined RQC was more efficient than individual compounds at inhibiting breast cancer cell proliferation and cell cycle progression $(16 ; 17)$. Therefore, RQC is expected to inhibit breast cancer progression via additional molecular mechanisms than inhibition of Akt activity alone. We tested the activity of AMPK, a negative regulator of mTOR, and mTOR by western blot analysis of total and phosphorylated AMPK and p70S6K, a direct downstream effector of mTOR. Treatment with $5 \mu \mathrm{M}$ each resveratrol, quercetin, or catechin did not affect AMPK activity of MDA-MB231 cells. However, combined RQC treatment significantly increased AMPK activity by 2-fold when 
compared to vehicle (Fig. 2B). Treatment with $5 \mu \mathrm{M}$ quercetin or $5 \mu \mathrm{M} R \mathrm{RQ}$ resulted in a $50 \%$ significant decrease in p70S6K phosphorylation of MDA-MB-231 cells. Individual treatment with resveratrol or catechin did not change p70S6K phosphorylation (Fig. 2C).

\section{Potential of RQC as a chemosensitization agent for gefitinib in vitro}

To test if RQC has potential as a chemosensitization agent for gefitinib, an EGFR inhibitor, the response of MDA-MB-231 cells to RQC and gefitinib, both as single treatments and in combination, was characterized. The MDA-MB-231 breast cancer cell line was chosen since this cell line overexpresses EGFR and is intrinsically resistant to gefitinib, with a $>10 \mu M \operatorname{IC}_{50}(35 ; 36)$. The response of MDA-MB-231 cells to various concentrations of RQC or gefitinib for $48 \mathrm{~h}$ was determined by quantifying the number of viable cells. The $\mathrm{IC}_{50}$ for inhibition of cell number by gefitinib was $15.8 \mu \mathrm{M}$ (Fig. 3A) and $2.4 \mu \mathrm{M}$ for RQC (Fig. 3B). Concentrations from 0.5-5 $\mu \mathrm{M}$ for RQC and 10-30 $\mu \mathrm{M}$ for gefitinib were used to determine the effect of RQC and gefitinib combined treatment. Out of the many combinations tested (supplemental data, figure 1) the combination showing a greater decrease in cell proliferation when compared to either RQC or gefitinib treatment alone was $5 \mu \mathrm{M} R \mathrm{R}+30 \mu \mathrm{M}$ gefitinib, (approximately twice the $\mathrm{IC}_{50}$ for each compound alone) (Fig. 3C). At these concentrations, combined RQC and gefitinib treatments resulted in a $65 \%$ significant decrease in cell number, while individual 5 $\mu \mathrm{M} R \mathrm{RQ}$ or $30 \mu \mathrm{M}$ gefitinib demonstrated a $45 \%$ significant decrease in cell proliferation. The differences between the combined effect and either of the individual treatments were statistically significant. These results demonstrate that a combination of RQC and Gefitinib confers an advantage over RQC or gefitinib individual treatments and that RQC has potential as a chemosensitization agent for anti-EGFR therapy.

To further evaluate the potential of RQC as a chemosensitization agent for gefitinib, the activation of Akt, AMPK, and p70S6K were determined in MDA-MB-231 cells treated for 15 or 30 min with $5 \mu \mathrm{M}$ $\mathrm{RQC}$ or $30 \mu \mathrm{M}$ gefitinib alone, or in combination (Figure 4). We found that $30 \mu \mathrm{M}$ gefitinib alone did not significantly reduce Akt activity following 15 min but decreased Akt activity by $\sim 50 \%$ after 30 min (Fig. $4 \mathrm{~A}$ and $\mathrm{D})$. RQC alone or combined $5 \mu \mathrm{M} R \mathrm{RQC}$ and $30 \mu \mathrm{M}$ gefitinib for 15 or 30 min decreased Akt activity significantly by $\sim 50-80 \%$. The reduction of Akt activity by a 30 min treatment with either $5 \mu \mathrm{M}$ 
$\mathrm{RQC}$ or the combination of $5 \mu \mathrm{M} R Q C$ and $30 \mu \mathrm{M}$ gefitinib was significantly greater than the reduction mediated by $30 \mu \mathrm{M}$ gefitinib alone. As expected, $5 \mu \mathrm{M}$ RQC alone or in combination with gefitinib at 15 and 30 min increased AMPK activity of MDA-MB-231 cells by $\sim 2$-fold in a statistically significant

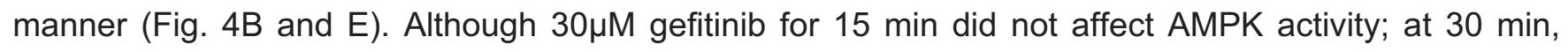
$30 \mu \mathrm{M}$ Gef significantly increased AMPK activity by $\sim 1.7$ fold. Finally, to assess if RQC in combination with gefitinib inhibit mTOR signaling, phosphorylation levels of p70S6K were determined by western

blot analysis to total and phospho-p70S6K ${ }^{(\text {Thr389) }}$. Treatment with RQC alone or in combination with gefitinib for 15 or 30 min resulted in a significant decrease of $\sim 50 \%$ in p70S6K activity, while gefitinib alone had no effect (Fig. 4C and F).

\section{Potential of RQC as a chemosensitization agent for gefitinib in vivo}

The efficacy of RQC to potentiate effects of gefitinib in vivo was tested in SCID mice. Mammary fat pad tumors from GFP-tagged MDA-MB-231 breast cancer cells were established as previously described (17). One week following tumor establishment, mice (10-12 mice/group), were gavaged with vehicle, $5 \mathrm{mg} / \mathrm{kg} \mathrm{BW} \mathrm{RQC}$, or $200 \mathrm{mg} / \mathrm{kg} \mathrm{BW}$ gefitinib every other day, or with $5 \mathrm{mg} / \mathrm{kg}$ BW RQC one day followed by $200 \mathrm{mg} / \mathrm{kg}$ BW the next day for 84 days. The RQC concentration used was selected based on our previous studies where $5 \mathrm{mg} / \mathrm{kg}$ BW RQC caused significant inhibition of mammary tumor growth and metastasis to bone and liver in nude mice $(16 ; 17)$. The concentration of gefitinib used was based on previous studies where $100-200 \mathrm{mg} / \mathrm{kg}$ BW gefitinib was orally gavaged to nude mice every day up to 100 days without any signs of toxicity $(37 ; 38)$. In the present study administration of RQC treatment alone for 84 days did not significantly affect the average weight of mice compared to controls. However, gefitinib at $200 \mathrm{mg} / \mathrm{kg}$ BW demonstrated a 20\% significant decrease in average weight; whereas, the combination treatment caused a $15 \%$ significant decrease in average weight (supplemental data, figure 4). Tumor progression was quantified by fluorescence image analysis once a week. The relative tumor area was calculated as the integrated density of fluorescence of each tumor on each day of imaging relative to the integrated density of fluorescence of the same tumor on day 1 of diet administration, as described in (16). As shown in Fig. 5A and 5B, tumor growth was significantly 
inhibited in mice treated with RQC and gefitinib combination, whereas mice treated with individual RQC or gefitinib showed no reduction in tumor size.

The effect of gefitinib and RQC on metastasis was investigated by fluorescence image analysis of excised organs, as described in (17). As was shown previously by us, in a nude mouse model of metastatic cancer (17), treatment with RQC did not affect the incidence of lung metastases but reduced liver and kidney metastases (Fig. 5C and D). Gefitinib alone reduced lung metastases by 50\%; however, this reduction was not statistically significant compared to controls. RQC in combination with gefitinib inhibited metastases to the lung by $97 \%$ in a statistically significant manner (Fig. 5C). In combined RQC+Gef treatment, only $40 \%$ of the mice presented with metastases and the average integrated density of metastatic foci was 0.03 compared to $\sim 1.0$ for vehicle controls, where $80 \%$ of mice presented with lung metastases. The number and integrated density of liver and kidney metastases followed a similar trend but was not statistically significant compared to vehicle controls. RQC treatment alone resulted in a $50 \%$ reduction in liver metastases, while gefitinib inhibited metastases by $70 \%$ and the combined treatment by $90 \%$ compared to controls. Similarly, kidney metastases were dramatically reduced by $99 \%$ following the combined RQC and gefitinib treatment (Fig. 5D). 


\section{Discussion}

A great deal of work has been conducted on the efficacy of grape polyphenols as cancer preventives. However, these studies are with individual grape polyphenols at high concentrations or combinations of grape polyphenols as grape seed extract, or red wine extract in the proportions that exist naturally. Our studies focus on the effects of an equimolar combination of resveratrol, quercetin, and catechin (RQC) at low concentrations on established metastatic cancers $(16 ; 17)$. Herein, we have characterized the molecular mechanisms of RQC in a metastatic breast cancer cell line and demonstrate a novel role for RQC in potentiating current anti-EGFR therapy.

The main objective of this study was to assess the potential of RQC to potentiate resistant breast cancer cells to the anti-EGFR therapeutic gefitinib. The inhibitory effects of RQC on breast cancer may be due to reduced cell survival and induction of cell cycle arrest and apoptosis. In this investigation, we focused on potential RQC-mediated regulation of the PI3-K/Akt/mTOR pathway, which is central to multiple cellular processes of tumorigenesis such as cell growth, cell proliferation, cell migration, and survival. The up-regulation of this pathway has been involved in mediation of gefitinib resistance in breast cancer cells $(27 ; 36)$. Our results show that individual polyphenols at low concentrations are as effective as RQC at reducing Akt activity, suggesting that each individual compound inhibits Akt via the same mechanism. Resveratrol and quercetin are direct inhibitors of PI3-K that have been shown to inhibit Akt activity in breast cancer (39-41). However, to our knowledge, this is the first time that the non-gallated monomeric catechin has been shown to inhibit Akt.

We also investigated a role for AMPK, a negative regulator of the mTOR pathway, in RQCmediated regulation of $\mathrm{mTOR}$ signaling. AMPK is a target of the anti-diabetic drug Metformin, which has been associated with decreased cancer incidence in epidemiological studies and with direct inhibition of cancer cell and tumor growth (42). Metformin has been implicated in chemosensitization to diverse anti-cancer agents through activation of AMPK and the subsequent inhibition of the mTOR pathway (31). Several studies have shown that induction of AMPK activity might be another mechanism through which resveratrol and quercetin inhibit cancer cell growth (43-47). Both Akt and AMPK regulate mTOR signaling via disparate regulation of TSC2, a negative regulator of mTOR (29;30). Although 
resveratrol or quercetin at high concentrations (50-200 $\mu \mathrm{M})$ increase AMPK activity (46;47); in our studies, at $5 \mu \mathrm{M}$, resveratrol, quercetin, or catechin did not affect phospho AMPK ${ }^{\top 172}$ levels. However, we show that RQC significantly increased AMPK activity by $\sim 2$-fold, predicting decreased mTOR activity. This result supports our previous reports of RQC being more effective than individual polyphenols $(16 ; 17)$. AMPK is known to affect lipid metabolism by inhibiting acetyl-coA carboxylase (ACC), which provides the malonyl-coA substrate for fatty acid biosynthesis (48). Accordingly, we have found that RQC inhibits ACC by increased phosphorylation (supplemental data, figure 2), indicating that RQC activation of AMPK regulates mechanisms other than mTOR signaling. Other effects of AMPK on autophagy and protein synthesis inhibition via phosphorylation of eukaryotic elongation factor 2 (eEF2) kinase (49) may also contribute to RQC effects on cancer, and will be the subject of future studies.

Interestingly, a parallel pattern of regulation as Akt inhibition or AMPK upregulation was not observed for individual and combined RQC effects on p70S6K activity. In the same breast cancer cell line, Akt was inhibited by individual and combined RQC, whereas AMPK was only activated by RQC, and p70S6K was inhibited by quercetin and RQC. It could be argued that the effect of RQC on p70S6K activity may also be via inhibition of mitogen activated protein kinase (MAPK) activity since the Ras/extracellular regulated kinase (ERK) pathway has been shown to affect p70S6K activity (50). However, we have found no effect of RQC on ERK activity (supplemental data, figure 3), or on other MAPKs p38 and Jun Kinase (data not shown). These results suggest a complex mode of regulation of mTOR signaling by RQC that may be dependent on cancer cell type and the tumor microenvironment.

EGFR is a key mediator of cancer progression and metastasis, thus representing an excellent target for cancer therapy. Gefitinib is a low molecular weight tyrosine kinase inhibitor with high specificity towards EGFR and therapeutic promise for the treatment of numerous human cancers; however, resistance to gefitinib greatly impairs its effectiveness in the clinic. In breast cancer, MAPK (specifically MEK/ERK), PI3-K/Akt, and mTOR pathways have been shown to be relevant for evasion to gefitinib treatment $(27 ; 28)$. Since the current approaches of combination therapies to overcome drug resistance often result in severe toxicity, the RQC formulation of natural non-toxic grape polyphenols was tested for its ability to potentiate the anticancer effects of gefitinib. 
Herein, we show that RQC alone or in combination with gefitinib can reduce breast cancer cell viability and Akt/mTOR signaling. Gefitinib does not affect RQC-mediated regulation of Akt, AMPK, and p70S6K. Since up-regulation of PI3-K/Akt/mTOR is known to be involved in drug resistance, these results further implicate $\mathrm{RQC}$ as a chemosensitization agent for gefitinib. Interestingly, 30 min treatment with gefitinib alone did not affect p70S6K activity; however at this time point, gefitinib significantly inhibits Akt and increases AMPK activity. This result suggests that resistance to gefitinib in the MDAMB-231 cell line may be downstream of mTOR signaling at the p70S6K level, possibly via activation of MAPK or other activators of p70S6K that are insensitive to gefitinib.

Our in vivo studies demonstrate that RQC has the potential to chemosensitize gefitinib resistant breast cancers, as shown by the significant inhibition in tumor growth induced by RQC and gefitinib combined treatment. Although we have previously reported RQC at $5 \mathrm{mg} / \mathrm{kg} \mathrm{BW}$ to significantly reduce tumor growth in nude mice bearing MDA-MB-435 and MDA-MB-231 tumor xenografts (16;17), RQC alone did not affect mammary fat pad tumor growth in the present study. This discrepancy may be accounted for by the differences in the experimental designs. In the previous study, MDA-MB-231 xenografts were implanted in nude mice as equal-size tumor slices from previously established tumors. In addition, the RQC treatments were administrated 1 day following xenograft implantation. Moreover, the RQC polyphenols were dissolved in $90 \%$ corn oil:10\% ethanol. In the present study, MDA-MB-231 cells in $50 \%$ Matrigel were inoculated directly at the mammary fat pad of SCID mice, treatments were started after tumor establishment (one week after breast cancer cell inoculation), and polyphenols were dissolved in $90 \%$ neobee oil: $10 \%$ ethanol. Therefore, the difference in mouse species (athymic nude mice vs. T- and B-cell deficient SCID mice), establishment of xenografts vs. cells, time of compound administration, and relative solubility of the polyphenols in corn oil vs. neobee oil may account for these observed differences in RQC responses. Regardless, in this study, we show the potential of RQC to inhibit breast cancer progression in the presence of gefitinib; and thus, act as a chemosensitizer for anti-EGFR therapy. RQC treatment may have a slight protective effect on gefitinib toxicity because the combined treatment did not decrease mouse weights to the same extent as gefitinib alone. 
A noteworthy finding is that combined RQC and gefitinib therapy induced a dramatic and significant reduction in lung metastases. We also found a trend in reduced kidney and liver metastases with combined RQC and gefitinib treatment. Interestingly, gefitinib alone at $200 \mathrm{mg} / \mathrm{kg} \mathrm{BW}$ caused a reduction in metastasis. This result indicates the utility of continuing gefitinib therapy in patients whose primary tumors are no longer responsive. Lung cancer is the leading cause of death from cancer in the USA and the reason for breast cancer mortality is usually due to metastasis to lung and other distant organs (1). Therefore, this study highlights the potential of combined RQC and gefitinib as a therapeutic regimen to impede progression of gefitinib resistant metastatic breast cancers.

We have elucidated an important role for RQC in potentiation of current anti-cancer therapy. Since development of therapy resistance is a common failure in cancer therapy, these studies are relevant for effective breast cancer treatment. Our future studies aim to identify additional mechanisms of chemosensitization by RQC. In conclusion, non-toxic RQC constitutes an ideal candidate for combinatorial therapy and its potential of chemosensitization towards other chemotherapy regimens will also be addressed in future experiments.

\section{Acknowledgements}

We thank Dr. Aldo Pérez Muñiz for his excellent technical assistance with animal protocols and Vanita Flanagan for assistance with imaging organs. We also acknowledge the services of the Animal Resources Center, Universidad Central del Caribe, Bayamón, Puerto Rico.

\section{Grant Support}

This research was supported by grant numbers DoD/BCRP W81XWH-07-1-0330 to SD; DoD/BCRP W81XWH-08-01-0258 to LCP; NIH/NCRR 2G12RR003035 to UCC; NIH/NCRR G12RR03051 to UPR MSC. 


\section{References}

1. Siegel R, Ward E, Brawley O, Jemal A. Cancer statistics, 2011: The impact of eliminating socioeconomic and racial disparities on premature cancer deaths. CA Cancer J.Clin. 2011;61:212-36.

2. Gonzalez-Angulo AM, Morales-Vasquez F, Hortobagyi GN. Overview of resistance to systemic therapy in patients with breast cancer. Adv.Exp.Med.Biol. 2007;608:1-22.

3. Engelman JA, Settleman J. Acquired resistance to tyrosine kinase inhibitors during cancer therapy. Curr.Opin.Genet.Dev. 2008;18:73-9.

4. Ricciardi S, Tomao S, de MF. Toxicity of targeted therapy in non-small-cell lung cancer management. Clin.Lung Cancer 2009;10:28-35.

5. Aggarwal BB, Shishodia S. Molecular targets of dietary agents for prevention and therapy of cancer. Biochem.Pharmacol. 2006;71:1397-421.

6. Park EJ, Pezzuto JM. Botanicals in cancer chemoprevention. Cancer Metastasis Rev. 2002;21:231-55.

7. Hakimuddin F, Paliyath G, Meckling K. Selective cytotoxicity of a red grape wine flavonoid fraction against MCF-7 cells. Breast Cancer Res. Treat. 2004;85:65-79.

8. Harris DM, Besselink E, Henning SM, Go VL, Heber D. Phytoestrogens induce differential estrogen receptor alpha- or Beta-mediated responses in transfected breast cancer cells. Exp.Biol.Med.(Maywood.) 2005;230:558-68.

9. Singletary KW, Stansbury MJ, Giusti M, van Breemen RB, Wallig M, Rimando A. Inhibition of rat mammary tumorigenesis by concord grape juice constituents. J.Agric.Food Chem. 2003;51:7280-6.

10. Singh RP, Tyagi AK, Dhanalakshmi S, Agarwal R, Agarwal C. Grape seed extract inhibits advanced human prostate tumor growth and angiogenesis and upregulates insulin-like growth factor binding protein-3. Int.J.Cancer 2004;108:733-40.

11. Kim H, Hall P, Smith M, Kirk M, Prasain JK, Barnes $S$ et al. Chemoprevention by grape seed extract and genistein in carcinogen-induced mammary cancer in rats is diet dependent. J Nutr. 2004;134:3445S-52S.

12. Lu J, Zhang K, Chen S, Wen W. Grape seed extract inhibits VEGF expression via reducing HIF1alpha protein expression. Carcinogenesis 2009;30:636-44.

13. Hanausek M, Spears E, Walaszek Z, Kowalczyk MC, Kowalczyk P, Wendel C et al. Inhibition of murine skin carcinogenesis by freeze-dried grape powder and other grape-derived major antioxidants. Nutr.Cancer 2011;63:28-38.

14. Radhakrishnan S, Reddivari L, Sclafani R, Das UN, Vanamala J. Resveratrol potentiates grape seed extract induced human colon cancer cell apoptosis. Front Biosci.(Elite.Ed) 2011;3:150923.

15. Levi F, Pasche C, Lucchini F, Ghidoni R, Ferraroni M, La Vecchia C. Resveratrol and breast cancer risk. Eur.J Cancer Prev. 2005;14:139-42. 
16. Schlachterman A, Valle F, Wall KM, Azios NG, Castillo L, Morell L et al. Combined resveratrol, quercetin, and catechin treatment reduces breast tumor growth in a nude mouse model. Transl Oncol 2008;1:19-27.

17. Castillo-Pichardo L, Martinez-Montemayor MM, Martinez JE, Wall KM, Cubano LA, Dharmawardhane S. Inhibition of mammary tumor growth and metastases to bone and liver by dietary grape polyphenols. Clin.Exp.Metastasis 2009;26:505-16.

18. Manach C, Williamson G, Morand C, Scalbert A, Remesy C. Bioavailability and bioefficacy of polyphenols in humans. I. Review of 97 bioavailability studies. Am.J.Clin.Nutr. 2005;81:230S42S.

19. Fridrich D, Teller N, Esselen M, Pahlke G, Marko D. Comparison of delphinidin, quercetin and ()-epigallocatechin-3-gallate as inhibitors of the EGFR and the ErbB2 receptor phosphorylation. Mol.Nutr.Food Res. 2008;52:815-22.

20. Azios NG, Dharmawardhane SF. Resveratrol and estradiol exert disparate effects on cell migration, cell surface actin structures, and focal adhesion assembly in MDA-MB-231 human breast cancer cells. Neoplasia 2005;7:128-40.

21. Jeong JH, An JY, Kwon YT, Li LY, Lee YJ. Quercetin-induced ubiquitination and downregulation of Her-2/neu. J Cell Biochem. 2008;105:585-95.

22. Chan SK, Hill ME, Gullick WJ. The role of the epidermal growth factor receptor in breast cancer. J Mammary.Gland.Biol.Neoplasia 2006;11:3-11.

23. Von PJ. Gefitinib (Iressa, ZD1839): a novel targeted approach for the treatment of solid tumors. Bull.Cancer 2004;91:E70-E76.

24. Kosaka T, Yamaki E, Mogi A, Kuwano H. Mechanisms of Resistance to EGFR TKls and Development of a New Generation of Drugs in Non-Small-Cell Lung Cancer. J.Biomed.Biotechnol. 2011;2011:165214.

25. Knight LA, Di NF, Whitehouse P, Mercer S, Sharma S, Glaysher S et al. The in vitro effect of gefitinib ('Iressa') alone and in combination with cytotoxic chemotherapy on human solid tumours. BMC.Cancer 2004;4:83.

26. Johnson ML, Riely GJ, Rizvi NA, Azzoli CG, Kris MG, Sima CS et al. Phase II Trial of Dasatinib for Patients with Acquired Resistance to Treatment with the Epidermal Growth Factor Receptor Tyrosine Kinase Inhibitors Erlotinib or Gefitinib. J.Thorac.Oncol. 2011;6:1128-31.

27. Brunner-Kubath C, Shabbir W, Saferding V, Wagner R, Singer CF, Valent P et al. The PI3 kinase/mTOR blocker NVP-BEZ235 overrides resistance against irreversible ErbB inhibitors in breast cancer cells. Breast Cancer Res.Treat. 2010.

28. O'Regan R, Hawk NN. mTOR inhibition in breast cancer: unraveling the complex mechanisms of mTOR signal transduction and its clinical implications in therapy. Expert.Opin.Ther.Targets. 2011;15:859-72.

29. Dobashi Y, Watanabe Y, Miwa C, Suzuki S, Koyama S. Mammalian target of rapamycin: a central node of complex signaling cascades. Int.J.Clin.Exp.Pathol. 2011;4:476-95. 
30. Shaw RJ. LKB1 and AMP-activated protein kinase control of mTOR signalling and growth. Acta Physiol (Oxf) 2009;196:65-80.

31. Berstein LM, Yue W, Wang JP, Santen RJ. Isolated and combined action of tamoxifen and metformin in wild-type, tamoxifen-resistant, and estrogen-deprived MCF-7 cells. Breast Cancer Res.Treat. 2010; 128:109-17.

32. van der Heijden MS, Bernards R. Inhibition of the PI3K pathway: hope we can believe in? Clin.Cancer Res. 2010;16:3094-9.

33. Garg AK, Buchholz TA, Aggarwal BB. Chemosensitization and radiosensitization of tumors by plant polyphenols. Antioxid.Redox.Signal. 2005;7:1630-47.

34. Phadke PA, Vaidya KS, Nash KT, Hurst DR, Welch DR. BRMS1 suppresses breast cancer experimental metastasis to multiple organs by inhibiting several steps of the metastatic process. Am.J Pathol. 2008;172:809-17.

35. McGovern UB, Francis RE, Peck B, Guest SK, Wang J, Myatt SS et al. Gefitinib (Iressa) represses FOXM1 expression via FOXO3a in breast cancer. Mol.Cancer Ther. 2009;8:582-91.

36. Ferrer-Soler L, Vazquez-Martin A, Brunet J, Menendez JA, De LR, Colomer R. An update of the mechanisms of resistance to EGFR-tyrosine kinase inhibitors in breast cancer: Gefitinib (Iressa) -induced changes in the expression and nucleo-cytoplasmic trafficking of HER-ligands (Review). Int.J.Mol.Med. 2007;20:3-10.

37. Arpino G, Gutierrez C, Weiss H, Rimawi M, Massarweh S, Bharwani L et al. Treatment of human epidermal growth factor receptor 2-overexpressing breast cancer xenografts with multiagent HER-targeted therapy. J.Natl.Cancer Inst. 2007;99:694-705.

38. Wakeling AE, Guy SP, Woodburn JR, Ashton SE, Curry BJ, Barker AJ et al. ZD1839 (Iressa): an orally active inhibitor of epidermal growth factor signaling with potential for cancer therapy. Cancer Res. 2002;62:5749-54.

39. Saeed SA, Connor JD, Imran, Quadri J, Tasneem S, Ahmed S et al. Inhibitors of phosphatidylinositide 3-kinase: effects on reactive oxygen species and platelet aggregation. Pharmacol.Rep. 2007;59:238-43.

40. He X, Wang $\mathrm{Y}$, Zhu J, Orloff M, Eng C. Resveratrol enhances the anti-tumor activity of the mTOR inhibitor rapamycin in multiple breast cancer cell lines mainly by suppressing rapamycininduced AKT signaling. Cancer Lett. 2011;301:168-76.

41. Gulati N, Laudet B, Zohrabian VM, Murali R, Jhanwar-Uniyal M. The antiproliferative effect of Quercetin in cancer cells is mediated via inhibition of the PI3K-Akt/PKB pathway. Anticancer Res. 2006;26:1177-81.

42. Gonzalez-Angulo AM, Meric-Bernstam F. Metformin: a therapeutic opportunity in breast cancer. Clin.Cancer Res. 2010;16:1695-700.

43. Hwang JT, Kwon DY, Yoon SH. AMP-activated protein kinase: a potential target for the diseases prevention by natural occurring polyphenols. N.Biotechnol. 2009;26:17-22.

44. Jung JH, Lee JO, Kim JH, Lee SK, You GY, Park SH et al. Quercetin suppresses HeLa cell viability via AMPK-induced HSP70 and EGFR down-regulation. J.Cell Physiol 2010;223:408-14. 
45. Lin JN, Lin VC, Rau KM, Shieh PC, Kuo DH, Shieh JC et al. Resveratrol modulates tumor cell proliferation and protein translation via SIRT1-dependent AMPK activation. J.Agric.Food Chem. 2010;58:1584-92.

46. Puissant A, Robert G, Fenouille N, Luciano F, Cassuto JP, Raynaud S et al. Resveratrol promotes autophagic cell death in chronic myelogenous leukemia cells via JNK-mediated p62/SQSTM1 expression and AMPK activation. Cancer Res. 2010;70:1042-52.

47. Lee YK, Park SY, Kim YM, Lee WS, Park OJ. AMP kinase/cyclooxygenase-2 pathway regulates proliferation and apoptosis of cancer cells treated with quercetin. Exp.Mol.Med. 2009;41:201-7.

48. Xue B, Kahn BB. AMPK integrates nutrient and hormonal signals to regulate food intake and energy balance through effects in the hypothalamus and peripheral tissues. J.Physiol 2006;574:73-83.

49. Wong AK, Howie J, Petrie JR, Lang CC. AMP-activated protein kinase pathway: a potential therapeutic target in cardiometabolic disease. Clin.Sci.(Lond) 2009;116:607-20.

50. Lehman JA, Gomez-Cambronero J. Molecular crosstalk between p70S6k and MAPK cell signaling pathways. Biochem.Biophys.Res.Commun. 2002;293:463-9. 


\section{Figure Captions}

Figure 1. Effect of RQC on apoptosis of MDA-MB-231 cells. Apoptosis of MDA-MB-231 cells was detected by caspase 3 activity assays following 48 and $96 \mathrm{~h}$ incubation with vehicle or $5 \mu \mathrm{M} R \mathrm{RQ}$. (A) Caspase 3 activity relative to vehicle (Veh) ( $n=3 \pm$ SEM) as quantified from absorbance at $405 \mathrm{~nm}$ of $\mathrm{p}$ nitroaniline, a product released by caspase 3 activity. An asterisk indicates statistical significance $(p \leq 0.05)$ when compared to vehicle. (B) Apoptotic signaling proteins regulated in MDA-MB-231 cells at $48 \mathrm{~h}$ following vehicle (Veh) or $5 \mu \mathrm{M}$ RQC treatment were studied using antibody arrays. A representative image of 3 biological replicates is presented. Proteins that were significantly regulated by RQC are highlighted.

Figure 2. Effect of individual and combined resveratrol, quercetin, and catechin (RQC) on Akt, AMPK, and p70S6K phosphorylation in MDA-MB-231 cells. Confluent MDA-MB-231 cells were serum-starved for $24 \mathrm{~h}$, treated with vehicle (Veh) or $5 \mu \mathrm{M}$ resveratrol (Res), quercetin (Quer), catechin (Cat), or RQC for 15 min, lysed immediately, and western blotted for active and total proteins: phospho$\mathrm{Akt}^{\mathrm{Ser} 43}$ and Akt, phospho-AMPK ${ }^{\text {Thr172 }}$ and AMPK, or phospho-p70S6K $\mathrm{K}^{\text {Thr389 }}$ and p70S6K. (A) Upper panel, representative western blots (from 4 separate experiments); lower panel, Akt activity (phosphoAkt/Akt) relative to vehicle, as quantified from Image $\mathrm{J}$ analysis of integrated density of positive bands. (B) Upper panel, representative western blots (from 4 separate experiments); lower panel, AMPK activity (phospho-AMPK/AMPK) relative to vehicle, as quantified from Image $\mathrm{J}$ analysis of integrated density of positive bands. (C) Upper panel, representative western blots (from 4 separate experiments); lower panel, p70S6K activity (phospho-p70S6K/p70S6K) relative to vehicle, as quantified from Image $\mathrm{J}$ analysis of integrated density of positive bands. An asterisk indicates statistical significance $(p \leq 0.05)$ when compared to vehicle.

Figure 3. Effect of individual and combined RQC and gefitinib on MDA-MB-231 cell proliferation. MDA-MB-231 cells in 5\% serum and phenol red-free media were treated for $48 \mathrm{~h}$ with vehicle (Veh), or 
$\mathrm{RQC}$ at $0.167,0.5,1.67,5$, or $15 \mu \mathrm{M}$ for the generation of $\mathrm{RQC}$ dose response curve. For the generation of gefitinib (Gef) dose response curve MDA-MB-231 cells were treated for $48 \mathrm{~h}$ with vehicle (Veh), or $0.1,1,10,20,30,40$, or $50 \mu \mathrm{M}$ Gef. Cell number was quantified from Pl-stained intact (nonapoptotic) nuclei. Percentage of viable MDA-MB-231 cells \pm SEM for 25 microscopic fields/treatment is shown ( $n=3$ ). Dose response curve for $(A) R Q C$ and $(B)$ Gef are presented. $I C_{50}$ values for $R Q C$ and gefitinib were obtained from dose response curve fittings using the non-linear regression function of GraphPad Prism®. (C) Cell number following Veh, $5 \mu \mathrm{M} R Q C, 30 \mu \mathrm{M}$ Gef, or combined RQC and Gef. An asterisk indicates statistical significance $(p \leq 0.05)$ when comparing combined treatment with either RQC or Gef individual treatments.

Figure 4. Effect of individual and combined RQC and gefitinib on Akt, AMPK, and p70S6K phosphorylation of MDA-MB-231 cells. Confluent MDA-MB-231 cells were serum starved for $24 \mathrm{~h}$, treated with vehicle (Veh), $5 \mu \mathrm{M} R Q C, 30 \mu \mathrm{M}$ gefitinib (Gef) or a combination of both for 15 or $30 \mathrm{~min}$, lysed immediately, and western blotted for active and total proteins: phospho-Akt ${ }^{\text {Ser473 }}$ and Akt, phospho-AMPK ${ }^{\text {Thr172 }}$ and AMPK, or phospho-p70S6K ${ }^{\text {Thr389 }}$ and p70S6K. (A and D) Upper panel, representative western blots (from 3 separate experiments); lower panel, Akt activity (phosphoAkt/Akt) relative to vehicle, as quantified from Image $\mathrm{J}$ analysis of integrated density of positive bands. (B and E) Upper panel, representative western blots (from 4 separate experiments); lower panel, AMPK activity (phospho-AMPK/AMPK) relative to vehicle, as quantified from Image $\mathrm{J}$ analysis of integrated density of positive bands. (C and F) Upper panel, representative western blots (from 4 separate experiments (15 min treatment) or 6 separate experiments (30 min treatment); lower panel, p70S6K activity (phospho-p70S6K/p70S6K) relative to vehicle, as quantified from Image $\mathrm{J}$ analysis of integrated density of positive bands. An asterisk indicates statistical significance $(p \leq 0.05)$ when compared to vehicle unless otherwise specified.

Figure 5. Effect of individual and combined RQC and Gefitinib on the progression of MDA-MB231 mammary fat pad tumors. GFP-tagged MDA-MB-231 cells $\left(1 \times 10^{6}\right)$ in Matrigel were inoculated at 
the mammary fat pad of female SCID mice, 5 to 6 wk old. One week following injection, mice were treated with vehicle (Veh), 5 mg/kg BW RQC (RQC), 200 mg/kg BW gefitinib (Gef) every other day, or a combination of $5 \mathrm{mg} / \mathrm{kg} \mathrm{BW} \mathrm{RQC} \mathrm{and} 200 \mathrm{mg} / \mathrm{kg} \mathrm{BW}$ Gef (RQC+Gef) by oral gavage. The group receiving the combination of $R Q C$ and Gef was treated one day with $R Q C$ and the following day with Gef. Whole body fluorescence images were acquired once a week. (A) Average relative tumor growth is presented as a function of days following injection. Relative tumor growth was calculated as fluorescence intensity on each imaging day as a function of the fluorescence intensity of the same tumor on day 1. (B) Relative tumor growth for each treatment group at day 84 is presented. (C and D) Effect of grape polyphenols on metastases. Following necropsy, lungs, livers, and kidneys were excised from mice with GFP-MDA-MB-435 mammary tumors that received either Veh, RQC, Gef, or $\mathrm{RQC}+$ Gef diets and analyzed for metastases by fluorescence microscopy followed by quantitative image analysis. (C) Lung metastatic efficiency expressed as average integrated density of fluorescence from lungs \pm SEM ( $n=10-12)$. (D) Liver and kidney metastatic efficiency expressed as average integrated density of fluorescence \pm SEM $(n=10-12)$. An asterisk denotes statistical significance at $p<0.05$. 
Table 1, Castillo-Pichardo, et al.

Table 1. Apoptotic signaling proteins regulated by $5 \mu \mathrm{M} R \mathrm{RQ}$

\begin{tabular}{cc|cc}
\hline \multicolumn{1}{c|}{$48 \mathrm{~h}$} & & \multicolumn{2}{c}{$96 \mathbf{h}$} \\
\hline Protein & FC & Protein & FC \\
\hline ClAP-1 & -1.75 & Trail R2/DR5 & -2.5 \\
Trail R2/DR5 & -3.07 & Fas/TNSF6 & 1.8 \\
HIF-1 alfa & -2.03 & Cleaved caspase 3 & 5.0 \\
HO-1/HMO/HSP32 & -1.89 & TNF R1/TNFRSF1A & 2.5 \\
HO-2/HMOX2 & -1.64 & & \\
SMAC/Diablo & -1.85 & & \\
Survivin & -1.81 & & \\
Trail R1/DR4 & -2.87 & & \\
FADD & -1.80 & & \\
\hline
\end{tabular}


A.

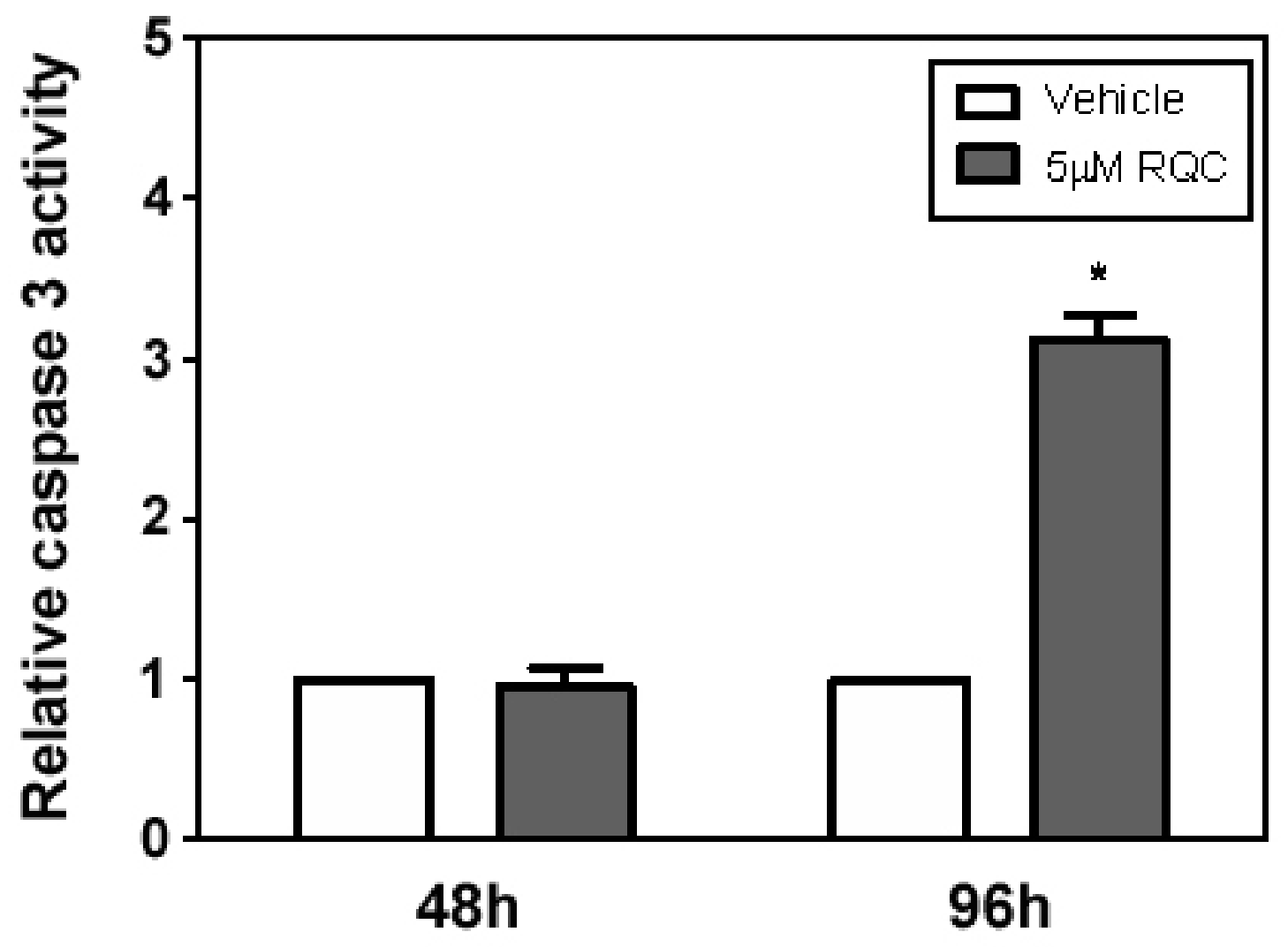

B.

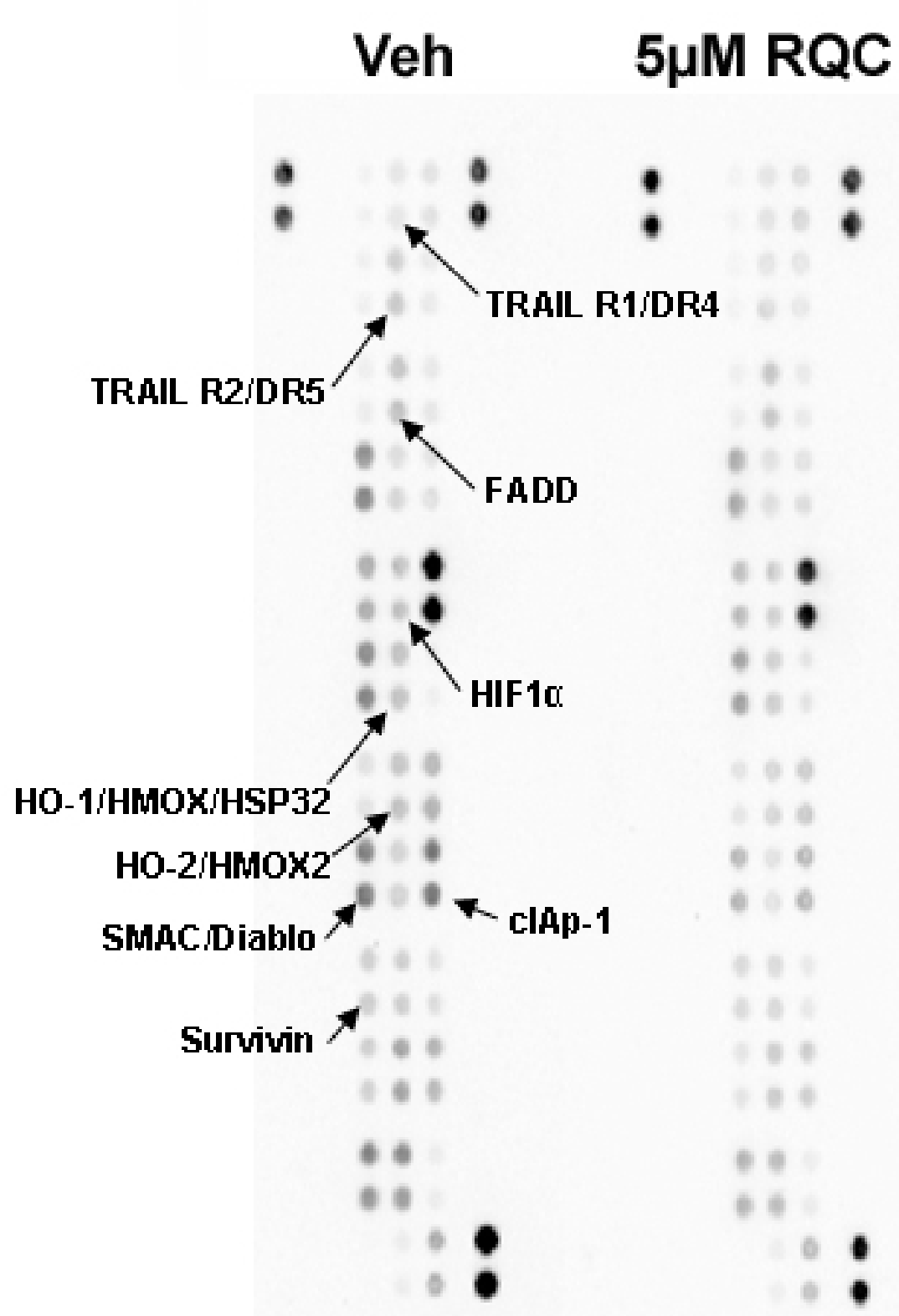


A.

B.

Veh Res Quer Cat RQC pAkt

Akt



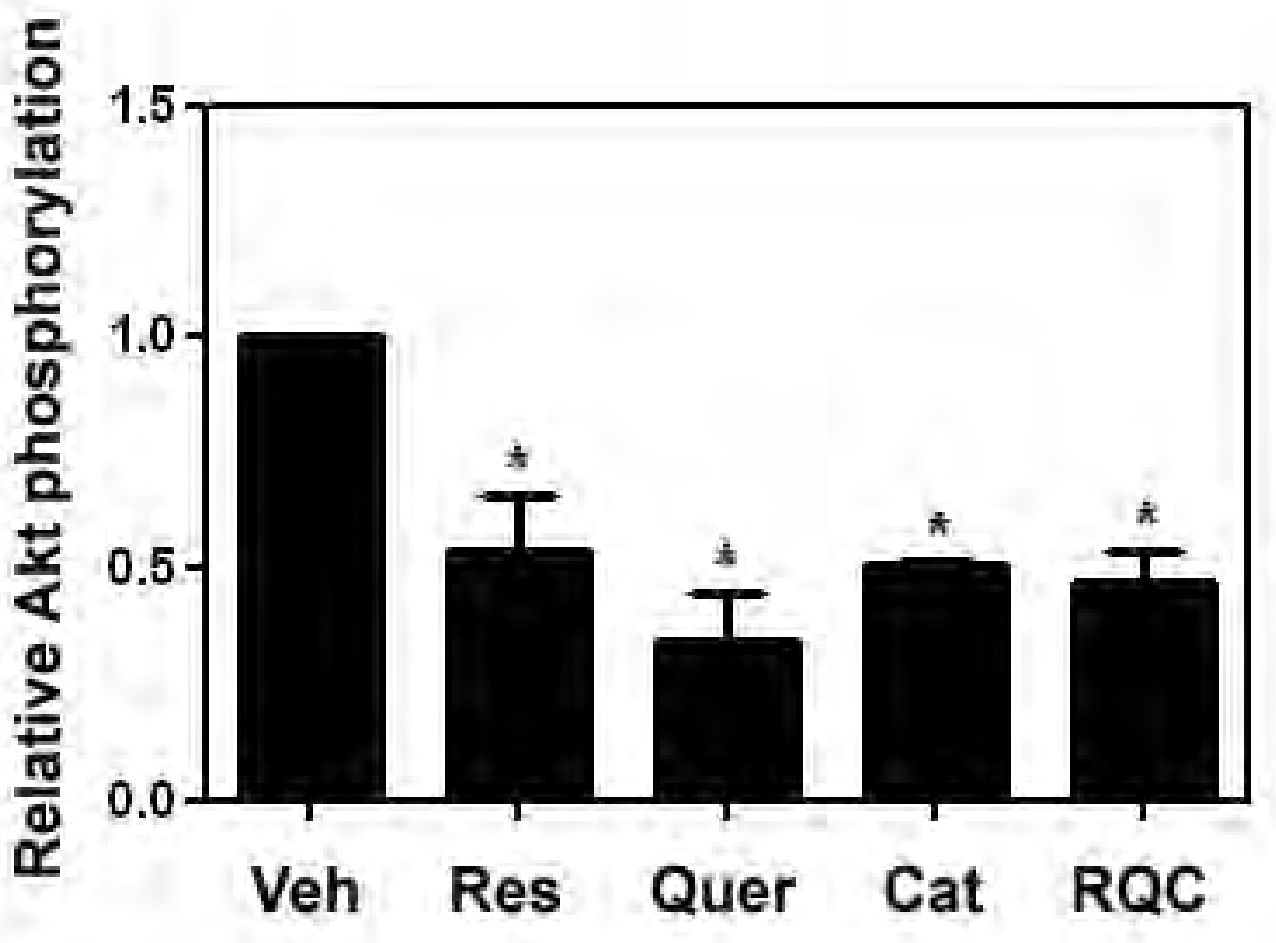

Veh Res Quer Cat RQC pAMPK — - - AMPK

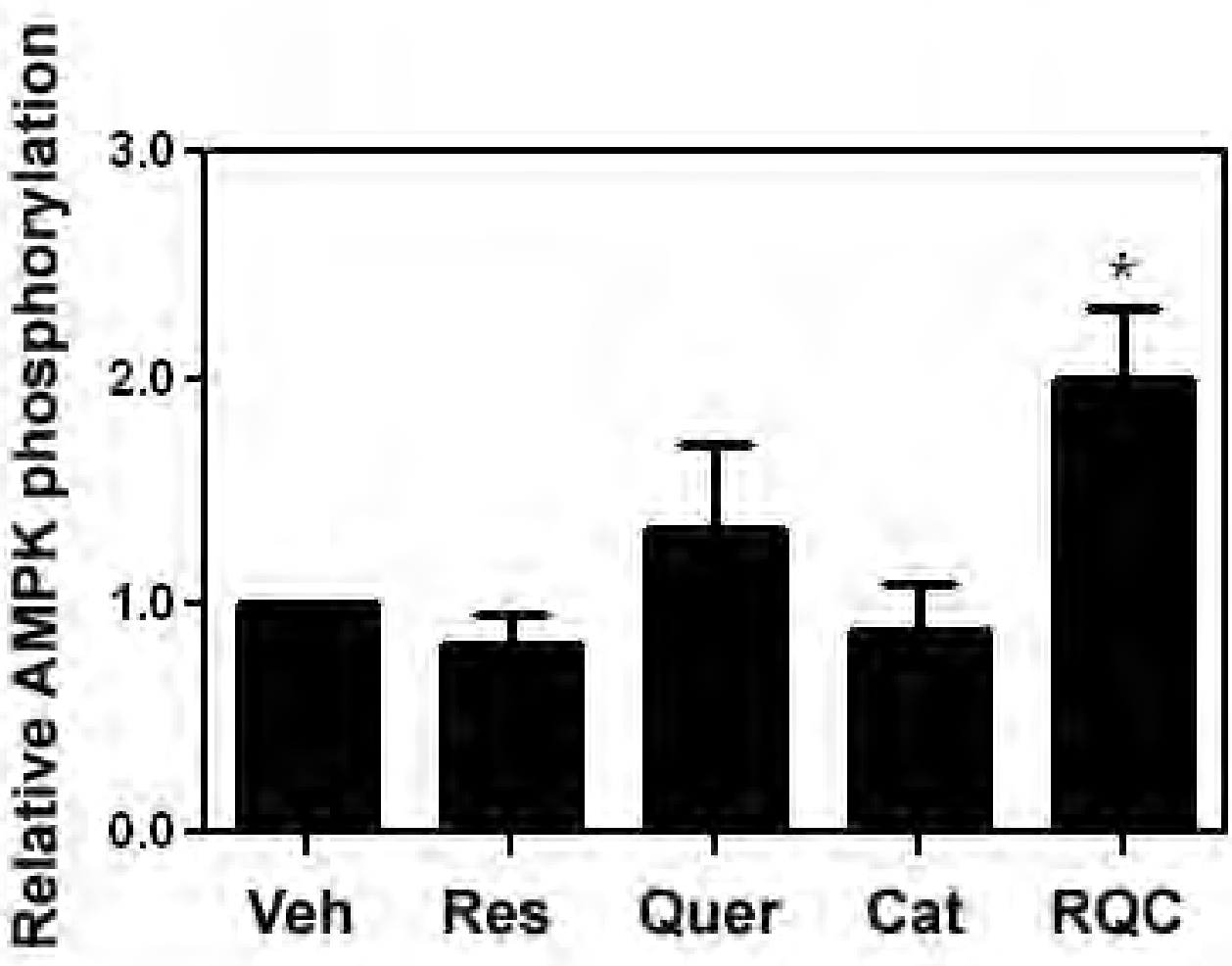

Veh Res Quer Cat RQC pp70s6K $-\div-\div$ p70S6K $=-\cdots$

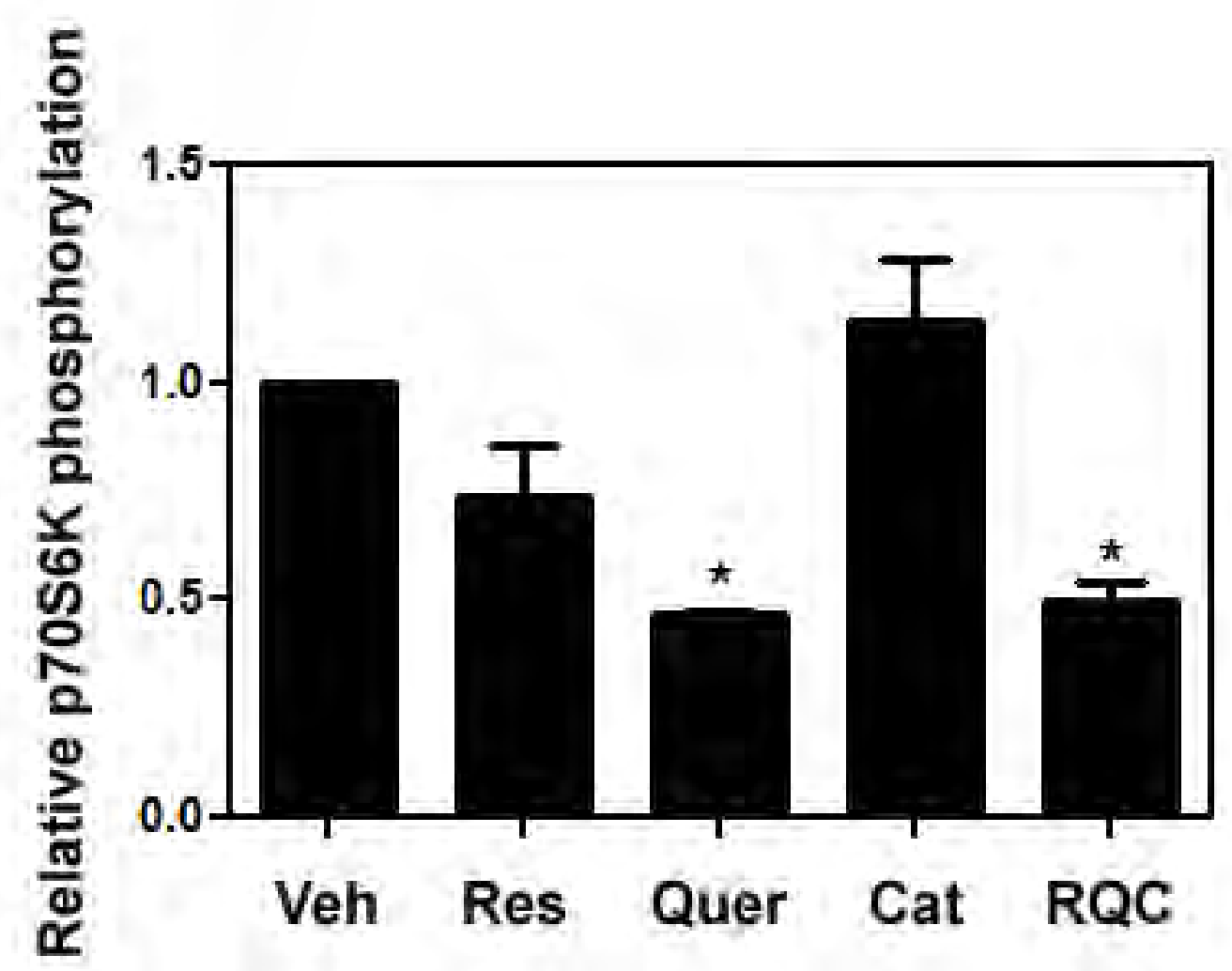


A.

Gefitinib Dose Response Curve

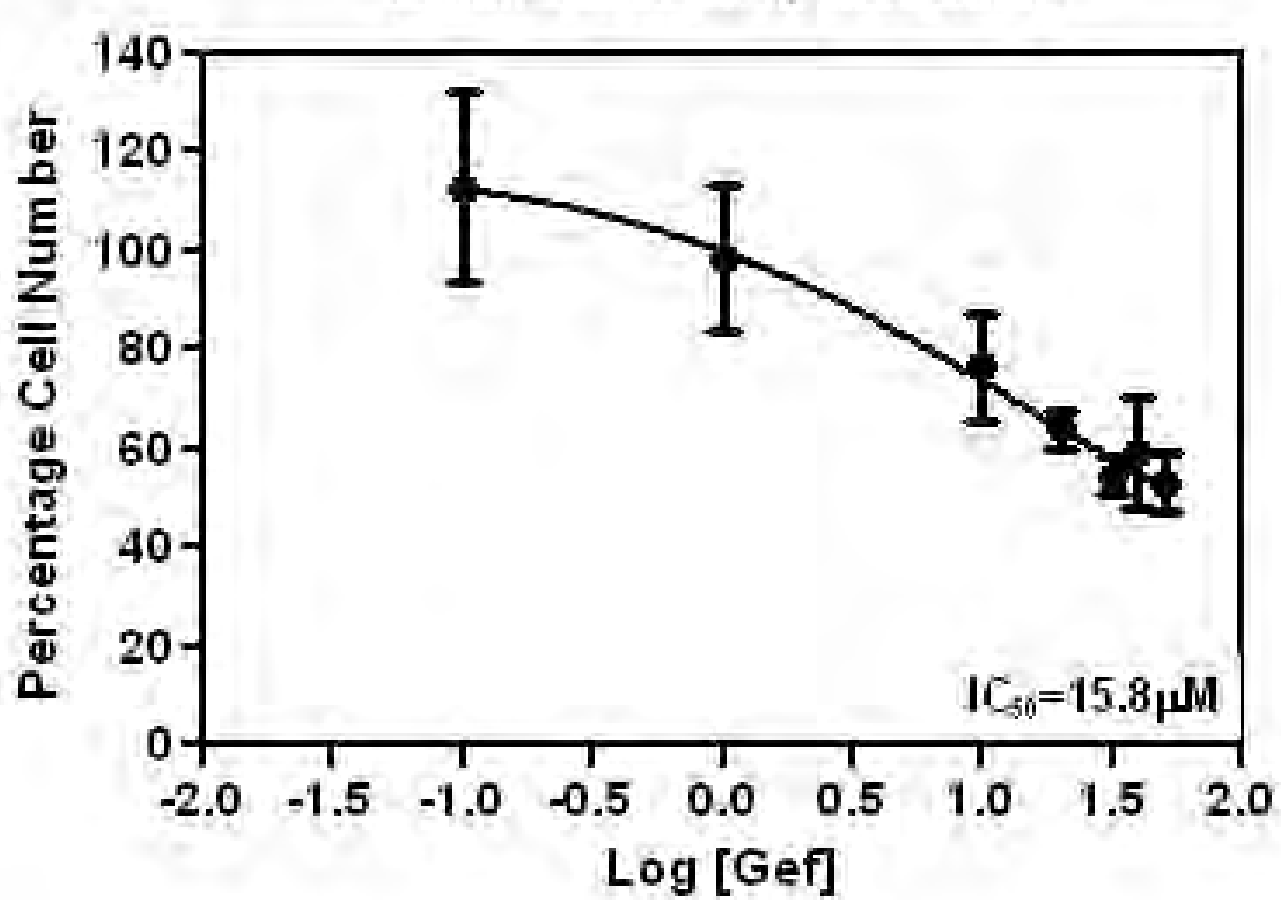

Log [Gef]
B.

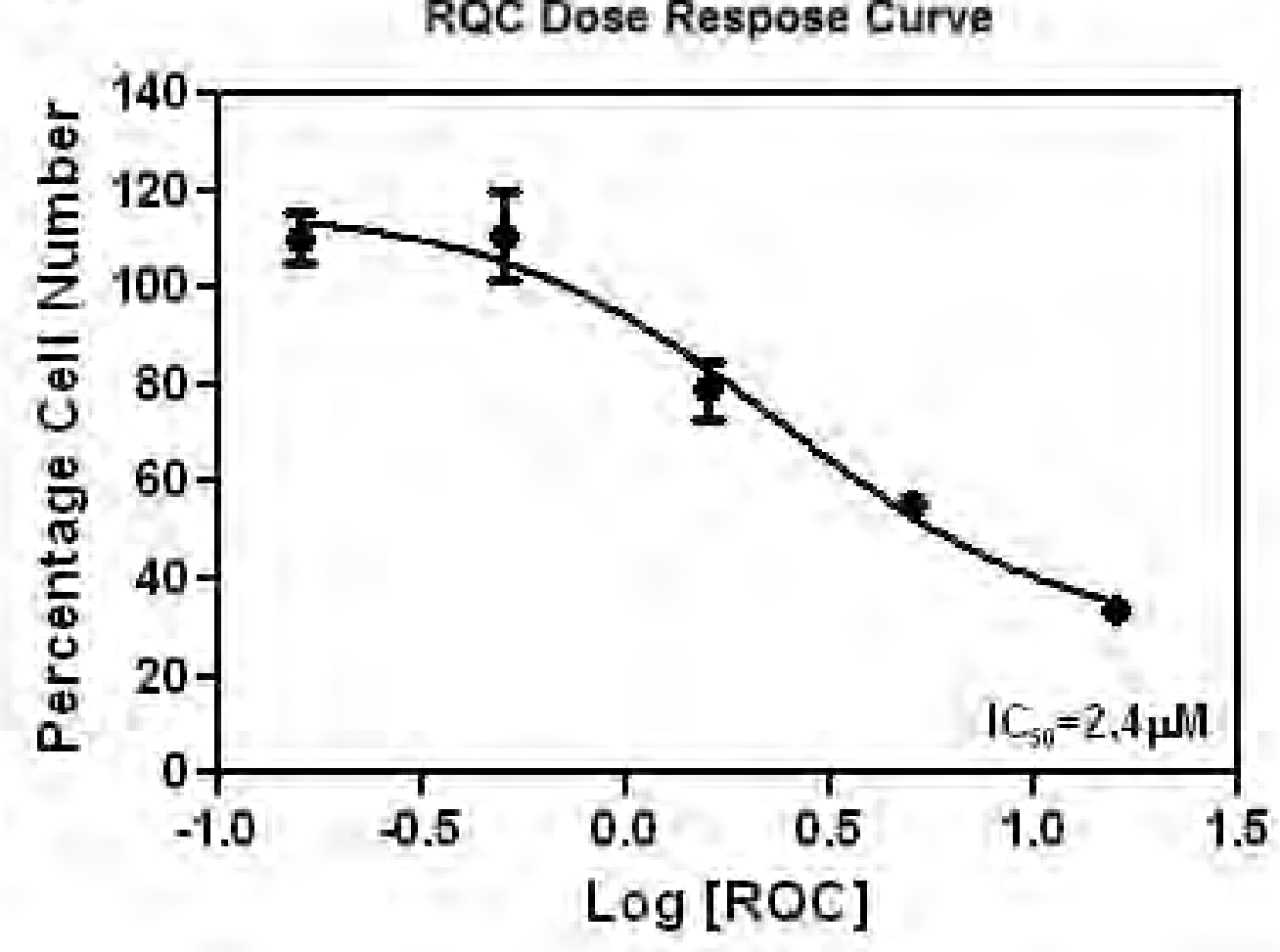

c.

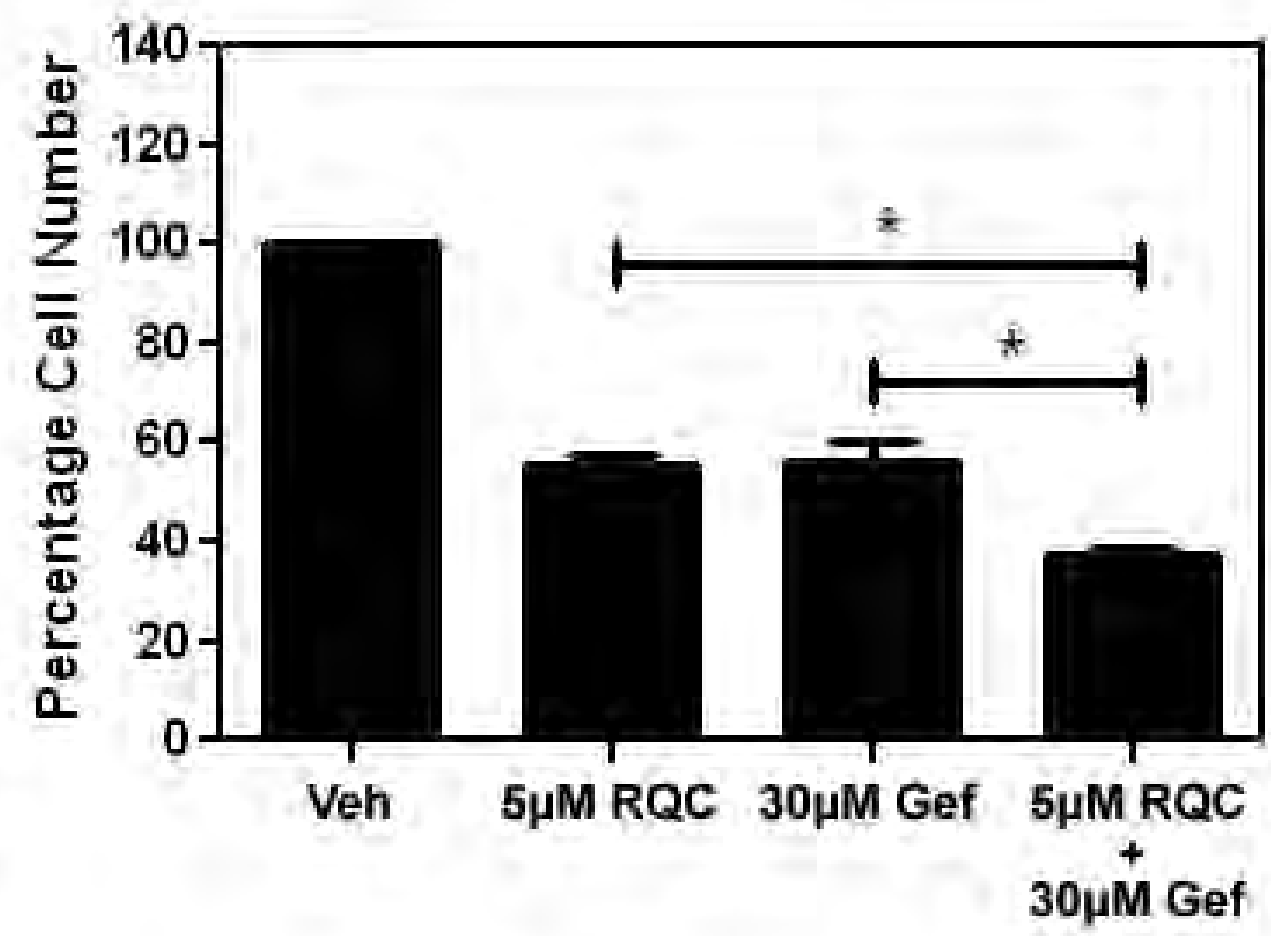


A.

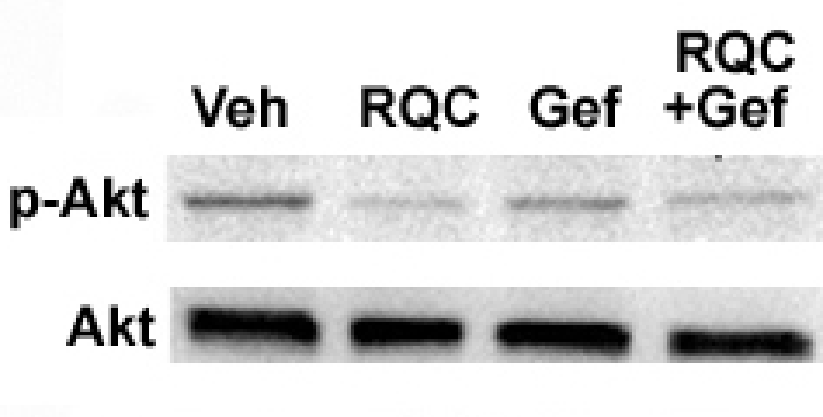

$15 \mathrm{~min}$

흘

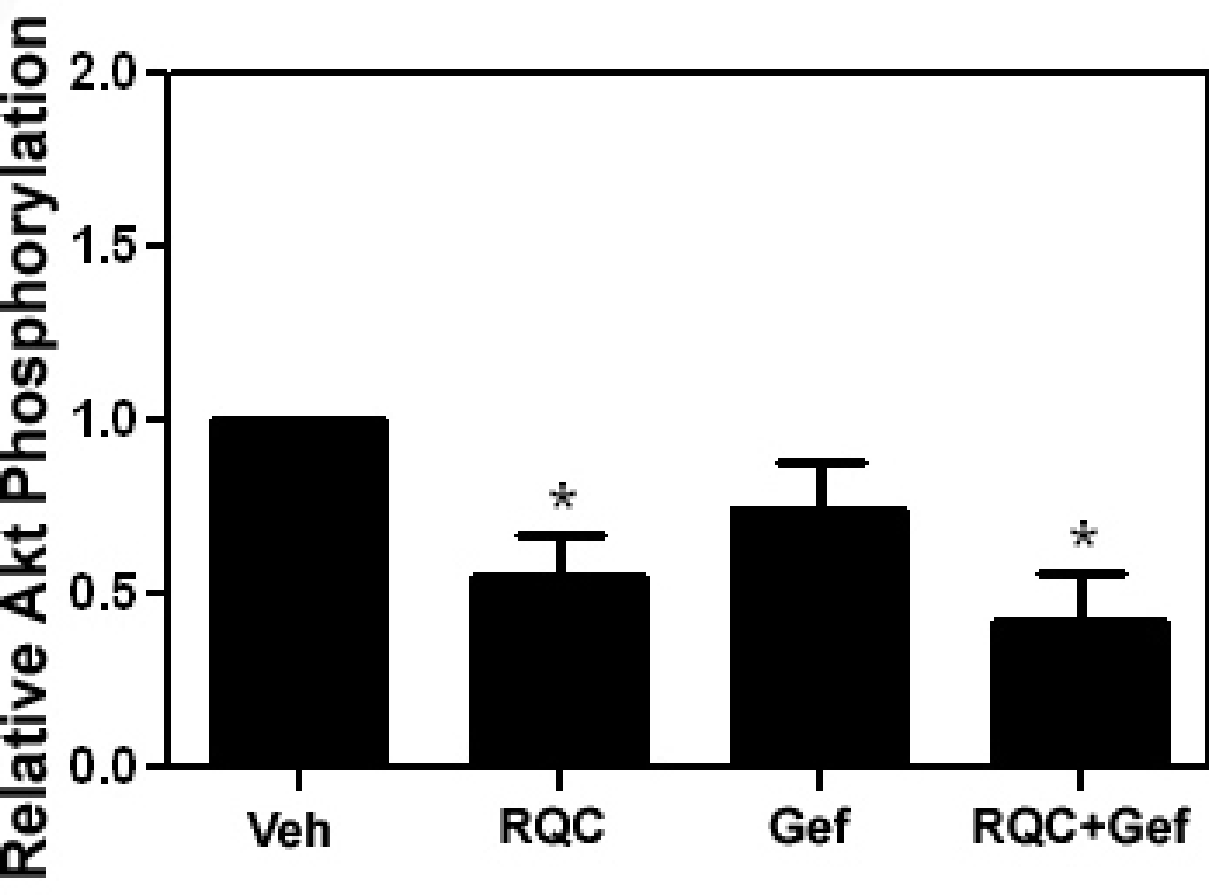

D. p-Akt 2 Veh RQC Gef $\begin{gathered}\text { RQC } \\ + \text { Gef }\end{gathered}$

$30 \mathrm{~min}$

은
B.

Veh RQC Gef

p-AMPK $-\cdots$

AMPK $-\div-$

$15 \mathrm{~min}$

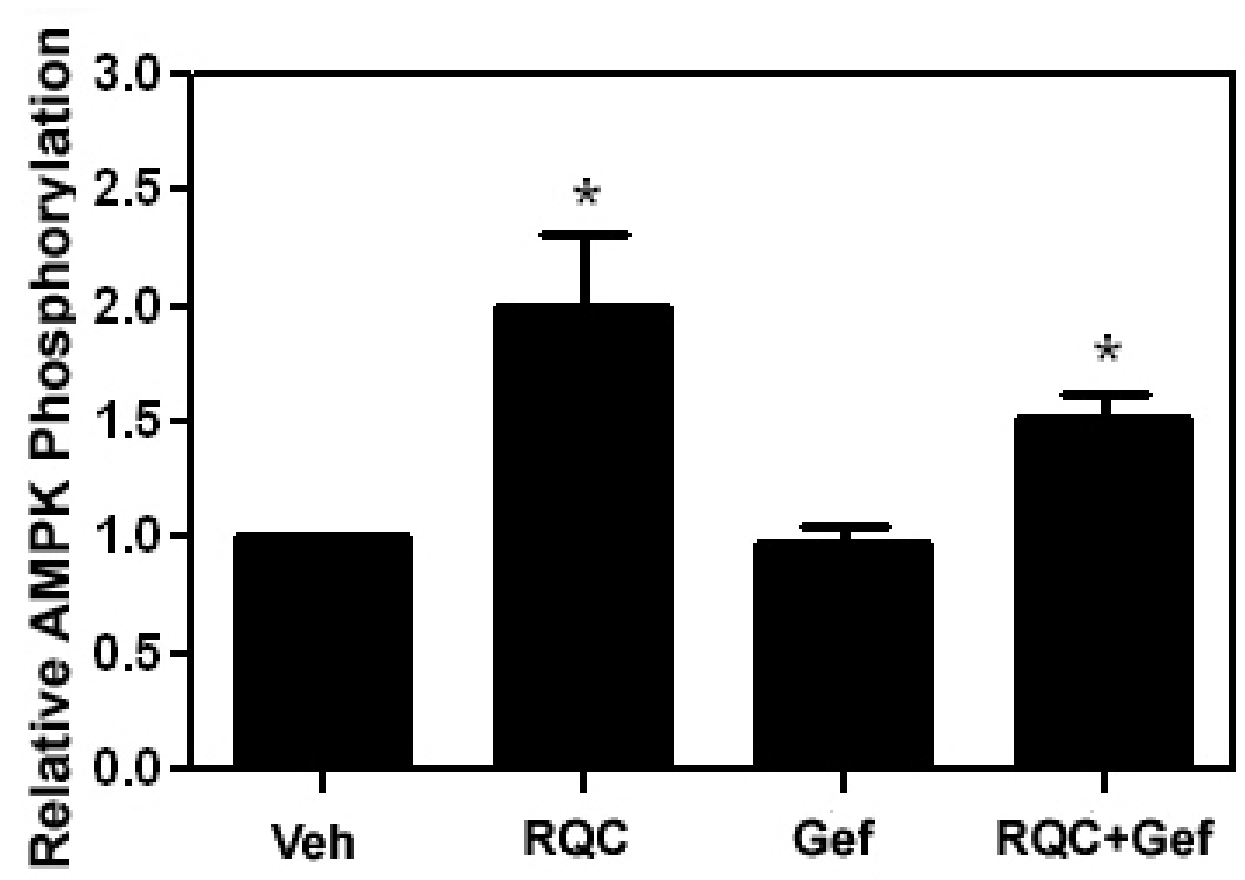

RQC

Veh RQC Gef +Gef

E. $\quad$-AMPK $m=-$

AMPK $=-$

$30 \mathrm{~min}$

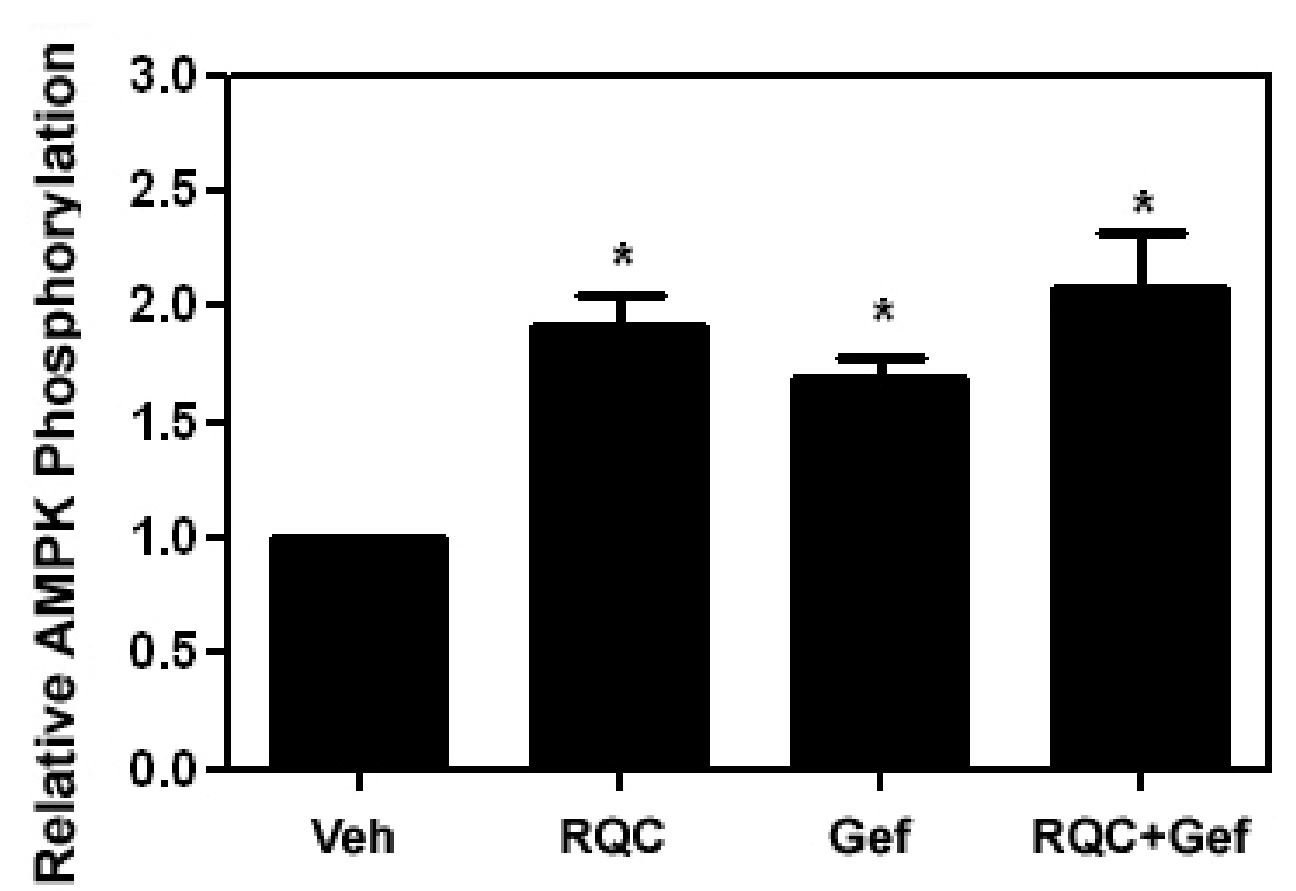

C. RQC Veh RQC Gef +Gef p-p70S6K - - p70S6K 15min

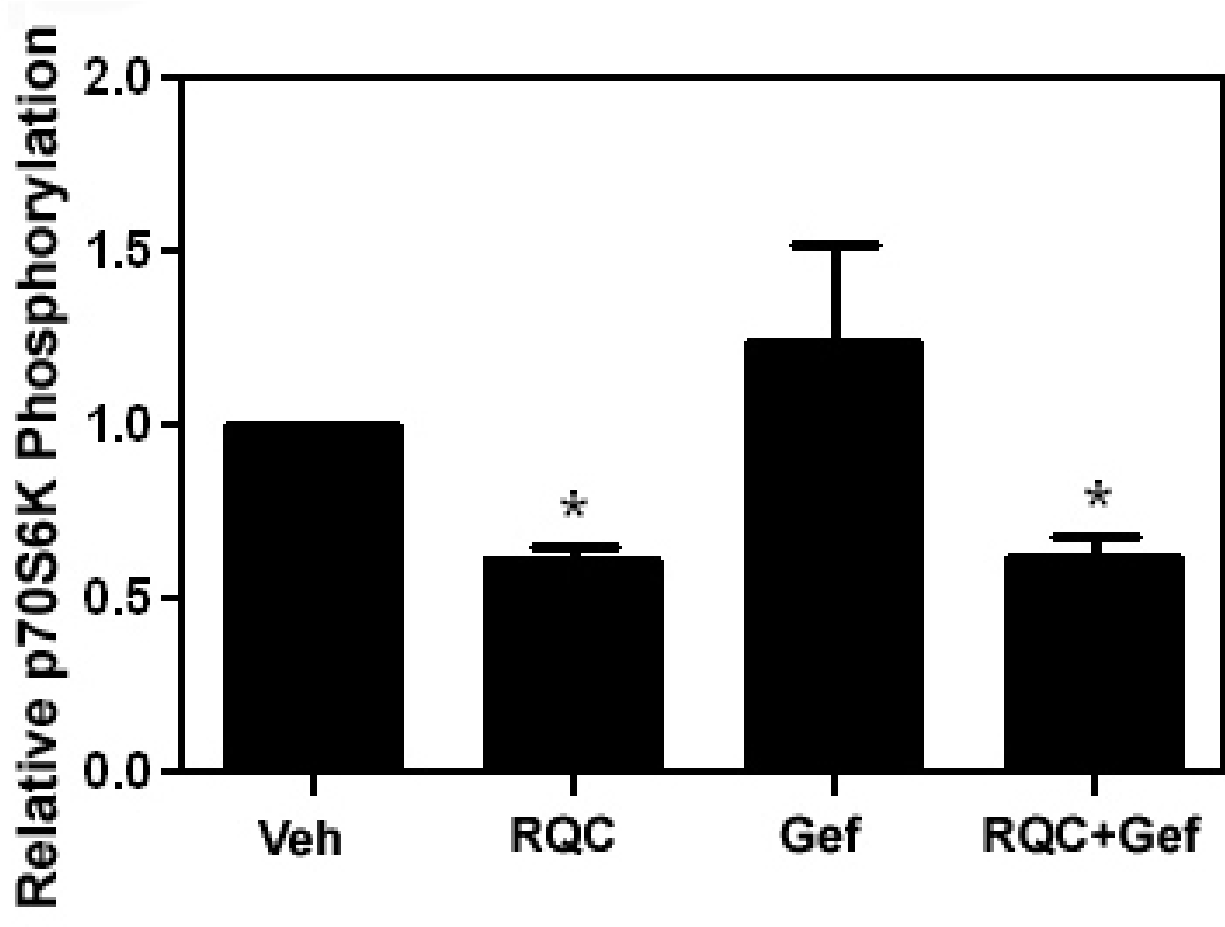

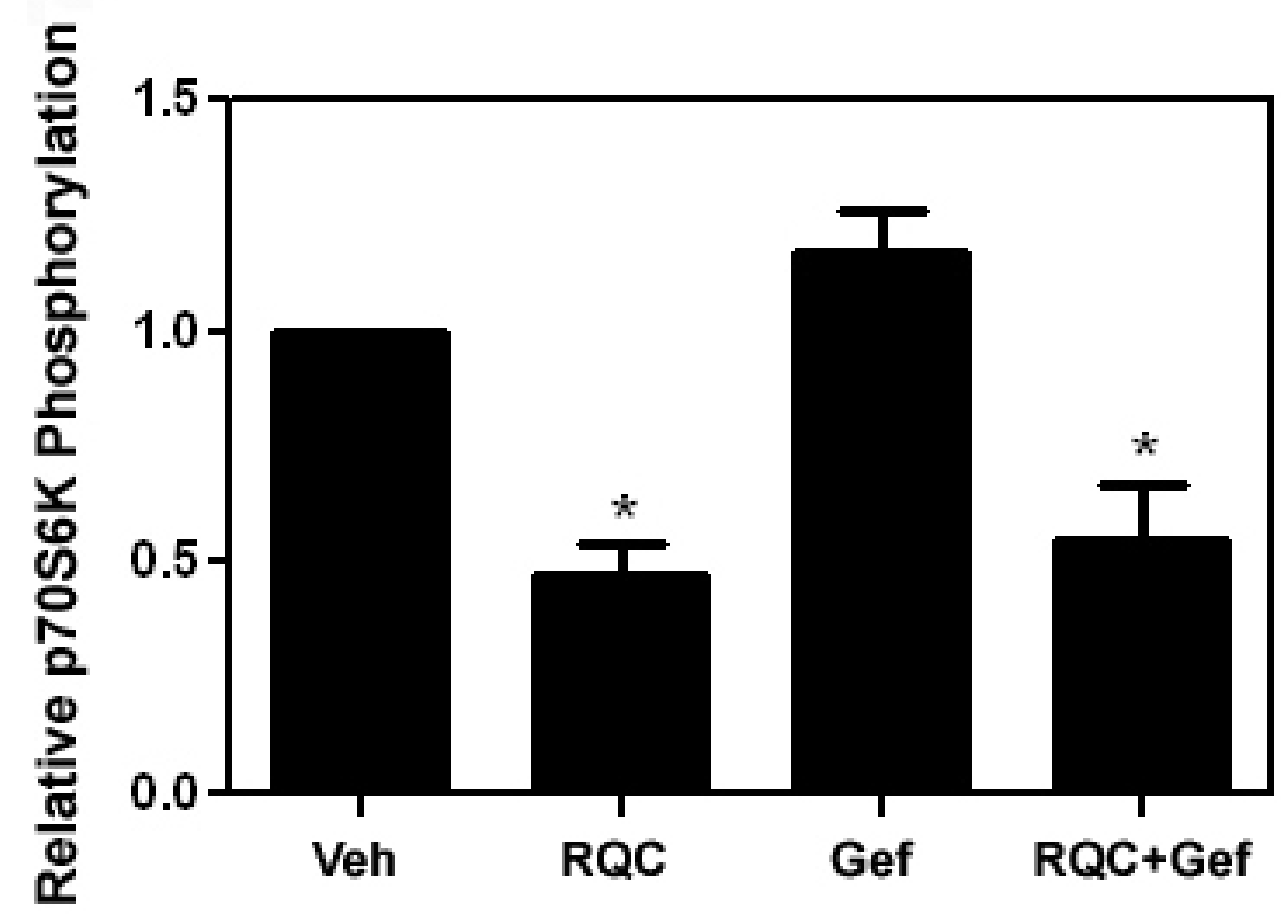




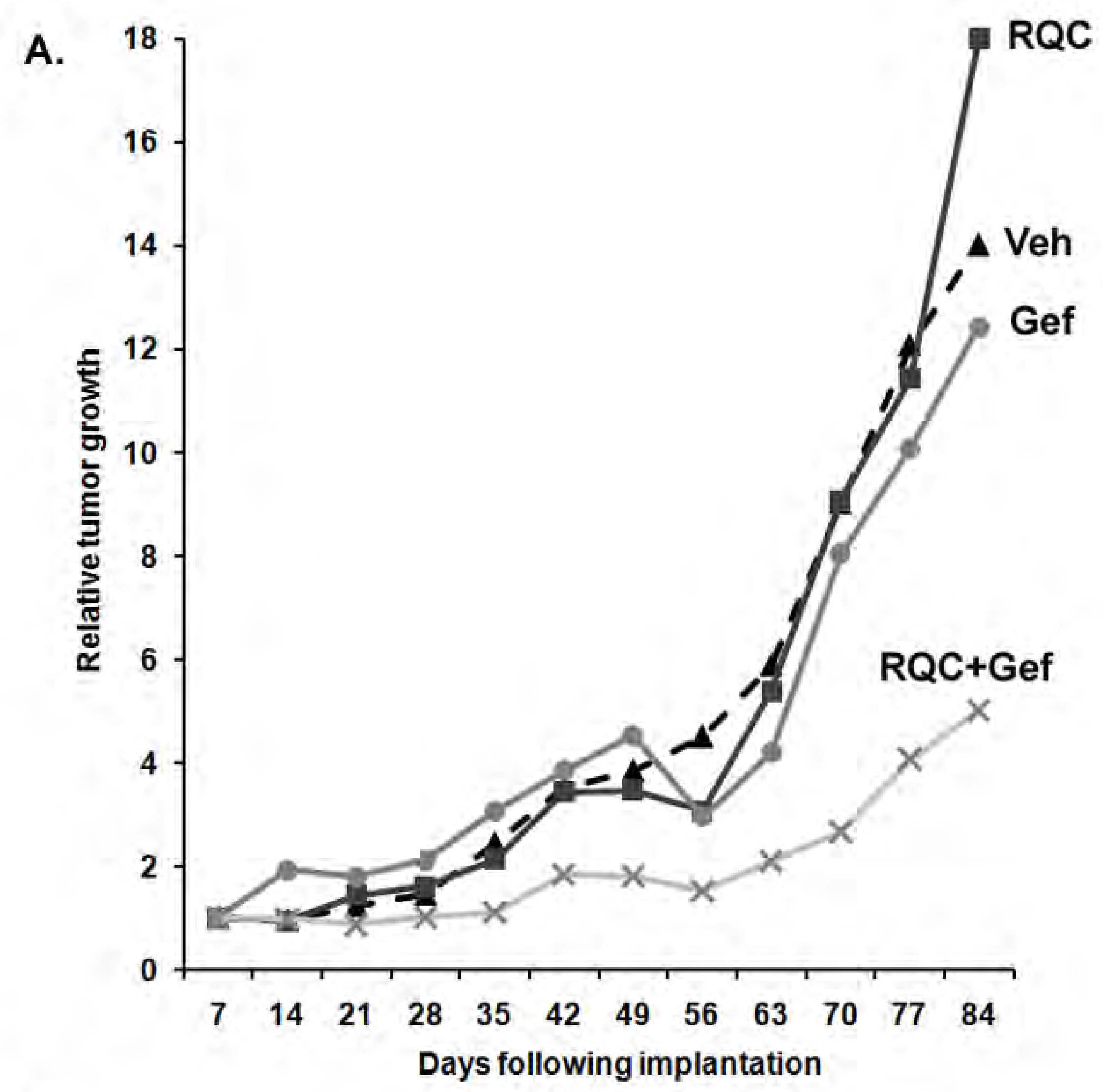

c.

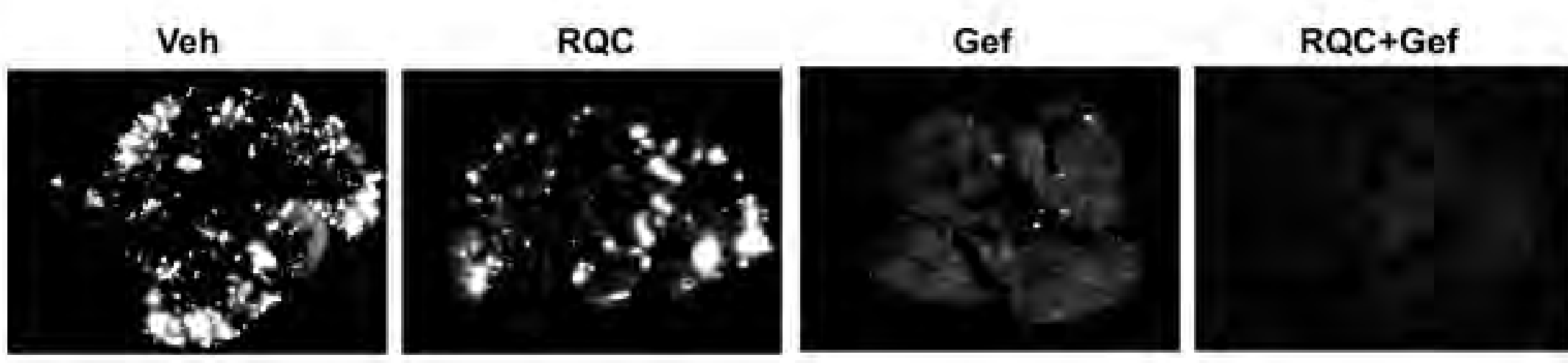

B.

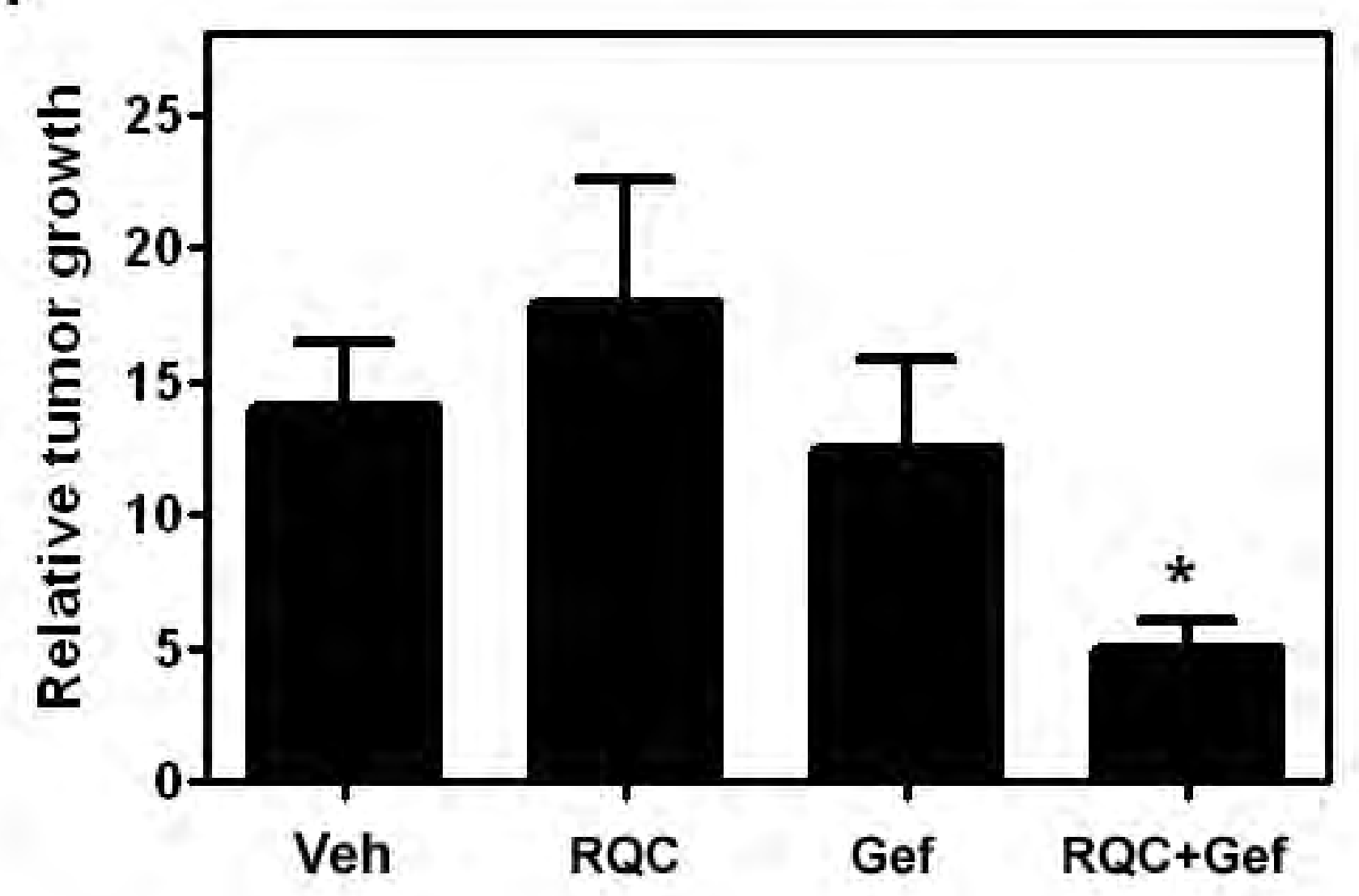

D.

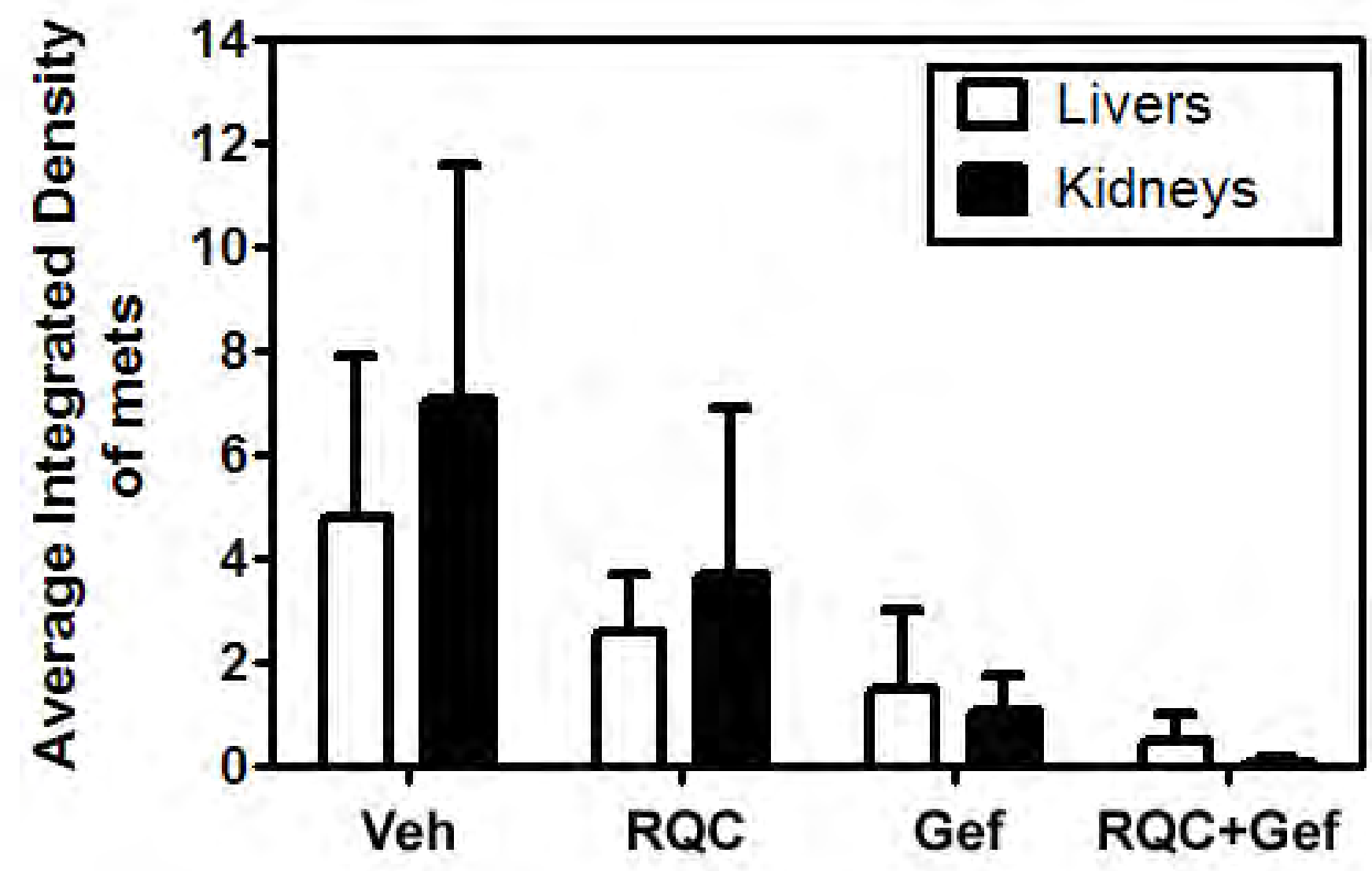




\section{- FULL-LENGTH ARTICLES •}

\section{Novel Inhibitors of Rac1 in Metastatic Breast Cancer}

Eliud Hernández, PhD*; Alina De La Mota-Peynadot; Surangani Dharmawardhane, PhD†‡; Cornelis P. Vlaar, PhD*

Objective: Rho family GTPases are molecular switches that control signaling pathways regulating a myriad of cellular functions. Rac1, a Rho family member, plays a critical role in several aspects of tumorigenesis, cancer progression, invasion, and metastasis. Rac proteins are not mutated in most invasive human cancers but are found to be overactive or over-expressed. Since Rho GTPases are activated by guanine nucleotide exchange factors (GEFs), inhibition of the interaction of Rac with its GEFs is a targeted strategy for blocking Rac activation.

Methods: The IC I0 $_{50}$ of NSC23766, an inhibitor of the interaction of Rac1 with a subset of GEFs, is too high for therapeutic use and more efficacious inhibitors are desired. Therefore, we initiated the synthesis of new derivatives of NSC23766 with modifications of the substituents connected to the central pyrimidine ring, and tested their Rac1 inhibitory activity.

Results: Several of the NSC23766 derivatives were shown to inhibit Rac1 activity of cancer cells with higher efficiency (20-50\% more) than NSC23766. The new compounds are not toxic to normal mammary epithelial cells and are more efficient $(60-70 \%)$ than NSC23766 in inhibiting cell migration and reducing cell spreading and extension of lamellipodia, cell functions regulated by Rac that contribute to cancer invasion.

Conclusion: Based on the results, we conclude that the novel compounds show promise of further development as small molecule inhibitors of invasive breast cancer progression. [P R Health Sci J 2010;4:348-356]

Key words: Rac1, GTPase, Inhibitor, Breast cancer, Metastasis

B reast cancer is the leading cancer type estimated for 2009 for US women and ranks first for death from all cancers at ages 20-59 (1). Early detection and aggressive breast cancer therapy in the US has resulted in a recent decline in mortality rates from breast cancer. However, in Puerto Rico, breast cancer mortality rates are rising and breast cancer has become the most frequently diagnosed form of cancer in women. Moreover, the recently released 2006 cancer statistics from the Centers for Disease Control and Prevention report that breast cancer is the number one killer of Hispanic women from all cancer related deaths. Breast cancer is most deadly when metastasis to other tissues occurs and novel therapies to inhibit spreading of the tumor are highly desired (2). We investigated Racl as a key protein involved in signaling pathways for metastasis, and synthesized novel small molecule compounds that can interfere with this process.

\section{The involvement of Rac1 in metastatic processes}

In metastasis, malignant cells migrate away from the original tumor site to other parts of the body. An important stage in the movement of these cells is the extension of actin-based protrusions by means of membrane ruffling and the formation of lamellipodia. Lamellipodia are sheet-like extensions of cross-linked networks of polymerized actin, and enable forward migration of the cells during invasion (3) and thus, regulate metastasis (4). A critical step for initiation of the cytoskeletal remodeling involved with lamellipodia formation is the activation of the small $(21 \mathrm{kD})$ GTP binding protein Rac1 (5). Therefore, inhibition of Racl activity could impede cell migration and provide a potential approach to prevent and halt metastasis (6).

\footnotetext{
*Department of Pharmaceutical Sciences, School of Pharmacy, Medical Sciences Campus University of Puerto Rico, San Juan, Puerto Rico; † Department of Anatomy and Cell Biology, Universidad Central del Caribe, Bayamón, Puerto Rico; ¥Department of Biochemistry, School of Medicine, University of Puerto Rico Medical Sciences Campus, San Juan, Puerto Rico

Author correspondence to: Surangani Dharmawardhane PhD, Department of Biochemistry, School of Medicine, Medical Sciences Campus University of Puerto Rico, PO Box 365067, San Juan, PR00936. Tel: 787-758-2525 ext. 1630/1610 • Fax: 787-274-8724 • E-mail: su.d@upr.edu \& Cornelis P. Vlaar PhD, Department of Pharmaceutical Sciences, School of Pharmacy, Medical Sciences Campus University of Puerto Rico, Tel: (787) 758-2525 ext. 5432/1236 • Fax: (787) 767-2796 • E-mail: cornelis.vlaar@upr.edu
} 


\section{Rho GTPases}

Rac1 belongs to the Rho family of GTPases, of which thus far, 22 members have been identified (7). Rho GTPases are important intracellular signaling proteins that control diverse cellular functions related to cancer development, including actin cytoskeleton organization, invasion and metastasis, transcriptional regulation, cell cycle progression, apoptosis, vesicle trafficking, and cell-to-cell and cell-to-extracellular matrix adhesions. Rho GTPases can be present in either a GDP-bound inactive conformation as well as in a GTP-bound active conformation, and is regulated mainly via GEFs (Guanine nucleotide exchange factors), GDIs (Guanine nucleotide dissociation inhibitors) and GAPs (GTPase activating proteins) (Figure 1) (8). When a GEF binds to a Rho GTPase in its GDPbound inactive state, a molecule of GDP is exchanged for GTP, upon which a conformational change occurs that brings the Rho GTPase into an active state. For some RhoGTPases GDIs have been identified that inhibit this exchange of GDP for GTP. In its GTP-bound active conformation, the Rho GTPase can bind to its down-stream effectors, which mainly via activation of kinases leads to a biological effect. On the other hand, when a GAP interacts with active Rho GTPase, GTPase activity is stimulated and the bound GTP is hydrolyzed to GDP, thus reestablishing the Rho GTPase in its inactive form. Each member of the Rho GTPase class is regulated by one or more GEFs or GAPs.

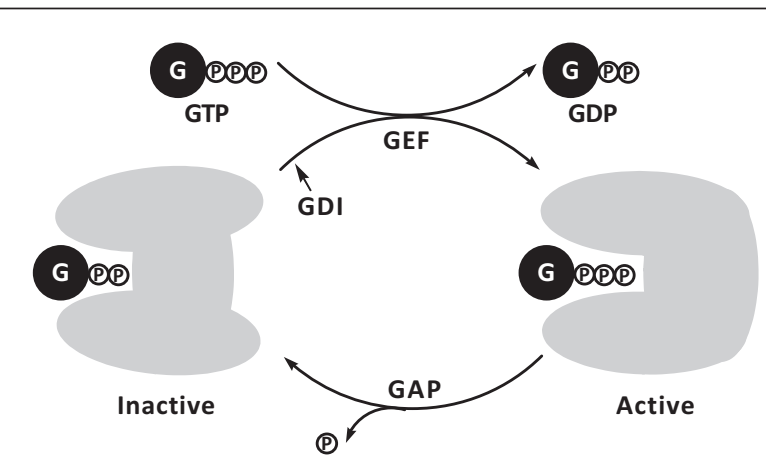

GDP: Guanosine diphosphate; GTP: guanosine triphosphate; GEF: Guanine nucleotide exchange factor; GDI: Guanine nucleotide dissociation inhibitor; GAP: GTPase activating protein; $\mathrm{P}$ : phosphate.

Figure 1. Regulation of Rho GTPases with different regulators

\section{Rac1 as a target for drug discovery}

The three main Rho GTPases are Rac1, Cdc42 and RhoA, and each has been shown to be specifically involved in lamellipodia formation, filopodia formation and stress fiber formation respectively $(3,7)$. For both Rac1 and Cdc42, evidence has been obtained for their role in tumor growth, invasion and cell migration in breast tumors. Alongside Trio and Vav (9), an important GEF of Rac1 is "T-cell lymphoma invasion and metastasis 1" (Tiam1), which is considered to be an invasion-inducing gene (10). Increased expression of Rac1 has been reported in breast, colon and lung tumors (11), while over-expression of Tiam 1 has been reported in highly invasive breast tumors and colon carcinomas (12). Increased Trio, Vav1, and Tiam 1 expression has been associated with high grade breast tumors (13). In addition, we and others have implicated hyperactive Racl with increased proliferation and invasion of breast cancer (14). Therefore, prevention of the binding of Tiam1 to Rac1 appears to be an attractive approach to inhibit the formation of lamellipodia and cell migration implicated with metastatic tumor cells.

\section{Identification of a lead structure}

The crystal structure of Racl with its GEF Tiam 1 has revealed specific binding site residues required for binding of Racl with Tiam1 (15). Recently, via a virtual screening procedure utilizing molecular docking of the NCI library in this binding site, the group of Zhang identified NSC23766 (compound 1, Figure 2) as a selective inhibitor of Rac1 (16). NSC23766 has been shown to inhibit Rac activity and cell invasion from a number of systems (17). However, in breast cancer, NSC23766 only inhibited the invasion of low metastatic human breast cancer cell lines and not high metastatic cells. As we were interested in compounds that interfere with metastatic processes, we investigated the Rac1 inhibitory activity of NSC23766 in the highly metastatic cancer cell line MDA-MB-435. In this cell line, even at a concentration up to $200 \mu \mathrm{M}$ of compound 1, only $40 \%$ inhibition of Rac 1 activity was observed. Therefore, we set out to utilize 1 as a lead structure for the synthesis of new derivatives with the potential for improved Rac1 inhibitory activity.

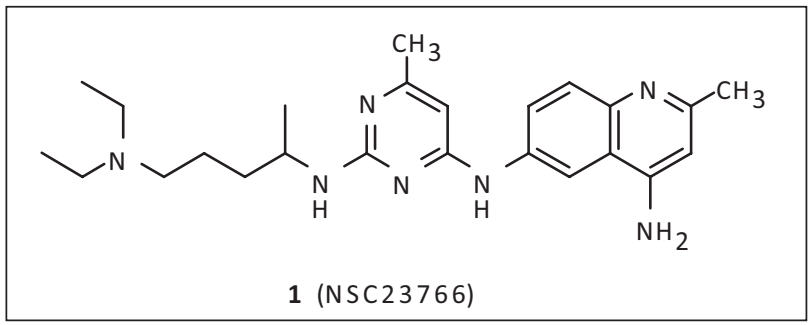

Figure 2. Lead structure for inhibitor design

\section{Materials and Methods}

\section{Syntheses}

Materials: All building blocks were purchased from SigmaAldrich Chemical company. Procedures: All novel NSC23766 derivatives were synthesized according to the reaction scheme provided in Scheme 1. As a representative example, the detailed two-step procedure for the synthesis of compound 7 is provided. Step 1: Synthesis of (2-Chloro-6-methyl-pyrimidin-4-yl)-(2,3dihydro-benzothiazol-6-yl)-amine (compound 8). To a solution of $1.63 \mathrm{~g}$ (10.0 mmol) 2,4-dichloro-6-methylpyrimidine in 10 $\mathrm{mL}$ iso-propanol, $1.97 \mathrm{~mL}(11.0 \mathrm{mmol})$ diisopropyl ethylamine 
(DIPEA) and $1.65 \mathrm{~g}$ (11.0 mmol) 6-aminobenzothiazole were added. The solution was refluxed for 18 hours, after which the starting materials were shown to be consumed as detected by TLC (thin layer chromatography) or by GC/MS (Gas Chromatography with Mass Spectrometry detector). After the reaction mixture was cooled to room temperature, $20 \mathrm{~mL}$ ethyl acetate and $10 \mathrm{~mL}$ distilled water were added, and after vigorous mixing, the layers were separated with the aid of a separation funnel. The organic layer was extracted with $10 \mathrm{~mL}$ brine, separated and dried on sodium sulfate, filtered and concentrated on a rotary evaporator to obtain $2.49 \mathrm{~g}(9.0 \mathrm{mmol}=90 \%)$ of a crude yellowish solid. According to GC/MS a 3.0 : 1.0 mixture of respectively the 4-substituted and 2-substituted regioisomers was obtained. After silica gel chromatography using $3: 1$ hexanes/ethyl acetate as the eluent, the 4-substituted compound 8 was obtained as a pure regioisomeric compound in a yield of $1.11 \mathrm{~g}(4.0 \mathrm{mmol}=44 \%$ yield from crude material $)$. The product was identified with NMR and GC/MS: ${ }^{1} \mathrm{H}$ NMR (DMSO-d, $400 \mathrm{MHz}) \delta 2.40(\mathrm{~s}, 3 \mathrm{H}), 6.61(\mathrm{~s}, 1 \mathrm{H}), 7.65(\mathrm{~d}, J=8.8 \mathrm{~Hz}, 1 \mathrm{H})$ $8.11(\mathrm{~d}, J=10.5,1 \mathrm{H}), 8.49(\mathrm{~s}, 1 \mathrm{H}), 9.30(\mathrm{~s}, 1 \mathrm{H}), 10.25(\mathrm{~s}, 1 \mathrm{H})$; ${ }^{13} \mathrm{C}\left(\mathrm{DMSO}-\mathrm{d}_{6}, 100 \mathrm{MHz}\right) \delta 23.2,103.7,112.9,120.1,12.9$, 123.1, 149.2, 154.7, 158.9, 161.8, 167.3; LRGC-MS m/z (rel\%): $[\mathrm{M}]^{+} 276(100),[\mathrm{M}-\mathrm{Cl}]^{+} 241(40),\left[\mathrm{M}-\mathrm{C}_{5} \mathrm{H}_{5} \mathrm{~N}_{3} \mathrm{Cl}\right]^{+} 134$ (26). Step 2: Synthesis of N4-Benzothiazol-6-yl-N2-(4-diethylamino1-methyl-butyl)-6-methyl-pyrimidine-2,4-diamine (compound $7)$. In the second step, in a $10 \mathrm{~mL}$ glass microwave tube, 0.28 $\mathrm{g}(1.0 \mathrm{mmol})$ of compound 8 obtained in step 1 was dissolved in $1.0 \mathrm{~mL} \mathrm{sec}$-butanol, and $522 \mu \mathrm{L}(3.0 \mathrm{mmol})$ DIPEA and 400 $\mu \mathrm{L}(2.0 \mathrm{mmol}) 2$-amino-5-diethylaminopentane were added. The tube was capped, placed in a CEM microwave synthesizer and heated to $120^{\circ} \mathrm{C}$ for 30 minutes. After the reaction mixture was cooled to room temperature, $10 \mathrm{~mL}$ ethyl acetate and $5 \mathrm{~mL}$ distilled water were added, and after vigorous mixing, the layers were separated with the aid of a separation funnel. The aqueous layer was extracted three times with $10 \mathrm{~mL}$ ethyl acetate, and after combining the organic phases they were extracted with 5 $\mathrm{mL}$ brine. The organic phase was separated and dried on sodium sulfate, filtered and concentrated on a rotary evaporator to obtain an off-white solid that was purified via silica gel chromatography to obtain $0.32 \mathrm{~g}(0.81 \mathrm{mmol}=81 \%)$ of product 7 . The product was identified to be essentially pure by NMR and GC/MS analysis: ${ }^{1} \mathrm{H}$ NMR (DMSO-d, $\left.400 \mathrm{MHz}\right) \delta 1.10(\mathrm{t}, J=7.1 \mathrm{~Hz}$, $9 \mathrm{H}), 1.35(\mathrm{~d}, J=6.4 \mathrm{~Hz}, 3 \mathrm{H}), 1.5-1.8(\mathrm{~m}, 2 \mathrm{H}) 2.80(\mathrm{~m}, 1 \mathrm{H})$, $3.40(\mathrm{~s}, 1 \mathrm{H}), 4.15(\mathrm{~m}, 2 \mathrm{H}), 6.0(\mathrm{~s}, 1 \mathrm{H}), 7.65(\mathrm{~d}, J=8.6 \mathrm{~Hz}$, $1 \mathrm{H}), 7.96$ (d, $J=8.8 \mathrm{~Hz}, 1 \mathrm{H}), 8.7(\mathrm{~s}, 1 \mathrm{H}), 9.11(\mathrm{~s}, 1 \mathrm{H}) ;{ }^{13} \mathrm{C}$ (DMSO-d, $100 \mathrm{MHz}) \delta 9.9,21.75,22.8,23.6,35.5,47.5$, 48.2, $53.3,96.5,113.2,121.1,123.7,135.9,140.2,149.5,155.0,163.2$, 166.8; LRGC-MS m/z (rel\%) $[\mathrm{M}]^{+} 398$ (4), $\left[\mathrm{M}-\mathrm{CH}_{2} \mathrm{CH}_{3}\right]+369$ (6), $\left[\mathrm{M}-\mathrm{C}_{5} \mathrm{H}_{12} \mathrm{~N}\right]^{+} 86(100)$.

\section{Cell culture}

MDA-MB-435 human metastatic breast cancer cells and MCF-10A mammary epithelial cells were purchased from ATCC and cultured in $10 \% \mathrm{DMEM}$ at $5 \% \mathrm{CO} 2$ and $37^{\circ} \mathrm{C}$ incubator as described in $(14 c, d)$. The origin of MDA-MB-435 cell line has been questioned by comparative genomic hybridization studies that report MDA-MB-435 and M14 melanoma to be identical cell lines. However, as reviewed in (18), both cell lines may be of MDA-MB-435 breast cancer origin rather than of melanoma origin due to the following rationale. The MDA-MB-435 cell line was isolated from a pleural effusion of a female patient with breast cancer and still has two X chromosomes; expresses milk proteins and lipids; and when transfected with the nm23 metastasis suppressor gene, MDA-MB-435 cells show the morphologic features of normal breast epithelial cells, including acinus formation in three-dimensional culture. Therefore, the MDA-MB-435 cell line was used as a model for a highly invasive and metastatic breast cancer with high Rac activity.

\section{Rac activity assay}

MDA-MB-435 cells were treated with vehicle ( $0.1 \%$ DMSO), or $50 \mu \mathrm{M}$ Rac Inhibitor for $24 \mathrm{hrs,} \mathrm{and} \mathrm{total} \mathrm{protein} \mathrm{extracts}$ were obtained using the lysis protocol and buffers in the G-LISA Rac1 Activation Assay (Cytoskeleton, Inc., Denver, CO). As per manufacturer's instructions, Rac activity was measured in a 96 well plate coated with the Rac.GTP binding domain of p21activated kinase (PAK) using the GLISA colorimetric assay.

\section{Cell viability assay}

Plates were seeded on a 96 well plate at a concentration of 2,000 cells/well in $100 \mu \mathrm{l}$ of Phenol Red (-) DMEM with 5\% fetal bovine serum (FBS). Cells were incubated in vehicle $(0.1 \%$ DMSO) or Rac inhibitors at $50 \mu \mathrm{M}$ for $24 \mathrm{hrs}$. Cell viability was measured using the MTT [3-(4,5-dimethylthiazol-2-yl)-2,5diphenyl tetrazolium bromide] cell survival and proliferation kit (Millipore, Inc., Billerica, MA). Absorbance at $600 \mathrm{~nm}$ of each experimental sample ( 3 biological repeats with 7 technical repeats), was measured from a 96 well plate on a Microplate Reader (Bio-Rad). The mean values $\pm \operatorname{SEM}(\mathrm{N}=3)$ are presented relative to vehicle (100\%).

\section{Cell migration assays}

Quiescent MDA-MB-435 breast cancer cells were treated with vehicle ( $0.1 \% \mathrm{DMSO})$, or $50 \mu \mathrm{M}$ Rac Inhibitor for $24 \mathrm{hrs}$. Cells were trypsinized and placed on the top well of Transwell chambers (Corning Life Sciences, Lowell, MA) in serum-free media with vehicle or $50 \mu \mathrm{M}$ inhibitors. The bottom well contained $10 \%$ serum. The number of cells that migrated through $8 \mu$ pores in the membrane of the top well in response to various treatments was quantified relative to vehicle (100\%) after 4 hrs. Data $( \pm$ SEM) were quantified from analysis of 20 microscopic fields/treatment from 3 biological replicates.

\section{Fluorescence microscopy}

Quiescent GFP-tagged MDA-MB-435 cells were treated with vehicle (0.1\% DMSO) or $50 \mu \mathrm{M}$ Rac Inhibitors for $24 \mathrm{hrs}$. Cells 
were fixed and stained for polymerized actin with Rhodamine Phalloidin as described in (14c). Representative microscopic fields are shown at $60 \mathrm{X}$ magnification.

\section{Results and Discussion}

\section{Synthetic design}

Compound 1 and analogous derivatives can be synthesized via successive connection of three chemical building blocks. The central building block is a pyrimidine core (A), which has been suggested to bind to a critical tryptophane (Trp56) residue of Rac1 (19). The second building block has a heterobicyclic arylamino group (B) connected to the 4-position of the pyrimidine ring, and the third building block is a primary or secondary aliphatic amine with a tail-end amino-group (C) connected to the 2-position of the pyrimidine ring. We developed a reaction scheme for the straightforward synthesis of a number of derivatives of compound 1 that allowed for variation in the building blocks (Scheme 1). In the first step, 2,4-dichloropymidine $A$ is reacted with the arylamine $B$ to give a 3:1 to 5:1 mixture of the 4-substituted and 2-substituted products. Via silica gel chromatography, the 4-substituted product is obtained purely, after which it is reacted with amine $\mathrm{C}$ to produce the desired novel derivatives of 1 . The inhibitory activity of the new compounds towards Racl is determined and compared with the inhibitory activity of 1 . The most active compounds were further investigated for their activity towards cell migration.

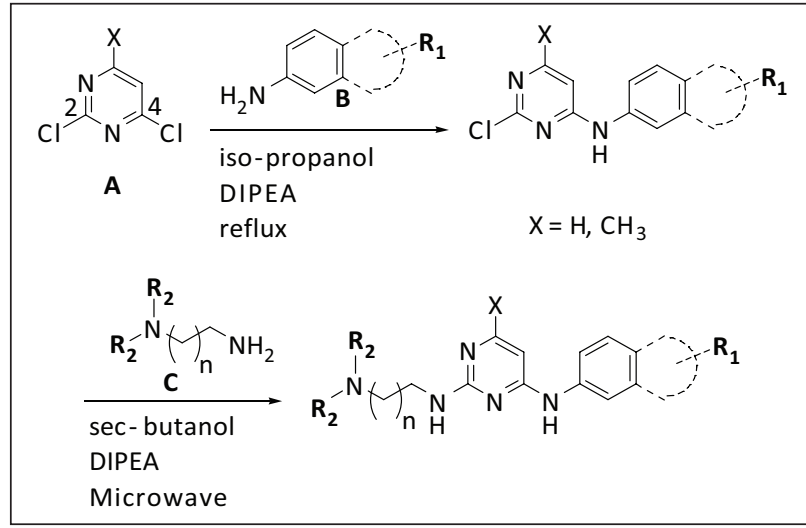

Scheme 1. Synthetic scheme for the preparation of analogues of NSC23766

\section{Initial screening}

All new compounds that were synthesized were tested for their Rac1 inhibitory activity in MDA-MB-435 metastatic breast cancer cells via a GLISA Racl activity assay. After incubation for 24 hours at a concentration of $50 \mu \mathrm{M}$, seven of the twenty compounds were shown to be more active inhibitors than NSC23766 (compound 1) in the screening for Rac1 inhibitory activity (Table 1). Seven other compounds from the library also showed inhibition of Rac1, but to a lesser extent than NSC23766, while four compounds did not have any significant effect at all. Finally, two of the compounds appeared to be activators of Racl. When analyzing the compounds grouped by the arylamino building blocks $\mathrm{B}$, the following can be remarked: Of all compounds, the 6-aminoquinoline derivative 2 is structurally most related to compound 1 , since it has both an identical amino-substituted aliphatic group $\mathrm{C}$ as well as a quinoline group in building block $\mathrm{B}$ as in 1 . Nevertheless, this compound appears to be a much less active Rac1 inhibitor than 1. In contrast, compound 3, which is lacking the amino-substituted aliphatic group $\mathrm{C}$ and instead has a chloro-substituent, appears to be one of the most active inhibitors in this set of compounds. This result, combined with observations in the other compound groups, indicates that the presence of an amino-substituted aliphatic group $\mathrm{C}$ is not a strict requirement for inhibitory activity. For compound 4, a very modest activation of Rac1 is observed. The 5-aminoindole derivatives 5 and 6 both are $\mathrm{Rac} 1$ inhibitors that are somewhat more active than compound 1 , whether an amino-substituted aliphatic side chain $\mathrm{C}$ is present (5) or not (6). Of the six 6-aminobenzothiazole derivatives, three $(7,11$ and 12$)$ were demonstrated to belong to the group of compounds that inhibit Racl to the largest extent of the currently available compound library. Interestingly, the other three compounds are less active (8) than NSC23766, or not significantly active at all (9 and 10). Of the four 5-aminobenzimidazole derivatives, three (13, 14 and 15) are much less active than 1 , while compound 16 appears to activate Rac1 with $30 \%$ compared with vehicle. The 5-aminobenzopyrazole derivatives are either much less active Rac1 inhibitors $(17,18)$ or only slightly more active inhibitors (19) than NSC23766. The anilines 20 and 21 are both much less potent Racl inhibitors than compound 1. From the above results, it was decided to further investigate the active compounds from the 6-aminobenzothiazole class.

\section{Effects of NSC23766 derivatives on cell viability}

In order to establish whether the active aminobenzothiazoles 7,11 and 12 , as well as compound 1 demonstrated general toxicity, the cell viability of both the epithelial cell line MCF-10A and the highly metastatic breast cancer cell line MDA-MB-435 in the presence of these compounds were determined. In these assays, both cell lines were exposed to $50 \mu \mathrm{M}$ of the Rac1 inhibitors for 24 hours. As can be seen in Figure 3, the observed cell viability with compounds 7 and 11 is comparable to NSC23766 (1) and does not demonstrate substantial toxicity to either cell lines, although compound 11 seems to be somewhat more toxic to the MDA-MB-435 cell line than the other compounds. While relatively comparable, compound 12 appeared to have the greatest effect on cell viability in both cell lines, and was not further studied. 
Table 1. Rac inhibition of novel derivatives compared with NSC23766 (1)

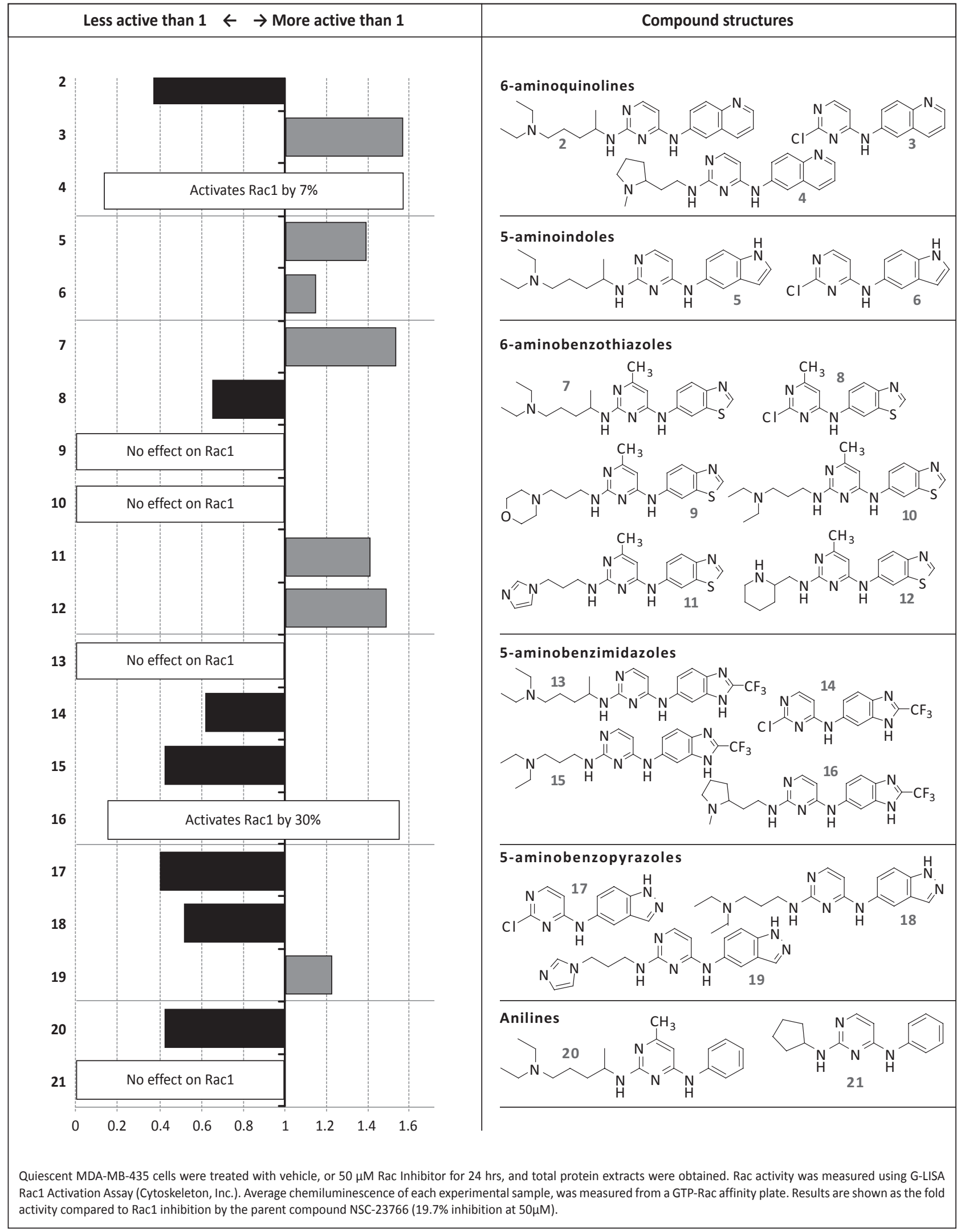




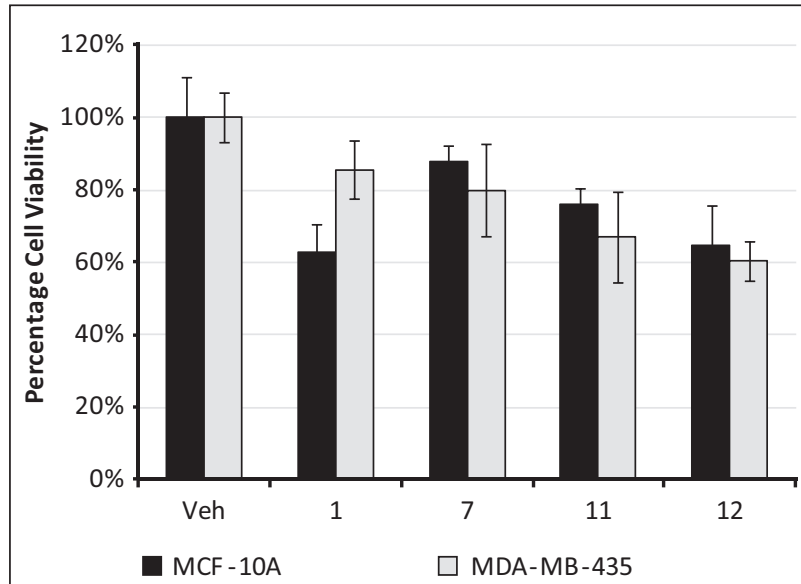

Quiescent MDA-MB-435 breast cancer cells or MCF-10A mammary epithelial cells were treated with vehicle (0.1\% DMSO, Veh), or $50 \mu \mathrm{M} \mathrm{1,} \mathrm{7,} 11$ and 12 for $24 \mathrm{hrs}$. Cell viability was measured using a MTT-Cell survival and proliferation kit (Millipore, Inc.). Average Abs. at $600 \mathrm{~nm}$ of each experimental sample $(\mathrm{N}=3)$, was measured from a 96 well plate on a Microplate Reader (Bio-Rad). The mean values \pm SEM are presented relative to vehicle (100\%).

Figure 3. Cell viability of MCF-10A and MDA-MB-435 in the presence of $1,7,11$ and 12 .

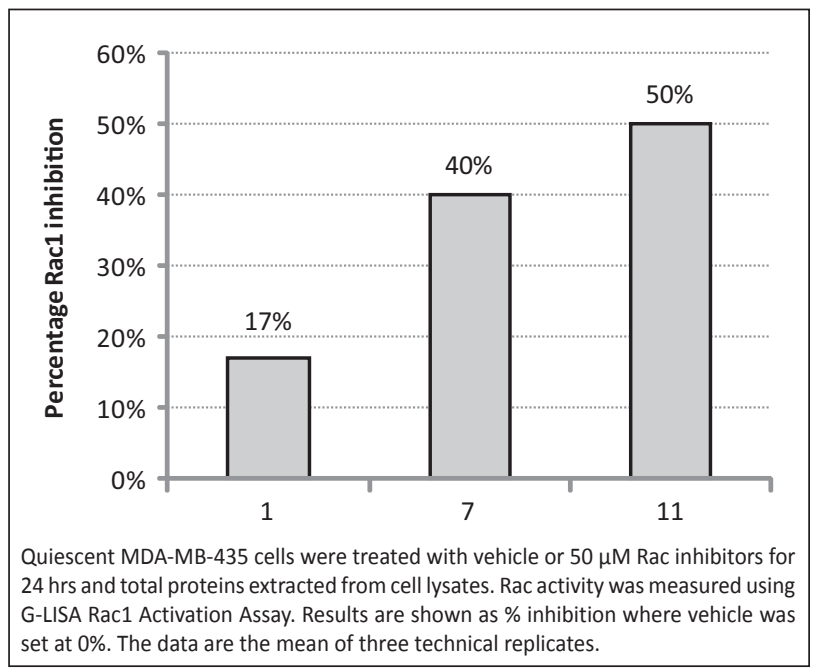

Figure 4. Inhibition of Rac1 activity by compounds 1, 7 and 11.

\section{Effect of selected NSC23766 derivatives on Rac activity}

Before further investigating the effects of the compounds of the 6-aminobenzothiazole class for their effects on cell migration and adhesion, we initially carried out a confirmatory assay of the Rac1 inhibitory activity of compounds 1, 7 and 11. A 24 $\mathrm{h}$ incubation of MDA-MB-435 cells with $50 \mu \mathrm{M}$ NSC23766 resulted in only a $17 \%$ inhibition of Rac1 activity. As can be seen in Figure 4, compounds 7 and 11 gave $40 \%$ and 50\% inhibition of $\mathrm{Racl}$ activity respectively under the same conditions. Therefore, this experiment confirms that NSC-23766 derivatives 7 and 11 are more efficient Racl inhibitors than the parent compound in the highly invasive cancer cell line MDA-MB-435.

\section{Effects of selected compounds on cell shape and cell migration}

We next tested the effect of compounds 1, 7 and 11 on cell shape, extension of cell surface actin structures called lamellipodia, and directed cell migration that are hallmarks of Rac-regulated cell functions. MDA-MB-435 cells were treated with vehicle or $50 \mu \mathrm{M}$ 1, 7 and 11 for $24 \mathrm{~h}$. From Figure 5 it can be observed that treatment of the cells with NSC23766 does not present a significant difference compared with vehicle. In contrast, compounds 7 and 11 are clearly much more efficient than NSC-23766 at reducing cell spreading and extension of lamellipodia, and directed migration towards serum. Compound 11 inhibited cell migration by about $60 \%$ more than parental compound 1 in a statistically significant manner. The effect of compounds 7 and 11 on cell migration was determined, and is represented in Figure 6. Interestingly, although at $50 \mu \mathrm{M}$ concentrations these compounds inhibit Racl activity only by $40-50 \%$, lamellipodia formation and cell migration is reduced by $80-90 \%$. It is possible that in vivo, a $50 \%$ inhibition of Rac1 activity may be sufficient to exhibit the observed effects. Alternatively, 7 and 11 may have broader specificity and inhibit close Rac1 homologs such as Rac3 and Cdc42 that also regulate cell migration. Moreover, unlike the parental compound, these inhibitors may be active at different localized compartments of the cell as well as inhibit other upstream regulators of Rac. Rac
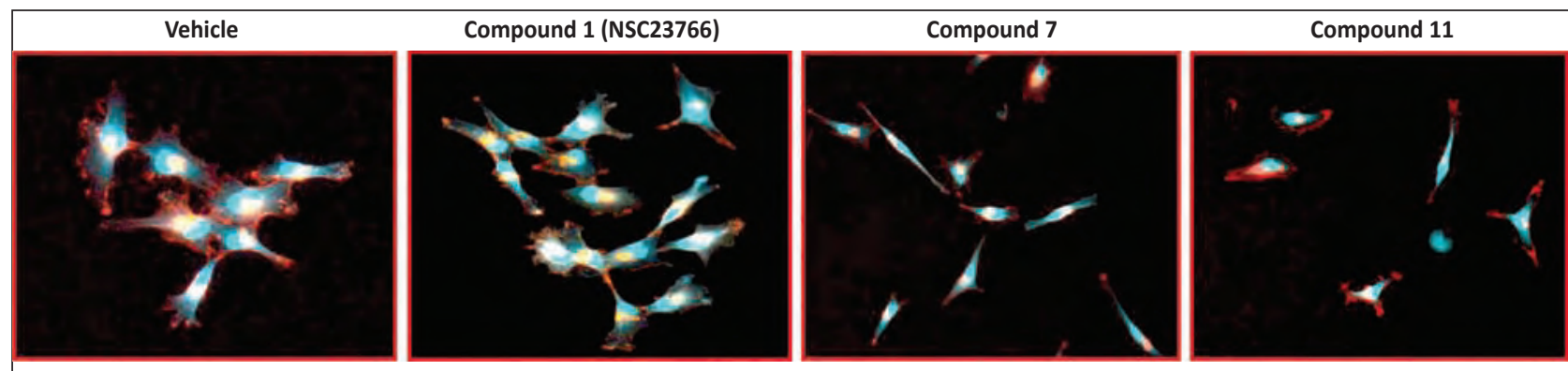

Cell shape following treatment with vehicle, and compounds 1, 7 and 11. GFP-tagged MDA-MB- 435 cells were treated with vehicle or $50 \mu \mathrm{M}$ compounds for $24 \mathrm{~h}$, fixed and stained with rhodamine phalloidin to visualize the actin cytoskeleton.

Figure 5. Effects of compounds 1, 7 and 11 on lamellipodia formation 
activity has recently been implicated in resistance to the anti Her2 therapeutic trastuzumab (20). Therefore, these novel anti Racl compounds have potential in combinatorial therapy to overcome resistance to common epidermal growth factor receptor-targeted therapies.

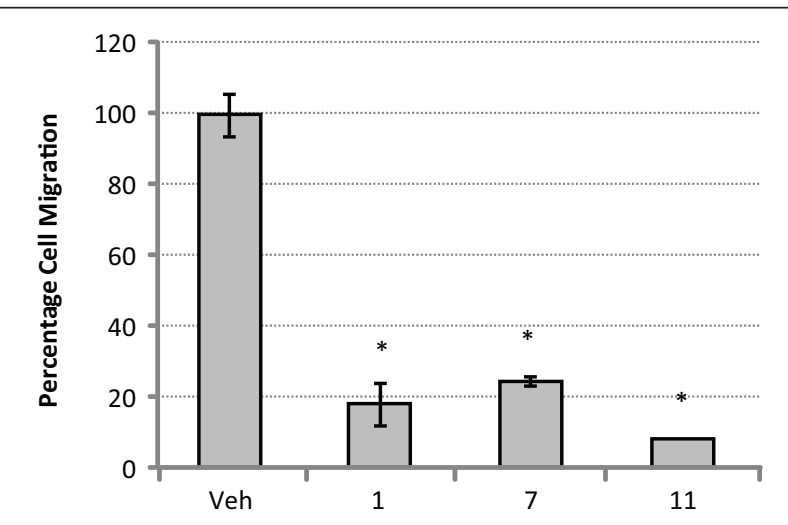

MDA-MB-435 cells were treated with vehicle or $50 \mu \mathrm{M}$ each of compounds 1,7 and 11 for $24 \mathrm{~h}$. Equal numbers of cells were placed on the top well of Transwell chambers that contain a membrane with $8 \mu$ diameter pores. The bottom well contained serum. The number of cells that migrated to the underside of the membrane was quantified for each treatment. Results are shown relative to vehicle (100\%). An asterisk denotes statistical significance of $p<0.05$.

Figure 6. Effects of compounds 1, 7 and 11 on cell migration

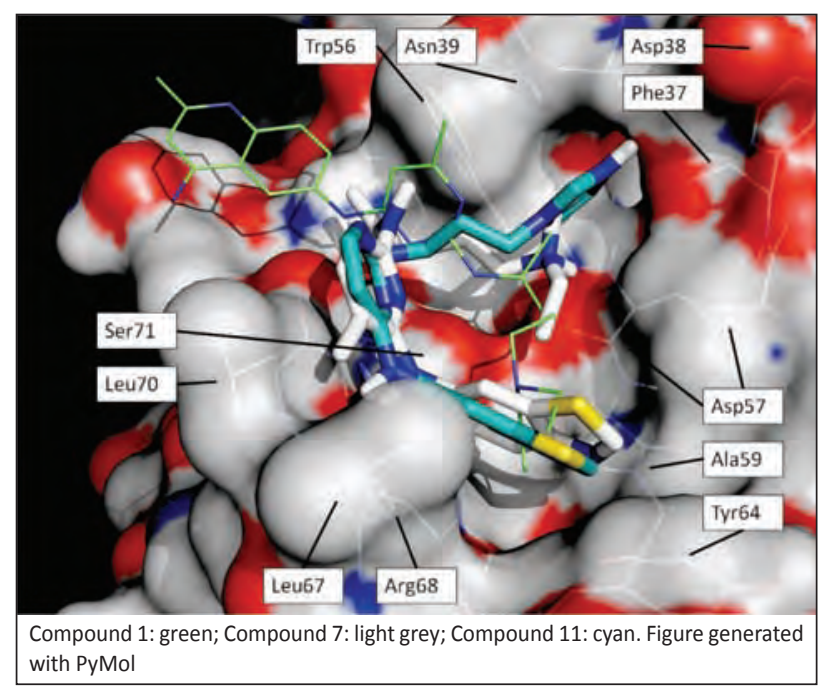

Figure 7. Compounds 7 and 11 docked into Rac1

\section{Docking of 7 and 11 in the crystal structure of Rac1}

The crystal structure of Rac1 with the inhibitor NSC23766 was recently revealed in a patent application (21). This structure has been used in a virtual screening of the ZINC database, and five new compounds with different core structures were identified as Rac1 inhibitors with IC50s from 12.2-57.2 $\mu \mathrm{M}$ (22). Utilizing Autodock 4 (23), we now docked our novel Rac1 inhibitors 7 and 11 in this crystal structure. Similar as the compounds identified from the ZINC database, both compounds 7 and 11 bind in multiple conformations of close energy within a binding pocket formed by amino acids Phe37, Asp38, Asn39, Trp56, Asp57, Thr58, Ala59, Tyr64, Leu67, Arg68, Leu70 and Ser71. The lowest energy conformation of the most populated cluster of the docking results of both compounds is represented in Figure 7, together with the position of compound 1 (green), in the crystal structure. Although NSC23766 (1) is stretched over the surface of Rac1, compounds 7 (light grey) and 11 (cyan), in all lowest energy conformations, including the ones shown, assume a bent shape and seem to dock deeper into the binding pocket. We will utilize docking in order to guide the design of inhibitors that will bind more tightly with Rac1.

\section{Conclusion}

Via minor structural modifications of NSC23766 we have identified two compounds (7 and 11) that are $2-3$ times more active as inhibitors of Rac1, while presenting minimal toxicity to epithelial cells. Both compounds were shown to have a much more dramatic effect on lamellipodia formation and cell migration than the lead compound NSC23766. Whether this is related to non-specific effects remains to be determined. Nevertheless, our experiments have demonstrated that the search for novel and more potent inhibitors of Racl can lead to compounds that are very effective in interfering with a key biological process related to metastasis. We expect that, utilizing molecular docking as an aid in the design, other compounds with increased efficacy can be synthesized and tested. Potentially, this could lead to a novel pharmaceutical treatment that prevents the spread of cancers to other tissues.

\section{Resumen}

Objetivo: La familia de Rho GTPasas son interruptores moleculares que controlan las vías de señalización y regulan una gran cantidad de funciones celulares. Rac1, un miembro de la familia de Rho, desempeña un papel crítico en varios aspectos de progresión del cáncer y metástasis. Rac no está mutada en cánceres humanos invasivos, pero se encuentra sobreexpresada. Debido a que las Rho GTPasas son activadas por factores de intercambio de nucleótido guanina (GEFs), inhibir la interacción de Rac con sus GEFs es una estrategia específica para el bloqueo de la activación de Rac. Métodos: El IC s0 $_{50}$ de NSC23766, un inhibidor específico de Racl con un subconjunto de GEFs, es demasiado alto para uso terapéutico, por lo que inhibidores más eficaces son necesarios. Por lo tanto, iniciamos la síntesis de nuevos derivados del NSC23766 con modificaciones en los sustituyentes conectados al anillo central pirimidina, y examinamos su actividad inhibitoria contra Rac1. Resultados: Varios derivados de NSC23766 
inhibieron la actividad de Rac1 en células cancerosas con mayor eficiencia (20-50\% más) que NSC23766. Los nuevos compuestos no son tóxicos para las células epiteliales mamarias normales, pero son más eficientes (60-70\%) que NSC23766 en la inhibición de migración celular y reducción de propagación y extensión de lamelipodia, funciones celulares controladas por Rac1 que contribuyen a la invasión de células cancerosas. Conclusión: Basado en los resultados, concluimos que los nuevos compuestos muestran un potencial de desarrollo como inhibidores de metástasis de cáncer de seno.

\section{Acknowledgments}

This research was supported by RCMI Grant \#G12RR03051 (to CPV), DoD/US Army BCRP W81XWH-07-1-0330 (to SD) and SNRP U54NS39408 and RCMI G12RR03035 to UCC. Dr. Luis Cubano (UCC) is acknowledged for salary support for AD-P. The authors wish to thank Melvin de Jesús, Department of Chemistry, Humacao Campus, University of Puerto Rico for assistance with the NMR facilities. The authors have no conflict of interest to disclose.

\section{References}

1. Jemal A, Sigel R, Ward E, Hao Y, Xu J, Murray T, Thun MJ. Cancer Statistics 2009. CA Cancer J Clin 2009:225-49.

2. Jones SE. Metastatic breast cancer: the treatment challenge. Clin. Breast Cancer 2008;8:224-233.

3. Ridley AJ. Rho GTPases and actin dynamics in membrane protrusions and vesicle trafficking. Trends Cell Biol 2006; 16:522-529.

4. (a) Hall A. Rho GTPases and the control of cell behaviour. Biochem Soc Trans 2005;33:891-895. (b) Lin M, van Golen KL. Rho-regulatory proteins in breast cancer cell motility and invasion. Breast Cancer Res Treat 2004;84:49-60. (c) Kleer CG, Griffith KA, Sabel MS, Gallagher G, van Golen KL, Wu ZF, Merajver SD. RhoC-GTPase is a novel tissue biomarker associated with biologically aggressive carcinomas of the breast. Breast Cancer Res Treat. 2005;93:101-110.

5. Chan AY, Coniglio SJ, Chuang YY, Michaelson D, Knaus UG, Philips MR, Symons M. Roles of the Rac1 and Rac3 GTPases in human tumor cell invasion. Oncogene 2005;24:7821-7829.

6. (a) Sawyer TK. Cancer metastasis therapeutic targets and drug discovery: emerging small-molecule protein kinase inhibitors. Expert Opin Investig Drugs 2004;13:1-19. (b) Karlsson R, Pedersen ED, Wang Z, Brakebusch C. Rho GTPase function in tumorigenesis. Biochim Biophys Acta (BBA) - Reviews on Cancer 2009;1796(2):91-98. (c) Lu Q, Longo FM, Zhou $\mathrm{H}$, Massa SM, Chen YH. Signaling through RhoGTPase pathway as viable drug target. Curr Med Chem 2009;16(11):1355-65. (d) Lu Q Longo FM, Zhou H, Massa SM, Chen YH. Signaling through RhoGTPase pathway as viable drug target. Curr Med Chem 2009;16(11):1355-65. (e) Surviladze Z, Waller A, Wu Y, Romero E, Edwards BS, Wandinger-Ness A, Sklar L. Identification of a Small GTPase Inhibitor Using a High-Throughput Flow Cytometry Bead-Based Multiplex Assay. J Biomol Screen 2010;15:10-20.

7. (a) Etienne-Manneville S, Hall A: Rho GTPases in cell biology. Nature 2002;420:629-635. (b) Jaffe AB, Hall A: Rho GTPases: biochemistry and biology. Ann Rev Cell Dev Biol 2005;21:247-269.

8. (a) Schmidt A, Hall A. Guanine nucleotide exchange factors for Rho GTPases: turning on the switch. Genes Dev 2002;16:1587-1609. (b) Bernards A. GAPs galore! A survey of putative Ras superfamily GTPase activating proteins in man and Drosophila. Biochim Biophys Acta 2003:160347-82.
9. (a) Palmby TR, Abe K, Karnoub AE, Der CJ. Vav transformation requires activation of multiple GTPases and regulation of gene expression. Mol Cancer Res 2004;2:702-711. (b) Miller SL, DeMaria JE, Freier DO, Riegel AM, Clevenger CM. Novel association of Vav2 and Nek3 modulates signaling through the human prolactin receptor. Mol Endocrinol 2005;19:939-949. (c) Sastry SK, Rajfur Z, Liu BP, Cote JF, Tremblay ML, Burridge K. PTP-PEST couples membrane protrusion and tail retraction via VAV2 and p190RhoGAP. J Biol Chem 2006;281:11627-11636. (d) Bouquier N, Vignal E, Charrasse S, Weill M, Schmidt S, Léonetti J-P, Blangy A, Fort P. A cell active chemical GEF inhibitor selectively targets the Trio/RhoG/Rac1 signalling pathway. Chem Biol 2009;16(6): 657-666.

10. (a) Minard ME, Kim LS, Price JE, Gallick GE. The role of the guanine nucleotide exchange factor Tiam1 in cellular migration, invasion, adhesion and tumor progression. Breast Cancer Res Treat 2004;82:21-32. (b) Strumane K, Rygiel T, van der Valk M, Collard JG. Tiam-1-deficiency impairs mammary tumor formation in MMTV-c-neu but not in MMTVc-myc. J Cancer Res Clin Oncol 2009; 135(1):69-80.

11. (a) Fritz G, Just I, Kaina B. Rho GTPases are over-expressed in human tumors. Int J Cancer 1999;81:682-687. (b) Kamai T, Yamanishi T, Shirataki H, Takagi K, Asami H, Ito Y, Yoshida K-I. Overexpression of RhoA, Rac1, and Cdc42 GTPases is associated with progression in testicular cancer. Clin Cancer Res 2004;10:4799-4805. (c) Liu S-Y, Yen C-Y, Yang S-C, Chiang W-F, Chang K-W. Overexpression of Rac-1 small GTPase binding protein in oral squamous cell carcinoma. Journal of Oral and Maxillofacial Surgery 2004;62 (6):702-707. (d) Gómez del Pulgar T, Bandrés E, Espina C, Valdés-Mora F, Pérez-Palacios R, García-Amigot F, García-Foncillas J, Lacal JC. Differential expression of Racl identifies its target genes and its contribution to progression of colorectal cancer. Int J Biochem Cell Biol 2007;39(12):2289-2302. (e) Engers R, Ziegle S, Mueller M, Walter A, Willers R, Gabbert HE. Prognostic relevance of increased Rac GTPase expression in prostate carcinomas. Endocr Relat Cancer 2007; 14(2):245256. (f) Espina C, Céspedes MV, García-Cabezas MA, Gómez del Pulgar MT, Boluda A, García Oroz L, Cejas P, Nistal M, Mangues R, Lacal JC. A critical role for Rac1 in tumor progression of human colorectal adenocarcinoma cells. Am J Pathol 2008;172(1):156-166. (g) Wang J, Rao Q, Wang M, Wei H, Xing H, Liu H, Wang Y, Tang K, Peng L, Tian Z, Wang $\mathrm{J}$. Overexpression of Rac1 in leukemia patients and its role in leukemia cell migration and growth. Biochem Biophys Res Commun 2009;386(4): 769-774.

12. (a) Adam L, Vadlamudi RK, McCrea P, Kumar R. Tiaml overexpression potentiates heregulin-induced lymphoid enhancer factor- $1 /$ beta-catenin nuclear signaling in breast cancer cells by modulating the intercellular stability. J Biol Chem 2001;276:28443-28450. (b) Liu L, Wu DH, Ding YQ. Tiam1 gene expression and its significance in colorectal carcinoma. World J Gastroenterol 2005;11:705-707. (c) Minard ME, Ellis LM, Gallick GE. Tiam1 regulates cell adhesion, migration and apoptosis in colon tumor cells. Clin Exp Metastasis 2006;23:301-313.

13. Lane J, Martin TA, Mansel RE, Jiang WG. The expression and prognostic value of guanine nucleotide exchange factors (GEFs) Trio, Vav1 and TIAM1 in human breast cancer. Int Seminars in Surgical Oncol 2008;5:23.

14. (a) Kleer CG, Griffith KA, Sabel MS, Gallagher G, van Golen KL, Wu ZF, Merajver SD. RhoC GTPase is a novel tissue biomarker associated with biologically aggressive carcinomas of the breast. Breast Cancer Res Treat 2005;93:101-110. (b) Burbelo P,Wellstein A, Pestell RG. Altered Rho GTPase signaling pathways in breast cancer cells. Breast Cancer Res Treat 2004;84:43-48. (c) Azios NG, Krishnamoorthy L, Harris M, Cubano LA, Cammer M, Dharmawardhane SF. Estrogen and resveratrol regulate Rac and $\mathrm{Cdc} 42$ signaling to the actin cytoskeleton of metastatic breast cancer cells. Neoplasia 2007;9:147-158. (d) Baugher PJ, Krishnamoorthy L, Price JE, Dharmawardhane SF. Rac1 and Rac3 isoform activation is involved in the invasive and metastatic phenotype of human breast cancer cells. Breast Cancer Res. 2005; 7:R965-R974.

15. Worthylake DK, Rossman KL, Sondek J. Crystal structure of Rac1 in complex with the guanine nucleotide exchange region of Tiam1. Nature 2000; 408(6813):682-688. 
16. Gao Y, Dickerson JB, Guo F, Zheng J, Zheng Y. Rational design and characterization of a Rac GTPase-specific small molecule inhibitor. PNAS 2004;101:7618-7623.

17. (a) Akbar H, Cancelas J, Williams DA, Zheng J, Zheng Y, Rational design and applications of a Rac GTPase-specific small molecule inhibitor. Methods Enzymol 2006;406:554-565. (b) Thomas EK, Cancelas JA, Chae HD, Cox AD, Keller PJ, Perrotti D, Neviani P, Druker BJ, Setchell KD, Zheng Y, Harris CE, Williams DA. Rac guanosine triphosphatases represent integrating molecular therapeutic targets for BCR-ABL-induced myeloproliferative disease. Cancer Cell 2007; 12:467-478. (c) Binker MG, Binker-Cosen AA, Gaisano HY, and Cosen-Binker LI. Inhibition of Racl decrease the severity of pancreatitis and pancreatitis-associated lung injury in mice. Exp Physiol 2008; 93:1091-1103. (d) Dokmanovic M, Hirsch DS, Shen Y, Wu WJ. Rac1 contributes to trastuzumab resistance of breast cancer cells: Racl as a potential therapeutic target for the treatment of trastuzumab-resistant breast cancer. Mol Cancer Ther 2009;8: 1557-1569.

18. Chambers AF. MDA-MB-435 and M14 cell lines: identical but not M14 melanoma? Cancer Res. 2009;69(13):5292-3.
19. Gao Y, Xing J, Streuli M, Leto TL, Zheng Y, Trp(56) of Rac1 specifies interaction with a subset of guanine nucleotide exchange factors. J Biol Chem 2001; 276:47530-47541.

20. Dokmanovic M., Hirsch, DS, Shen Y, Wu Wu J. Rac1 contributes to trastuzumab resistance of breast cancer cells: $\mathrm{Racl}$ as a potential therapeutic target for the treatment of trastuzumab-resistant breast cancer. Mol Cancer Ther. 2009 Jun;8(6):1557-69.

21. Zheng Y, Nassar N, Skowronek KR. GTPase inhibitors and methods of use and crystal structure of RAC-1 GTPase. 2007;US Patent Application \#20070155766.

22. Ferri N, Corsini A, Bottino P, Clerici F, Contini A. Virtual Screening Approach for the Identification of New Rac1 Inhibitors. J Med Chem 2009; 52(14):4087-4090

23. (a) Morris GM, Goodsell DS, Halliday RS, Huey R, Hart WE, Belew RK, Olson AJ. Automated docking using a Lamarckian genetic algorithm and empirical binding free energy function. J Comp Chem 1998;19:16391662. (b) Huey R, Morris GM, Olson AJ, Goodsell DS. A semiempirical free energy force field with charge-based desolvation. J Comp Chem 2007;28: 1145-1152. 


\title{
Inhibition of mammary tumor growth and metastases to bone and liver by dietary grape polyphenols
}

\author{
Linette Castillo-Pichardo - Michelle M. Martínez-Montemayor • \\ Joel E. Martínez · Kristin M. Wall · Luis A. Cubano • \\ Suranganie Dharmawardhane
}

Received: 13 October 2008/Accepted: 4 March 2009/Published online: 18 March 2009

(C) Springer Science+Business Media B.V. 2009

\begin{abstract}
The cancer preventive properties of grape products such as red wine have been attributed to polyphenols enriched in red wine. However, much of the studies on cancer preventive mechanisms of grape polyphenols have been conducted with individual compounds at concentrations too high to be achieved via dietary consumption. We recently reported that combined grape polyphenols at physiologically relevant concentrations are more effective than individual compounds at inhibition of $\operatorname{ER} \alpha(-)$, $\mathrm{ER} \beta(+)$ MDA-MB-231 breast cancer cell proliferation, cell cycle progression, and primary mammary tumor growth (Schlachterman et al., Transl Oncol 1:19-27, 2008). Herein, we show that combined grape polyphenols induce apoptosis and are more effective than individual resveratrol, quercetin, or catechin at inhibition of cell proliferation, cell cycle progression, and cell migration in the highly metastatic ER (-) MDA-MB-435 cell line. The combined effect of dietary grape polyphenols $(5 \mathrm{mg} / \mathrm{kg}$ each resveratrol, quercetin, and catechin) was tested on progression of mammary tumors in nude mice created from green fluorescent protein-tagged MDA-MB-435 bone metastatic variant. Fluorescence image analysis of primary tumor growth demonstrated a statistically significant decrease in tumor area by dietary grape polyphenols. Molecular analysis of excised tumors demonstrated that
\end{abstract}

L. Castillo-Pichardo $\cdot$ S. Dharmawardhane

Department of Biochemistry, School of Medicine, University of Puerto Rico, Medical Sciences Campus, San Juan, PR, USA

M. M. Martínez-Montemayor · J. E. Martínez ·

K. M. Wall - L. A. Cubano - S. Dharmawardhane $(\square)$ Department of Anatomy and Cell Biology, School of Medicine, Universidad Central del Caribe, P.O. Box 60327, Bayamón, PR 00960-6032, USA

e-mail: surangi@uccaribe.edu reduced mammary tumor growth may be due to upregulation of FOXO1 (forkhead box O1) and NFKBIA ( $\mathrm{I} \kappa \mathrm{B} \alpha$ ), thus activating apoptosis and potentially inhibiting $\mathrm{Nf} \kappa \mathrm{B}$ (nuclear factor $\kappa \mathrm{B}$ ) activity. Image analysis of distant organs for metastases demonstrated that grape polyphenols reduced metastasis especially to liver and bone. Overall, these results indicate that combined dietary grape polyphenols are effective at inhibition of mammary tumor growth and site-specific metastasis.

Keywords Breast cancer - Catechin - Metastasis . Quercetin · Resveratrol

\section{Introduction}

Breast cancer is the most commonly diagnosed form of cancer and the second major cause of death from cancer in women [1,2]. Recent clinical advances have remarkably increased the survival rates from primary breast cancer; however, the prognosis of breast cancer patients is still limited by metastases that can occur years after initial diagnosis and potential cure. Malignant breast cancers often overexpress epidermal growth factor receptor (EGFR) isoforms such as Her-2 that further confound effective treatment of metastatic breast cancer [3]. Therefore, investigation of the effect of dietary alternatives and their mechanisms of action specifically on Her-2 overexpressing metastatic cancers can lead to alternative therapeutic strategies.

Grape skins and thus red wine, contain many polyphenols that have anticancer properties [4,5]. Grape polyphenols have been implicated in cancer protection in numerous in vitro studies due to antioxidant and pro-apoptotic effects as well as inhibition of a number of tumorigenic pathways 
[6-8]. Combined grape polyphenols extracted from red wine have been shown to specifically inhibit the growth of breast cancer cells with low cytotoxicity towards normal mammary epithelial cells [9]. However, the effects of grape polyphenols on metastatic breast cancer remain to be investigated.

Resveratrol, quercetin, and catechin, grape polyphenols selected for this study, represent about $70 \%$ of the total polyphenols in red wine and have been shown to be the most effective anticancer compounds in red wine $[8,10]$. Resveratrol is found in low, but significant amounts in red wine and comprises about $1 \%$ of total polyphenols $[10,11]$. In breast cancer, resveratrol has been implicated in prevention of multistage carcinogenesis [12, 13]. Quercetin comprises about $6 \%$ of total polyphenols in red wine [10] and has been reported to decrease Her-2 expression [14]. Her-2 is often overexpressed in metastatic cancers including the MDA-MB-435 cell line that was used for this study. The monomeric form of catechin constitutes up to 65-70\% of total red wine polyphenols and has been shown to delay tumor initiation [10, 15, 16]. Resveratrol, quercetin, and catechin are all viable chemopreventives because they are absorbed and metabolized rapidly in vivo and can be detected in plasma and urine samples in the intact form in humans and rodent models [17-20].

Individually, resveratrol, quercetin, or catechin induce cell cycle arrest and apoptosis in cancer cells [21-23], prevent breast carcinogenesis and cancer progression in rodent models [24-26], and inhibit angiogenesis [27]. Much of the data on the cancer preventive effects of grape polyphenols have been generated from estrogen receptor $(\mathrm{ER})(+)$ tissue culture cell lines and rodent models using pharmacological concentrations of individual polyphenols $[16,24-26,28,29]$. We previously reported that in $\mathrm{ER} \alpha(-)$, $\mathrm{ER} \beta(+)$ MDA-MB-231 breast cancer cells, resveratrol is inhibitory at high pharmacological concentrations and acts similar to estrogen by increasing cell functions and signaling relevant for metastasis at low dietary levels [30, 31]. However, the effects of combined grape polyphenols at low, dietary concentrations are only now beginning to be assessed.

Recently, we reported that combined resveratrol, quercetin, and catechin (RQC) treatment at physiologically relevant concentrations was more efficient than individual grape polyphenols at inhibition of cell proliferation, cell cycle progression, and primary mammary tumor growth of MDA-MB-231 cells [1]. In this study, we were limited in investigation of the role of grape polyphenols as potential metastasis preventives because the low metastatic MDAMB-231 cell line formed only a few lung metastases. Most breast cancers preferentially metastasize to bone and liver, where $\sim 80 \%$ of patients with advanced breast cancer develop bone cancer, causing severe morbidity and mortality [32]. Therefore, for the current study, we selected a bone metastatic variant of the highly metastatic cancer cell line, MDA-MB-435 [33], to test the effect of grape polyphenols on cell proliferation, cell cycle progression, apoptosis, cell migration, tumor growth, and metastatic progression. Mammary fat pad tumors were established in nude mice and we show that dietary grape polyphenols inhibit both primary tumor growth and metastatic cancer progression from the breast to bone and liver. Our results show that this inhibition may be due to upregulation of caspase 3 activity and expression of FOXO1 transcription factor and NFKBIA; molecules known to regulate cancer progression [34-36].

\section{Materials and methods}

Cell culture

Human metastatic cancer cell lines MDA-MB-231 (ER $\alpha-$, $\mathrm{ER} \beta+$ ) (American Type Culture Collection, Manassas, VA, USA) and a bone metastatic variant of MDA-MB-435 (ER-) stably expressing GFP were used for the study (kind gift of Dr. Danny Welch, The University of Alabama at Birmingham, AL, USA) [37]. Cells were cultured in DMEM with $10 \%$ heat-inactivated FBS as described in $[1,33]$.

\section{Cell proliferation and cell cycle progression}

MDA-MB-435 $\left(2 \times 10^{5}\right)$ cells in 5\% charcoal-stripped FBS were treated every $48 \mathrm{~h}$ for $96 \mathrm{~h}$ with vehicle $(0.2-$ $0.5 \% \mathrm{DMSO}), 0.5,5$, or $20 \mu \mathrm{M}$ resveratrol, quercetin, or catechin or a combination RQC at $0.5,5$, or $20 \mu \mathrm{M}$ each. Cells were fixed, nuclei stained with PI and cell proliferation quantified as the number of cells with intact nuclei. Cell cycle stage of MDA-MB-435 cells was determined by flow cytometry of PI-stained cells as previously described in [1], following treatment with $5 \mu \mathrm{M}$ resveratrol, quercetin, or catechin or $5 \mu \mathrm{M}$ RQC every $48 \mathrm{~h}$ for $96 \mathrm{~h}$.

\section{Caspase 3 activity assay}

Apoptosis was analyzed by the caspase 3 activity of cell lysates following vehicle $(0.2 \%$ DMSO) or 0.5 or $5 \mu \mathrm{M}$ RQC for 48 h using a Caspase-3 Colorimetric Assay Kit as per manufacturer's instructions (Sigma-Aldrich, St Louis, MO, USA). Briefly, the $p$-nitroaniline (pNA) moiety resulting from hydrolysis of acetyl-Asp-Glu-Val-Asp $p$-nitroanilide (Ac-DEVD-pNA) by caspase 3 activity was detected at $405 \mathrm{~nm}\left(\varepsilon_{\mathrm{mM}}=10.5\right)$ after incubating the reaction mixture at $37^{\circ} \mathrm{C}$ for $22 \mathrm{~h}$. The concentration of the pNA released from the substrate was calculated from the absorbance values at $405 \mathrm{~nm}$ using a calibration curve prepared with pNA standards. Concentration of pNA was 
further converted to caspase 3 activity in $\mu \mathrm{mol}$ of pNA $\min ^{-1} \mathrm{ml}^{-1}$.

\section{Annexin V staining}

Apoptotic cells were detected by fluorescence microscopy of Annexin V-Cy3-18 stained cells as per manufacturer's instructions (Sigma-Aldrich, St Louis, MO, USA). Briefly, MDA-MB-435 cells grown on coverslips were treated with vehicle $(0.2 \%$ DMSO) or $5 \mu \mathrm{M}$ RQC for $48 \mathrm{~h}$ and stained with Annexin V-Cy3-18 in binding buffer $(10 \mathrm{mM}$ HEPES/NaOH, pH 7.5, 0.14 M NaCl, $2.5 \mathrm{mM} \mathrm{CaCl}_{2}$ ) for $15 \mathrm{~min}$ at room temperature. Coverslips were washed in binding buffer and fixed with $3.7 \%$ paraformaldehyde prior to fluorescence microscopy. Images were digitally acquired from an Olympus inverted fluorescence microscope using Metamorph software (Molecular Devices, Sunnyvale, CA, USA) and quantified from ten random microscopic fields $(20 \times$ mag.)/coverslip.

\section{Cell migration}

Equal numbers of viable quiescent GFP-tagged MDA-MB231 or MDA-MB-435 cells $\left(1 \times 10^{5}\right)$ were placed in the top well of Transwell chambers where the bottom well contained vehicle $(0.2 \%$ DMSO), 0.5 or $5 \mu \mathrm{M}$ resveratrol, quercetin, or catechin or 0.5 or $5 \mu \mathrm{M}$ RQC in serum-free and phenol red-free media. Following $8 \mathrm{~h}$ incubation, the cells on top of the membrane of the inner well were removed and the number of cells that migrated to the underside of the membrane through $8 \mu \mathrm{m}$ diameter pores quantified following PI staining as described in [31].

\section{Animals}

Female athymic nu/nu mice, 5-6 week old (Charles River Laboratories, Inc., Wilmington, MA, USA) were maintained under pathogen-free conditions in Hepa-filtered cages under controlled light (12 h light and dark cycle), temperature $\left(22-24^{\circ} \mathrm{C}\right)$, and humidity $(25 \%)$. Throughout the experiment, the animals were provided with autoclaved AIN 76-A phytoestrogen-free diet (Tek Global, Harlan Teklad, Madison, WI, USA) and water ad libitum. This project was approved by the Universidad Central del Caribe Institutional Animal Care and Use Committee.

\section{Tumor model}

GFP-MDA-MB-435 cells $\left(\sim 1 \times 10^{6}\right)$ in Matrigel (BD Biosciences, San Jose, CA, USA) were injected into the fourth right mammary fat pad of female nude mice under isoflurane inhalation to produce orthotopic primary tumors as described in [38]. After tumor establishment (1 week post-inoculation), the animals were randomly divided into experimental treatment groups. About 3-5 animals per group were eliminated due to failure of tumor take, small or too large tumor area in 1 week, or due to penetration of the peritoneum that resulted in immediate GFP fluorescence in the intestines. Mice with similar tumor area as quantified by integrated density of fluorescence images were selected for further study.

Diet administration

Nude mice ( $n=10$ /experimental group) were orally gavaged either with vehicle (90\% corn oil, $10 \%$ ethanol) or a combination of $5 \mathrm{mg} / \mathrm{kg}$ body weight (BW) resveratrol, $5 \mathrm{mg} / \mathrm{kg} \mathrm{BW}$ quercetin, and $5 \mathrm{mg} / \mathrm{kg} \mathrm{BW}$ catechin (RQC) in a $100 \mu \mathrm{l}$ volume three times per week. The number of mice/group is in the range of previously published similar studies that demonstrated statistically significant differences in dietary treatments [39-41].

Whole body fluorescence image analysis

Mammary tumor growth was quantified as changes in intensity and integrated density of GFP-fluorescence as per our previously described methods [1, 42]. Anesthetized mice were imaged immediately following breast cancer cell inoculation and two times per week thereafter. A 300 Watt power source with two optical delivery systems fitted with excitation filters $(470 / 40 \mathrm{~nm})$ was used for whole body imaging of GFP fluorescence (LT99D2, Lightools Research, Encinitas, CA, USA). Images were captured with a Spot II charge-coupled device (CCD) camera (Diagnostic Instruments, Sterling Heights, MI, USA) mounted with a 530/25 nm emission filter (Chroma Technology, Rockingham, VT, USA).

Tumor fluorescence intensities were analyzed using ImageJ software (National Institutes of Health, Bethesda, MD, USA). The final images were acquired on day 77. Relative tumor area was calculated as the fluorescence intensity of each tumor on each day of imaging relative to the fluorescence intensity of the same tumor on day 1 of diet administration.

\section{Analysis of metastases}

Following sacrifice, lungs, kidneys, livers, femurs, and hearts were excised and immediately stored in liquid $\mathrm{N}_{2}$. Stored organs were thawed and analyzed using an Olympus MV10 fluorescence macro zoom system microscope and images acquired with an Olympus DP71 digital camera. Each organ was imaged on both sides. The fluorescent lesions (green component of RGB images) were quantified for integrated intensity and area using Image $\mathbf{J}$ software. 
Pixel values ranging from 0 to 255 were detected and a signal cut off of 58 (approximately one standard deviation above the mean of the maximum noise) was used to separate background signal from GFP signal. To eliminate potential false positives, a minimum fluorescent area threshold of $0.003 \mathrm{~mm}^{2}$ was used (roughly four pixels). Areas identified as metastases were also validated by visual inspection and false positives eliminated from further analysis.

Real time reverse transcriptase $\left(\mathrm{RT}^{2}\right)$-PCR analysis

At the end of the study, solid primary tumors at the mammary fat pad were immediately stored in "RNA later" (Ambion, Austin, TX, USA). Total RNA extraction and DNAase treatment was performed using the Qiagen RNeasy Kit (Qiagen, Valencia, CA, USA) following manufacturer's protocol. RNA concentration was detected using a NanoDrop (Thermo Scientific, Wilmington, DE, USA), while RNA integrity and quality analysis were evaluated using the Experion automated electrophoresis system (BioRad, Hercules, CA, USA). C-13 kit (SA Biosciences, Frederick, MD, USA) was used to synthesize cDNA from the extracted RNA $(0.5 \mu \mathrm{g})$ and used to investigate gene expression profiles by the commerciallyavailable phosphoinositide 3-kinase (PI3-K) Pathway Finder $\mathrm{RT}^{2}$ Profiler ${ }^{\mathrm{TM}} \mathrm{PCR}$ arrays (SA Biosciences, Frederick, MD, USA). This $\mathrm{RT}^{2}$ Profiler ${ }^{\mathrm{TM}}$ PCR Array is designed to simultaneously profile the expression of 84 PI3-K pathwayspecific genes, plus five housekeeping genes and seven RNA quality controls. The spreadsheets, gene tables, and template formulas included with the PCR array package were used to calculate relative changes in gene expression and perform statistical analyses. Reproducibility was maintained by using RNA from three tumors per treatment (three biological replicates).

\section{Statistical analysis}

Data are expressed as the mean \pm SEM. Statistical analyses were done using Microsoft Excel or GraphPad Prism 5 software. Differences between means were determined using Student's $t$-Test and two-way ANOVA.

\section{Results and discussion}

Effect of grape polyphenols on metastatic breast cancer cells in vitro

Previously, we demonstrated that a combination of resveratrol, quercetin, and catechin at $0.5,5$, or $20 \mu \mathrm{M}$ reduced cell number significantly from control and was more efficient than individual compounds in the MDA-MB-231 ER $\alpha$ (-) $\operatorname{ER} \beta(+)$ human low metastatic breast cancer cell line [1]. However, due to the low metastatic nature of this cell line, we did not observe adequate metastases in a nude mouse model to enable a statistical analysis of the role of grape polyphenols on metastasis. Therefore, we tested the effect of dietary RQC on a highly metastatic ER (-) cancer cell line, MDA-MB-435. The origin of the MDA-MB-435 cell line has been called into question by several recent microarray studies that show expression of melanomaassociated genes [43]. However, MDA-MB-435 cells
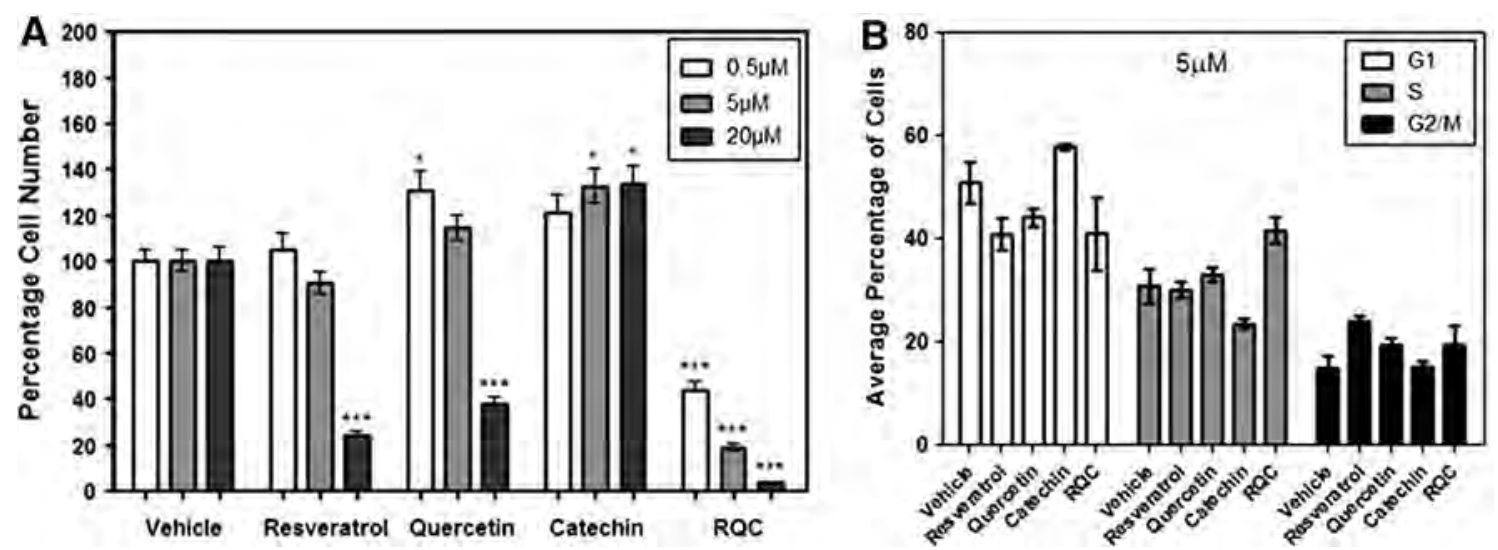

Fig. 1 Effect of grape polyphenols on MDA-MB-435 cell proliferation and cell cycle progression. Cells in 5\% serum and phenol redfree media were treated with vehicle, $0.5,5$, or $20 \mu \mathrm{M}$ resveratrol, quercetin, or catechin, or a combination of $0.5,5$, or $20 \mu \mathrm{M}$ each (RQC) every $48 \mathrm{~h}$ for $96 \mathrm{~h}$. Data was quantified from PI-stained intact (non-apoptotic) nuclei. a Cell proliferation. Percentage of viable cells \pm SEM for 20 microscopic fields/triplicate treatments is presented. b Cell cycle progression. Cell cycle stage following $5 \mu \mathrm{M}$ treatment with individual resveratrol, quercetin, or catechin or combined RQC. An asterisk indicates statistical significance of $P<0.05$ and three asterisks indicate $P<0.001$ when compared to vehicle 
express breast differentiation-specific proteins and secrete milk lipids [44]. Since the patient had no evidence of melanoma but was diagnosed with only a breast carcinoma; and, since melanocytes do not produce milk, the simplest conclusion is that MDA-MB-435 is a very poorly differentiated breast carcinoma. This cell line has been extensively used to investigate metastasis from mammary fat pad inoculations, and remains as one of few models available for experimental metastasis of breast cancer in nude mice $[33,45]$.

As shown in Fig. 1a, 0.5 or $5 \mu \mathrm{M}$ treatment with resveratrol, quercetin, or catechin alone did not decrease MDA-MB-435 cell proliferation. Resveratrol or quercetin at high concentrations $(20 \mu \mathrm{M})$ significantly inhibited cell proliferation by 80 and $60 \%$ while catechin alone increases cell proliferation significantly. Therefore, the effects on cell proliferation at $20 \mu \mathrm{M}$ RQC appear to be an additive effect of resveratrol and quercetin. The combined RQC treatment significantly inhibited MDA-MB-435 cell proliferation by $\sim 50,80$, and $90 \%$ at $0.5,5$, or $20 \mu \mathrm{M}$ of each polyphenol (Fig. 1a). These compounds were more effective in the MDA-MB-231 cell line where both resveratrol and quercetin inhibited cell proliferation at 5 and $20 \mu \mathrm{M}$ by $\sim 60$ and $\sim 95 \%$; while combined resveratrol, quercetin, and catechin (RQC) treatment at $0.5,5$, and $20 \mu \mathrm{M}$ each inhibited cell proliferation by $\sim 60,85$, and $98 \%$, respectively, compared to vehicle controls [1]. Since combined RQC treatment induced a significant reduction on MDAMB-435 cell proliferation, we then tested the cell cycle stage of MDA-MB-435 cells following $5 \mu \mathrm{M}$ RQC treatment and found that these compounds arrested MDA-MB-435 cells at $\mathrm{S}$ phase as was shown before with MDA-MB-231 cells (Fig. 1b), [1]. However, unlike with the MDA-MB-231 cells, the $\mathrm{S}$ phase arrest of the MDAMB-435 cells in response to RQC demonstrated a $P$ value of 0.06 .

The method we used to recover cells for analysis of cell cycle stage (i.e., trypsinization followed by centrifugation, fixing, staining, and washing) does not account for potentially apoptotic, non-adherent, or weakly adherent cells that may become removed during the repeated washings. Moreover, the observed increase in cells at S-phase does not correlate with the $80 \%$ decrease in cell number observed with $5 \mu \mathrm{M}$ RQC (Fig. 1a, b). Therefore, we investigated the effect of RQC treatment on apoptosis of MDA-MB- 435 cells by caspase 3 activity. This downstream effector caspase was selected to assess the effect of RQC on both receptor-regulated and mitochondrial apoptotic pathways. As shown in Fig. 2a, $5 \mu \mathrm{M}$ RQC treatment increased caspase 3 activity by twofold at a $P<0.06$ when compared to vehicle, while $\mathrm{RQC}$ at $0.5 \mu \mathrm{M}$ did not affect caspase 3 activity in a significant manner. Similarly, Annexin V staining of MDAMB-435 cells to detect phosphatidyl serines on the outer
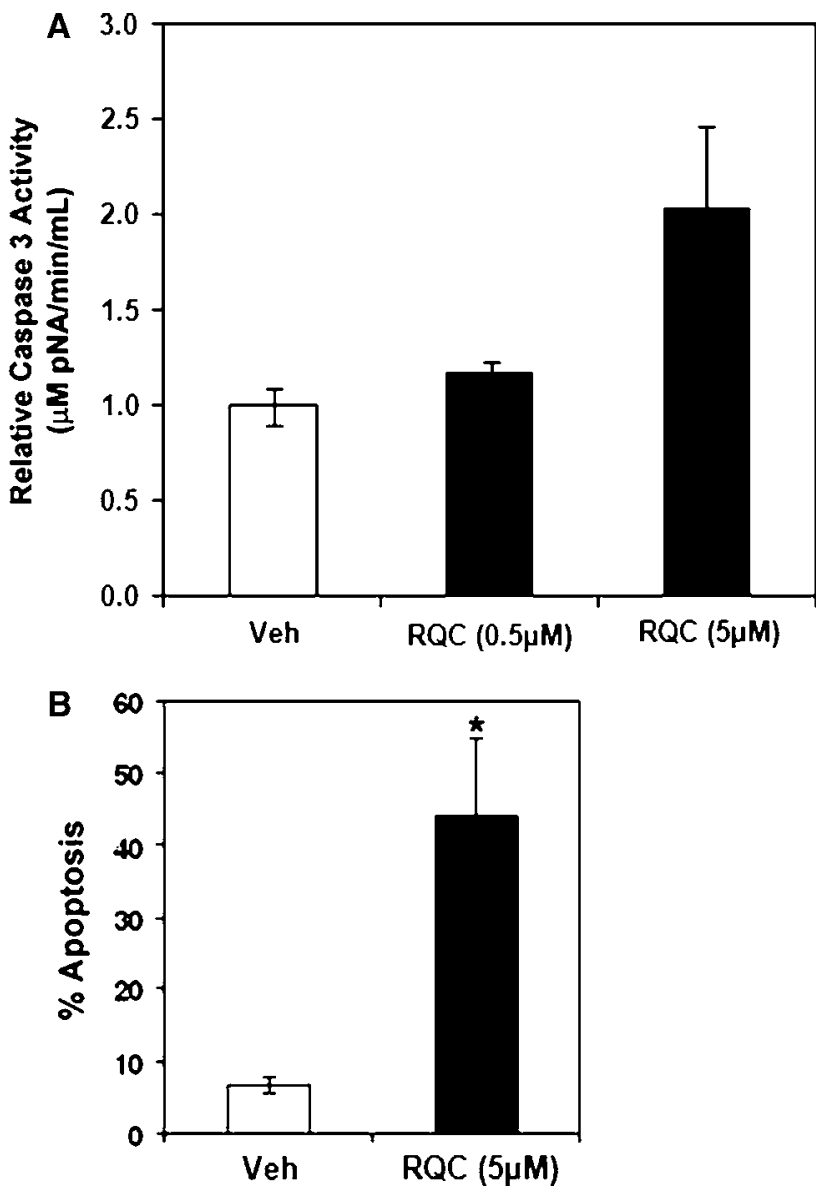

Fig. 2 Effect of grape polyphenols on apoptosis of MDA-MB-435 cells. Apoptosis of MDA-MB-435 cells was detected by caspase 3 activity assays (a) or fluorescence microscopy for Annexin V staining (b) following $48 \mathrm{~h}$ incubation with vehicle or RQC. a Average caspase 3 activity in $\mu \mathrm{mol}$ of pNA $\mathrm{min}^{-1} \mathrm{ml}^{-1}$ relative to vehicle $(n=4 \pm \mathrm{SEM})$ as quantified from absorbance at $405 \mathrm{~nm}$ of the pNA released by caspase 3 activity. b Percentage of cells undergoing apoptosis was calculated by Image $\mathbf{J}$ analysis of brightfield (total number of cells) and red fluorescence (apoptotic cells stained with Annexin V-Cy3) from ten random microscopic fields/coverslip. Averages \pm SEM are shown for two separate experiments with duplicates for each experiment $(n=4)$. An asterisk indicates statistical significance $(P<0.05)$ when compared to vehicle

leaflet of the cell membrane indicated that at $48 \mathrm{~h}$ following $5 \mu \mathrm{M}$ RQC, $44 \%$ of cells were significantly apoptotic $(P<0.01)$ compared to only $6.8 \%$ of vehicle-treated cells (Fig. 2b). Resveratrol and quercetin at high concentrations have been implicated in apoptosis of cancer cell lines by inducing caspase activity and inhibition of cell survival via PI3K/Akt pathways [23, 46, 47]. In MDA-MB-231 cells, by western blotting with total Akt and phospho-Akt ${ }^{\text {ser-473 }}$ antibodies, $5 \mu \mathrm{M}$ RQC (15 min) was found to decrease Akt activity by $\sim 50 \%$ compared to vehicle (data not shown). Therefore, the observed decrease in breast cancer cell numbers in response to RQC treatment is thought to be due 


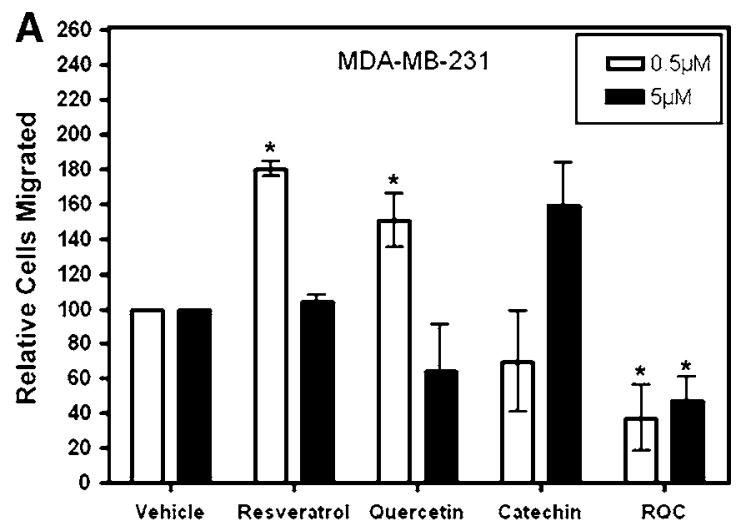

Fig. 3 Effect of grape polyphenols on breast cancer cell migration. Quiescent MDA-MB-231 (a) or MDA-MB-435 (b) cells were placed on the top well of Transwell chambers in serum-free, phenol red-free media and the number of cells that migrated through the membrane of the top well in response to various treatments was quantified relative

to a block in cell cycle progression, increased apoptosis, and reduced cell survival signaling.

Since directed cell migration has been implicated with metastatic efficiency, we tested the effect of individual and combined grape polyphenols on cell migration. Migration assays were performed using Transwell chambers where individual resveratrol, quercetin, or catechin or combined RQC treatment was added to the bottom well while the inner well contained serum-starved MDA-MB-231 or MDA-MB-435 cells. In MDA-MB-231 cells, resveratrol and quercetin at $0.5 \mu \mathrm{M}$ increased cell migration in a statistically significant manner (Fig. 3a). The effect of resveratrol is similar to our previous results that reported low concentrations of resveratrol to act comparable to estrogen and increase cell migration [31]. None of the other grape polyphenols significantly changed breast cancer cell migration. At 0.5 and $5 \mu \mathrm{M}$, combined RQC treatment significantly reduced MDA-MB-231 cell migration by $\sim 60 \%$ when compared to vehicle controls; whereas, $0.5 \mu \mathrm{M}$ combined RQC treatment reduced MDA-MB-435 cell migration by $\sim 20 \%$, and $5 \mu \mathrm{M}$ RQC significantly reduced cell migration by $40 \%$ (Fig. 3 ).

The lower response of the inhibitory effect of RQC treatment in the ER (-) MDA-MB-435 cells compared to the $\operatorname{ER} \beta(+)$ MDA-MB-231 cells may be due to grape polyphenols acting as antiestrogenic compounds in the MDA-MB-231 cells. Also, since MDA-MB-435 cells are Her $2^{++}$it is possible that combined grape polyphenols are not as efficient at inhibiting the increased Her-2 signaling in this highly aggressive cancer cell line. However, mechanistic studies need to be conducted to further address the differences in response to grape polyphenols between these two cancer cell lines.

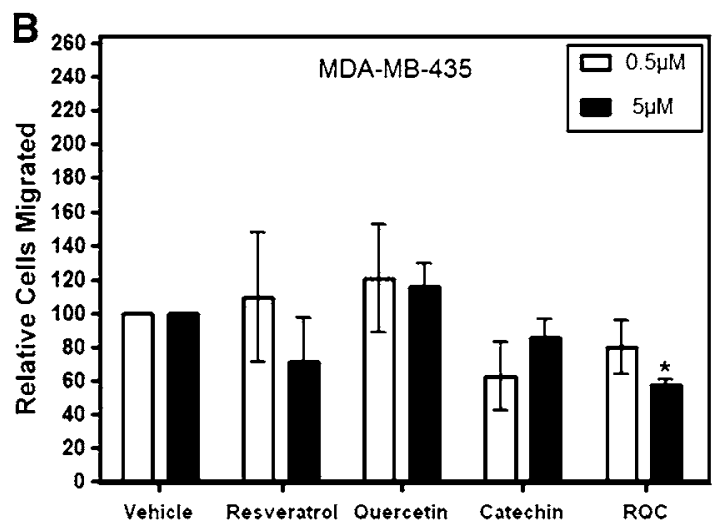

to control. Data are quantified from analysis of 25 microscopic fields/ treatment $(n=3 \pm$ SEM). The bottom well contained the following for $8 \mathrm{~h}$ : vehicle, 0.5 or $5 \mu \mathrm{M}$ resveratrol, quercetin, catechin or a combination of 0.5 or $5 \mu \mathrm{M}$ each (RQC). An asterisk indicates statistical significance $(P<0.05)$ when compared to vehicle

Effect of grape polyphenols on mammary tumor growth in vivo

To test the effect of resveratrol, quercetin, and catechin on metastatic breast cancer progression in vivo, we established mammary fat pad tumors from GFP-tagged highly metastatic MDA-MB-435 cancer cells as previously described [42]. As quantified from the integrated density of fluorescent images, mice ( $n=10$ per group) with similar initial tumor volumes (vehicle group $=9,036.6 \pm 654$ and RQC group $=9,825 \pm 501$ ) were selected for further study.

One week following tumor establishment, mice were gavaged with vehicle (90\% oil, $10 \%$ ethanol) or $5 \mathrm{mg} / \mathrm{kg}$ BW RQC three times a week. This dietary concentration was selected based on our previous study where administration of $0.5,5$, or $20 \mathrm{mg} / \mathrm{kg}$ BW RQC demonstrated that the inhibitory effect on mammary tumor growth plateaued at $5 \mathrm{mg} / \mathrm{kg}$ BW [1]. Tumor progression was quantified by fluorescence image analysis twice a week. The relative tumor area was calculated as the fluorescence intensity of each tumor on day of imaging relative to the fluorescence intensity of the same tumor on day 1 of diet administration as described in [1]. As shown in Fig. 4a, tumor growth remained linear and similar for both vehicle and RQC treated mice for 60 days. After 60 days, the RQC-treated mice demonstrated reduced tumor growth compared to vehicle. At the end of the study on day 77, the mice following RQC diet demonstrated smaller tumors that were reduced by $\sim 37 \%$ in a statistically significant manner (Fig. 4b). Previously, we reported a 69\% decrease in MDA-MB-231 mammary tumor growth with $5 \mathrm{mg} / \mathrm{kg} \mathrm{BW}$ RQC treatment [1]. The present data demonstrates that, as with the in vitro effects, dietary RQC treatment of nude 


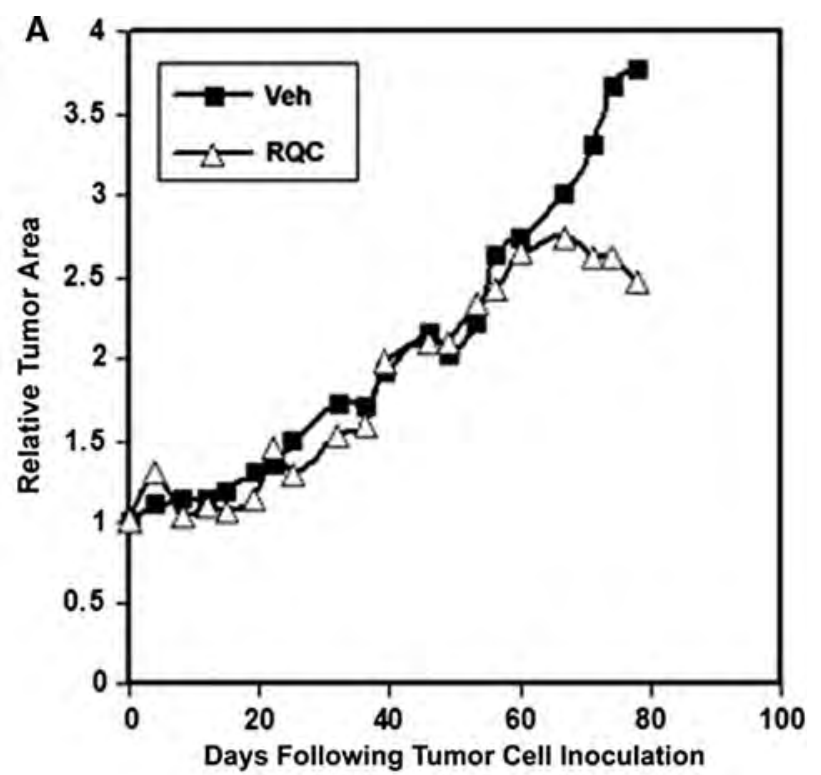

B
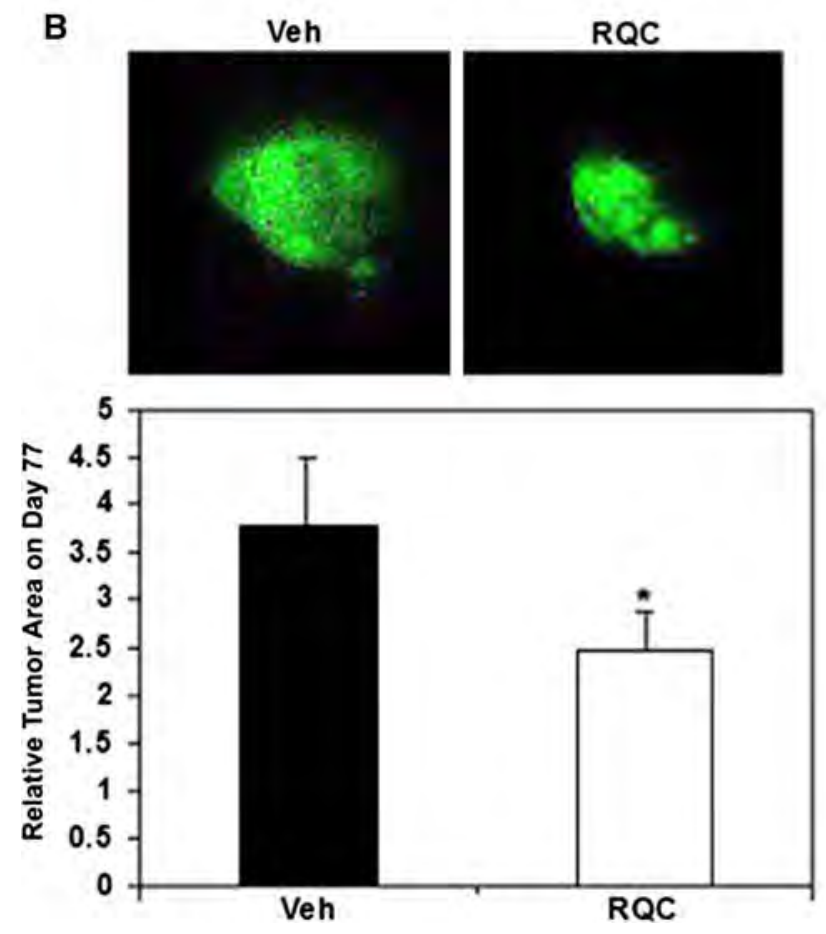

Fig. 4 Effect of grape polyphenols on the growth of MDA-MB-435 mammary fat pad tumors. MDA-MB-435 cells $\left(10^{6}\right)$ in Matrigel were inoculated at the mammary fat pad of nude mice. One week following injection, mice were fed vehicle or a combination of $5 \mathrm{mg} / \mathrm{kg} \mathrm{BW}$ Res, $5 \mathrm{mg} / \mathrm{kg} \mathrm{BW}$ Quer, and $5 \mathrm{mg} / \mathrm{kg} \mathrm{BW}$ Cat (RQC) three times a week by oral gavage. Whole body fluorescence images were acquired two times a week. a Average relative tumor area as a function of days following injection. Relative tumor area was calculated as the area of fluorescence, measured by fluorescence intensity on each day of imaging as a function of the fluorescence intensity of the same tumor on day 1. b GFP-MDA-MB-435 tumors following vehicle or RQC diets at day 77. Representative digital images and mammary tumor area as quantified from digital images acquired on day 77, made relative to same tumor image on day 1 . Asterisk denotes statistical significance at $P<0.05$ mice with MDA-MB-435 mammary tumors results in a significant inhibition of primary tumor growth but this effect is less compared to the effect of RQC treatment on MDA-MB-231 mouse mammary xenografts.

At the end of the study (77 days), there were no statistically significant differences in body weights from mice treated with vehicle $(24.35 \mathrm{~g} \pm 1.6)$ or RQC (24.04 $\mathrm{g} \pm$ 1.7). This is similar to our previous report where 118 days of dietary RQC treatment at concentrations as high as $25 \mathrm{mg} / \mathrm{kg}$ BW did not significantly change mouse weights from vehicle controls [1]. Therefore, the decrease in tumor area at the end of the study was not due to toxic effects of dietary RQC. This data indicates that combined grape polyphenols can be safe and effective therapeutics and preventives of primary tumor growth of ER (-) breast cancer.

To initiate a molecular analysis of the effect of grape polyphenols on breast cancer, we analyzed changes in expression of PI3-K pathway genes because this pathway is a central regulator of cancer cell survival and invasion [48]. Interestingly, real-time PCR arrays for PI3-K pathway genes from tumor extracts revealed that expression of FOXO1 transcription factor was upregulated significantly by 1.87 -fold in mouse mammary tumors following RQC treatment (Table 1). FOXO factors have been shown to function as tumor suppressors in a variety of cancers. They are actively involved in promoting apoptosis in a mitochondria-independent and -dependent manner by inducing the expression of death receptor ligands and pro-apoptotic Bcl-2 family members [35]. Forkhead proteins have been shown to be important for the anticancer activities of resveratrol [49]. This is the first time that elevation of death promoting genes have been implicated in vivo for a combination of dietary grape polyphenols in reducing mammary tumor growth. Since FOXO1 can be inactivated via Akt-mediated phosphorylation, elevation of FOXO1 transcripts may not necessarily result in increased protein activity. Interestingly, AKT1 expression was also decreased by threefold in the PCR array but this was not statistically significant. Moreover, RQC treatment of breast

Table 1 Effect of RQC treatment on expression of PI3-kinase pathway genes

\begin{tabular}{lll}
\hline Gene & $\begin{array}{l}\text { Fold difference } \\
\text { RQC/vehicle }\end{array}$ & $P$ value \\
\hline FOXO1, forkhead box 01A & 1.87 & 0.007 \\
$\begin{array}{l}\text { NFKBIA, nuclear factor of kappa } \\
\quad \text { light polypeptide gene enhancer }\end{array}$ & 1.70 & 0.041 \\
$\quad \begin{array}{l}\text { in B-cells inhibitor, alpha } \\
\text { TLR4, toll-like receptor 4 }\end{array}$ & 1.91 & 0.003 \\
\hline
\end{tabular}

Only genes that demonstrated $>1.5$-fold difference and $P$ value of $<0.05$ from $\mathrm{RT}^{2} \mathrm{PCR}$ arrays are shown 
cancer cells significantly reduces active phospho Akt1 ( $p$ Akt ser ${ }^{473}$ ) levels in 15 min without affecting total Akt1 levels (data not shown). The relative contribution of decreased phospho Akt1 levels and increased FOXO1 levels and caspase 3 activity to RQC-mediated effects on cell survival and apoptosis is currently under investigation.

$\mathrm{Nf} \kappa \mathrm{B}$ transcription factor that regulates tumorigenic and immunomodulatory signaling is a potential target for the chemopreventive activity of grape polyphenols, resveratrol, and quercetin [50-53]. NFKBIA, which codes for $\mathrm{I} \kappa \mathrm{B}$, the subunit that sequesters $\mathrm{Nf} \kappa \mathrm{B}$ in an inactive state, was also upregulated significantly by 1.7 -fold in mammary tumors following $\mathrm{RQC}$ treatment (Table 1). This data indicates that inhibition of $\mathrm{Nf} \kappa \mathrm{B}$ signaling may contribute to the observed reduced mammary tumor growth and metastasis by grape polyphenols. However, $\mathrm{I} \kappa \mathrm{B}$ proteins can become inactivated via phosphorylation-induced, proteasomemediated degradation by $\mathrm{I} \kappa \mathrm{B}$ kinase (IKK) activity. Therefore, increased NFKBIA gene expression by RQC treatment may not reflect increased stable protein levels. Future experiments will determine the stability and phosphorylation status of $\mathrm{I} \kappa \mathrm{B}$ in response to RQC. In addition, we also found a significant increase in Toll-like receptor 4 (TLR4) expression that have been implicated in cancer progression (Table 1). However, TLRs may also stimulate apoptosis under certain conditions [54] and can be negatively regulated by PI3-K signaling [55]. Therefore, the significance of this result warrants further investigation.

Previous in vivo studies have also supported a role for grape polyphenols in cancer prevention. Grape juice, grape seed extract, and red wine have been shown to significantly reduce cancer in rodent models [56-58]. Grape skin extract, which is concentrated in red wine, was recently shown to contain more growth inhibitory effects than grape pulp, juice, or seeds on mouse mammary tumor growth [59]. Since the effect of grape polyphenols on cancer metastasis remains to be evaluated, we next analyzed the effect of dietary grape polyphenols on breast cancer metastasis.

Effect of grape polyphenols on metastasis

Our macro imaging system easily detected surface primary tumors, local invasion into the circulatory system, lymphatics, and metastatic tumors in the GI tract through the skin of nude mice. However, the resolution of this imaging system allows detection of only $\sim 10^{4}$ GFP-tagged cells and is thus limited in sensitivity for detection of micrometastases. Therefore, fluorescent metastatic lesions were quantified by microscopy following surgical removal of organs. Only eight mice/treatment were used for analysis of metastasis due to early death of two from the vehicle group and one from the RQC group. This number is similar to a previous study that reported the effect of dietary genistein on metastasis from MDA-MB-435 mammary tumors [39]. All of the mice following vehicle or RQC treatment presented with lung metastases. Therefore, lungs were further analyzed by Image $\mathbf{J}$ for quantification of the area of fluorescence. The number of metastatic lesions/lung was reduced in RQC-treated mice in a statistically significant manner when compared to vehicle treatment. However, the area of fluorescence calculated from these lesions was not statistically different for mice treated with vehicle or RQC (Fig. 5a, b, c; Table 2). Therefore, we conclude that RQC treatment does not block metastases to the lung from this cancer cell variant.

The MDA-MB-435 cell line used in this study was selected as a bone metastatic variant by intracardiac injection in nude mice [33]. Since breast cancers preferentially metastasize to the bone [60], this trend was simulated by inoculating the MDA-MB-435 bone metastatic variant into the mammary fat pad. The ability of the GFP-MDA-MB-435 mammary tumors to invade bone was investigated by fluorescent image analysis of excised, cleaned femurs from mice
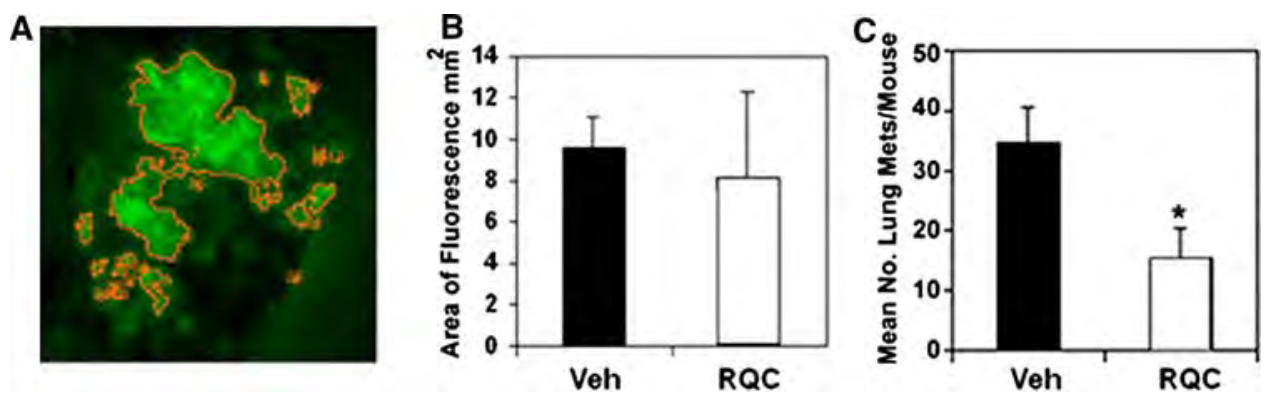

Fig. 5 Effect of grape polyphenols on lung metastasis. Following necropsy, lungs were excised from mice with GFP-MDA-MB-435 mammary tumors that received either vehicle or RQC diets and analyzed for metastases by fluorescence microscopy followed by quantitative image analysis. a Green fluorescence image of a representative lung demonstrating analysis of traced fluorescence area. b Lung metastatic efficiency expressed as average area of fluorescence from lungs of vehicle or RQC treated mice \pm SEM $(n=8)$. c Average number of fluorescent metastatic foci/lung for vehicle or RQC treated mice. Asterisk denotes statistical significance at $P<0.05$ 
Table 2 Distant metastases in mice following vehicle or combined resveratrol, quercetin, and catechin (RQC) treatment

\begin{tabular}{|c|c|c|c|c|}
\hline & \multicolumn{2}{|c|}{$\begin{array}{l}\text { Number of mice with } \\
\text { metastases }(N=8)\end{array}$} & \multicolumn{2}{|c|}{$\begin{array}{l}\text { Number of metastatic } \\
\text { lesions/organ with } \\
\text { metastases }\end{array}$} \\
\hline & Veh & RQC & Veh & RQC \\
\hline Bone & 5 & 2 & 11.4 & 3 \\
\hline Heart & 4 & 1 & 1.5 & 1 \\
\hline Kidney & 3 & 3 & 15.7 & 1.33 \\
\hline Liver & 8 & 2 & 22 & 11 \\
\hline Lung & 8 & 8 & 34.7 & 15.7 \\
\hline Lymph node & 3 & 3 & 2 & 1.7 \\
\hline
\end{tabular}

on vehicle control or RQC diets as described in [33]. In vehicle controls, $5 / 8$ mice presented with bone metastases while only $2 / 8$ mice following RQC treatment demonstrated fluorescent metastatic foci in femurs. Of the mice with bone metastases, the number of metastatic lesions were higher for vehicle treated mice compared to RQC treatments in a statistically significant manner (Fig. 6a, b; Table 2). Similarly, the number of mice with liver metastases and the number of metastatic lesions/liver were also significantly lower in RQC treated mice compared to vehicle controls (Fig. 6c, d; Table 2). The mean fluorescent area or integrated density for a single metastatic lesion were similar for bone or liver metastases from vehicle or RQC treated mice (data not shown); however, very few the RQC-treated mice presented bone or liver metastases and exhibited lower numbers of metastatic foci/organ.

Table 2 also shows that less RQC treated mice presented with heart metastases when compared to vehicle treated mice. However, the number of metastatic foci/heart in RQC treated mice was only slightly less when compared to vehicle. When kidneys were examined for metastases, the number of mice with kidney metastases did not change but there were more metastatic lesions/kidney in the vehicle treated mice. Only three mice for vehicle or RQC treatments demonstrated lymph node metastases. Since the numbers of mice with heart, kidney, or lymph node metastases were low even for vehicle treatments, it is not possible to analyze these results in a statistically significant manner or derive definitive conclusions on the effect of RQC treatment compared to controls.

To our knowledge, this is the first report of an inhibitory effect of grape polyphenols on breast cancer metastasis. The differential effects of RQC on site-specific metastases
Fig. 6 Effect of grape polyphenols on bone and liver metastasis. Following necropsy, femurs and livers were excised from mice with GFP-MDAMB-435 mammary tumors that received either vehicle or RQC diets and analyzed for metastases by fluorescence microscopy followed by quantitative image analysis. a Green fluorescence image of a representative femur from vehicle treated mouse. b Average number of fluorescent metastatic foci/femur for vehicle or RQC treated mice. c Green fluorescence image of a representative liver from vehicle treated mouse. d Average number of fluorescent metastatic foci/liver for vehicle or RQC treated mice. Asterisk denotes statistical significance at $P<0.05$

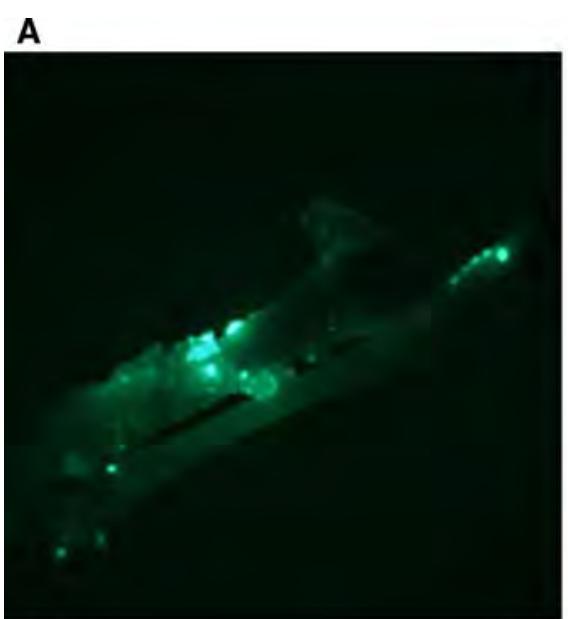

\section{B}

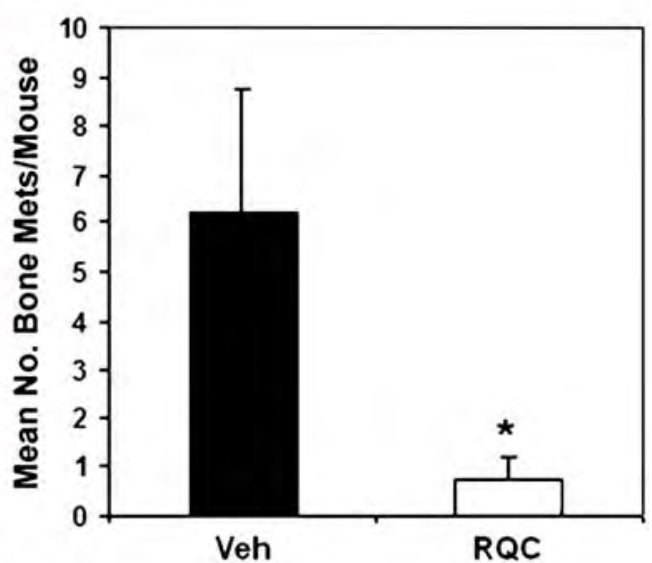

C

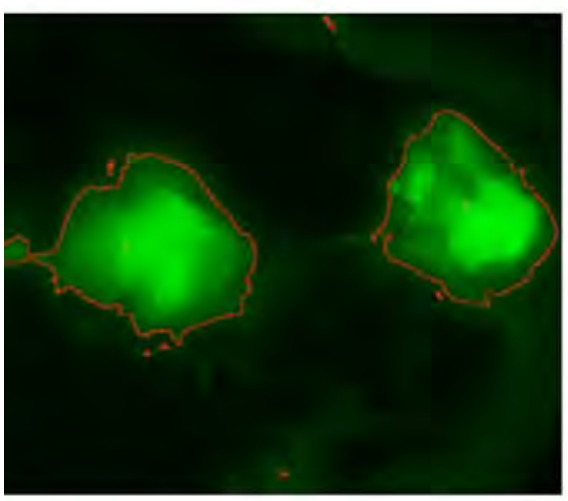

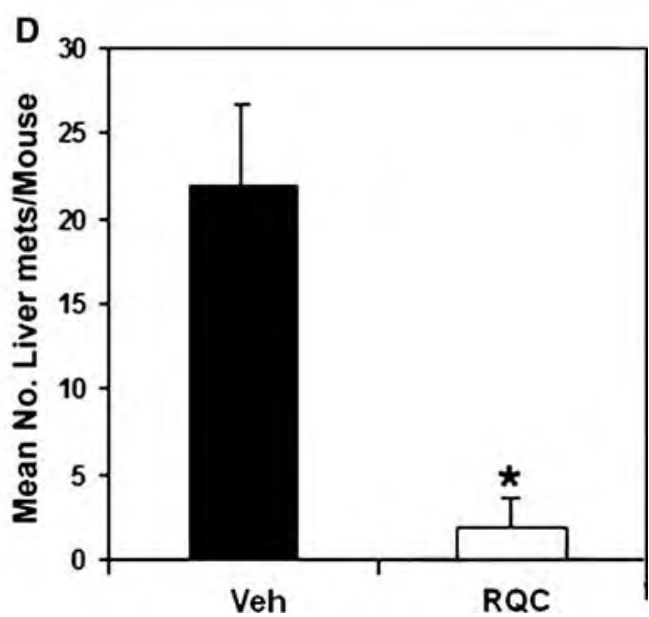


indicate that RQC treatment did not inhibit metastatic cancer cells from being released to the lymphatics or the vascular system from the primary tumors at the mammary fat pad. RQC treatment also did not block the entry of cells into the lungs, where all of the mice in the study presented with lung metastases. Interestingly, subsequent metastases to the bone and liver were reduced by RQC treatment, indicating that these compounds may affect establishment of further metastases either by regulation of exit from the lung vasculature or at the entry points of localized signaling at liver and bone microenvironments. Our intriguing data that demonstrates upregulation of NFKBIA levels in mammary tumors following RQC treatment implicates inhibition of $\mathrm{Nf} \kappa \mathrm{B}$ signaling by dietary grape polyphenols as a potential pathway that regulates breast cancer progression. Interestingly, $\mathrm{Nf} \kappa \mathrm{B}$ signaling has been associated with bone and liver metastasis [61-63]. The mechanistic basis for these interesting possibilities and the ability of grape polyphenols to specifically inhibit components of the bone and (or) liver molecular signature are currently under investigation.

Acknowledgments We acknowledge the excellent technical assistance of Alexander Schlachterman, Felix Valle, and Alina De La MotaPeynado with the animal protocols. This research was supported by grant numbers AICR IIG 03-31-06 and DoD/BCRP W81XWH-07-10330 to SD; DoD/BCRP W81XWH-08-01-0258 to LCP; NCCR/NIH 2G12RR003035, S06GM050695, and G11HD052352 to UCC; and NIH/RCMI G12-RR03051 and MBRS-RISE 5R25GM061838-08 to UPR-MSC. The content is solely the responsibility of the authors and does not necessarily represent the official views of NCRR, NICHD, NIGMS or the National Institutes of Health.

\section{References}

1. Schlachterman A, Valle F, Wall KM, Azios NG, Castillo L, Morell L, Washington AV, Cubano LA, Dharmawardhane SF (2008) Combined resveratrol, quercetin, and catechin treatment reduces breast tumor growth in a nude mouse model. Transl Oncol 1:19-27

2. Jemal A, Siegel R, Ward E, Hao Y, Xu J, Murray T, Thun MJ (2008) Cancer statistics, 2008. CA Cancer J Clin 58:71-96. doi: 10.3322/CA.2007.0010

3. Rastelli F, Crispino S (2008) Factors predictive of response to hormone therapy in breast cancer. Tumori 94:370-383

4. Peregrin T (2005) Wine-a drink to your health? J Am Diet Assoc 105:1053-1054. doi:10.1016/j.jada.2005.05.016

5. de Lorimier AA (2000) Alcohol, wine, and health. Am J Surg 180:357-361. doi:10.1016/S0002-9610(00)00486-4

6. Aggarwal BB, Shishodia S (2006) Molecular targets of dietary agents for prevention and therapy of cancer. Biochem Pharmacol 71:1397-1421. doi:10.1016/j.bcp.2006.02.009

7. Park EJ, Pezzuto JM (2002) Botanicals in cancer chemoprevention. Cancer Metastasis Rev 21:231-255. doi:10.1023/A:1021254 725842

8. Damianaki A, Bakogeorgou E, Kampa M, Notas G, Hatzoglou A, Panagiotou S, Gemetzi C, Kouroumalis E, Martin PM, Castanas E (2000) Potent inhibitory action of red wine polyphenols on human breast cancer cells. J Cell Biochem 78:429-441. doi:10.1002/ 1097-4644(20000901)78:3<429::AID-JCB8>3.0.CO;2-M

9. Hakimuddin F, Paliyath G, Meckling K (2004) Selective cytotoxicity of a red grape wine flavonoid fraction against MCF-7 cells. Breast Cancer Res Treat 85:65-79. doi:10.1023/B: BREA.0000021048.52430.c0

10. Faustino RS, Sobrattee S, Edel AL, Pierce GN (2003) Comparative analysis of the phenolic content of selected Chilean, Canadian and American Merlot red wines. Mol Cell Biochem 249:11-19. doi:10.1023/A:1024745513314

11. Nigdikar SV, Williams NR, Griffin BA, Howard AN (1998) Consumption of red wine polyphenols reduces the susceptibility of low-density lipoproteins to oxidation in vivo. Am J Clin Nutr 68:258-265

12. Delmas D, Lancon A, Colin D, Jannin B, Latruffe N (2006) Resveratrol as a chemopreventive agent: a promising molecule for fighting cancer. Curr Drug Targets 7:423-442. doi:10.2174/ 138945006776359331

13. Busquets S, Ametller E, Fuster G, Olivan M, Raab V, Argiles JM, Lopez-Soriano FJ (2007) Resveratrol, a natural diphenol, reduces metastatic growth in an experimental cancer model. Cancer Lett 245:144-148. doi:10.1016/j.canlet.2005.12.035

14. Jeong JH, An JY, Kwon YT, Li LY, Lee YJ (2008) Quercetininduced ubiquitination and down-regulation of Her-2/neu. J Cell Biochem 105:585-595. doi:10.1002/jcb.21859

15. Yilmaz Y, Toledo RT (2004) Major flavonoids in grape seeds and skins: antioxidant capacity of catechin, epicatechin, and gallic acid. J Agric Food Chem 52:255-260. doi:10.1021/jf030117h

16. Ebeler SE, Brenneman CA, Kim GS, Jewell WT, Webb MR, Chacon-Rodriguez L, MacDonald EA, Cramer AC, Levi A, Ebeler JD, Islas-Trejo A, Kraus A, Hinrichs SH, Clifford AJ (2002) Dietary catechin delays tumor onset in a transgenic mouse model. Am J Clin Nutr 76:865-872

17. Gescher AJ, Steward WP (2003) Relationship between mechanisms, bioavailability, and preclinical chemopreventive efficacy of resveratrol: a conundrum. Cancer Epidemiol Biomark Prev 12:953-957

18. Soleas GJ, Grass L, Josephy PD, Goldberg DM, Diamandis EP (2002) A comparison of the anticarcinogenic properties of four red wine polyphenols. Clin Biochem 35:119-124. doi:10.1016/ S0009-9120(02)00275-8

19. Meng X, Maliakal P, Lu H, Lee MJ, Yang CS (2004) Urinary and plasma levels of resveratrol and quercetin in humans, mice, and rats after ingestion of pure compounds and grape juice. J Agric Food Chem 52:935-942. doi:10.1021/jf030582e

20. Manach C, Williamson G, Morand C, Scalbert A, Remesy C (2005) Bioavailability and bioefficacy of polyphenols in humans. I. Review of 97 bioavailability studies. Am J Clin Nutr 81:230S$242 \mathrm{~S}$

21. Nifli AP, Kampa M, Alexaki VI, Notas G, Castanas E (2005) Polyphenol interaction with the T47D human breast cancer cell line. J Dairy Res 72 Spec No:44-50. doi:10.1017/S0022029 905001172

22. Kim YA, Choi BT, Lee YT, Park DI, Rhee SH, Park KY, Choi YH (2004) Resveratrol inhibits cell proliferation and induces apoptosis of human breast carcinoma MCF-7 cells. Oncol Rep $11: 441-446$

23. Gulati N, Laudet B, Zohrabian VM, Murali R, Jhanwar-Uniyal M (2006) The antiproliferative effect of Quercetin in cancer cells is mediated via inhibition of the PI3K-Akt/PKB pathway. Anticancer Res 26:1177-1181

24. Whitsett T, Carpenter M, Lamartiniere CA (2006) Resveratrol, but not EGCG, in the diet suppresses DMBA-induced mammary cancer in rats. J Carcinog 5:15-25. doi:10.1186/1477-3163-5-15

25. Garvin S, Ollinger K, Dabrosin C (2006) Resveratrol induces apoptosis and inhibits angiogenesis in human breast cancer 
xenografts in vivo. Cancer Lett 231:113-122. doi:10.1016/j. canlet.2005.01.031

26. Dechsupa S, Kothan S, Vergote J, Leger G, Martineau A, Beranger S, Kosanlavit R, Moretti JL, Mankhetkorn S (2007) Quercetin, Siamois 1 and Siamois 2 induce apoptosis in human breast cancer MDA-MB-435 cells xenograft in vivo. Cancer Biol Ther 6:56-61

27. Cao Y, Cao R, Brakenhielm E (2002) Antiangiogenic mechanisms of diet-derived polyphenols. J Nutr Biochem 13:380-390. doi:10.1016/S0955-2863(02)00204-8

28. Baur JA, Sinclair DA (2006) Therapeutic potential of resveratrol: the in vivo evidence. Nat Rev Drug Discov 5:493-506. doi: $10.1038 / \mathrm{nrd} 2060$

29. Bhat KP, Lantvit D, Christov K, Mehta RG, Moon RC, Pezzuto JM (2001) Estrogenic and antiestrogenic properties of resveratrol in mammary tumor models. Cancer Res 61:7456-7463

30. Azios NG, Dharmawardhane SF (2005) Resveratrol and estradiol exert disparate effects on cell migration, cell surface actin structures, and focal adhesion assembly in MDA-MB-231 human breast cancer cells. Neoplasia (New York, NY) 7:128-140. doi: 10.1593/neo.04346

31. Azios NG, Krishnamoorthy L, Harris M, Cubano LA, Cammer M, Dharmawardhane SF (2007) Estrogen and resveratrol regulate Rac and Cdc42 signaling to the actin cytoskeleton of metastatic breast cancer cells. Neoplasia (New York, NY) 9:147-158. doi: 10.1593/neo.06778

32. Mundy GR (2002) Metastasis to bone: causes, consequences and therapeutic opportunities. Nat Rev Cancer 2:584-593. doi: $10.1038 / \mathrm{nrc} 867$

33. Phadke PA, Mercer RR, Harms JF, Jia Y, Frost AR, Jewell JL, Bussard KM, Nelson S, Moore C, Kappes JC, Gay CV, Mastro AM, Welch DR (2006) Kinetics of metastatic breast cancer cell trafficking in bone. Clin Cancer Res 12:1431-1440. doi: 10.1158/1078-0432.CCR-05-1806

34. Krajewski S, Krajewska M, Turner BC, Pratt C, Howard B, Zapata JM, Frenkel V, Robertson S, Ionov Y, Yamamoto H, Perucho M, Takayama S, Reed JC (1999) Prognostic significance of apoptosis regulators in breast cancer. Endocr Relat Cancer 6:29-40. doi:10.1677/erc.0.0060029

35. Fu Z, Tindall DJ (2008) FOXOs, cancer and regulation of apoptosis. Oncogene 27:2312-2319. doi:10.1038/onc.2008.24

36. Cortes SM, Rodriguez FV, Sanchez PI, Perona R (2008) The role of the NFkappaB signalling pathway in cancer. Clin Transl Oncol 10:143-147. doi:10.1007/s12094-008-0171-3

37. Welch DR, Harms JF, Mastro AM, Gay CV, Donahue HJ (2003) Breast cancer metastasis to bone: evolving models and research challenges. J Musculoskelet Neuronal Interact 3:30-38

38. Price JE, Polyzos A, Zhang RD, Daniels LM (1990) Tumorigenicity and metastasis of human breast carcinoma cell lines in nude mice. Cancer Res 50:717-721

39. Vantyghem SA, Wilson SM, Postenka CO, Al-Katib W, Tuck $\mathrm{AB}$, Chambers AF (2005) Dietary genistein reduces metastasis in a postsurgical orthotopic breast cancer model. Cancer Res 65:3396-3403

40. Singh RP, Deep G, Blouin MJ, Pollak MN, Agarwal R (2007) Silibinin suppresses in vivo growth of human prostate carcinoma PC-3 tumor xenograft. Carcinogenesis 28:2567-2574. doi: 10.1093/carcin/bgm218

41. Singh RP, Tyagi A, Sharma G, Mohan S, Agarwal R (2008) Oral silibinin inhibits in vivo human bladder tumor xenograft growth involving down-regulation of survivin. Clin Cancer Res 14:300308. doi:10.1158/1078-0432.CCR-07-1565

42. Carlson AL, Hoffmeyer MR, Wall KM, Baugher PJ, RichardsKortum R, Dharmawardhane SF (2006) In situ analysis of breast cancer progression in murine models using a macroscopic fluorescence imaging system. Lasers Surg Med 38:928-938. doi: $10.1002 / 1 \mathrm{sm} .20409$

43. Lacroix M (2009) MDA-MB-435 cells are from melanoma, not from breast cancer. Cancer Chemother Pharmacol 63:567. doi: 10.1007/s00280-008-0776-9

44. Sellappan S, Grijalva R, Zhou X, Yang W, Eli MB, Mills GB, Yu D (2004) Lineage infidelity of MDA-MB-435 cells: expression of melanocyte proteins in a breast cancer cell line. Cancer Res 64:3479-3485. doi:10.1158/0008-5472.CAN-3299-2

45. Price JE, Zhang RD (1990) Studies of human breast cancer metastasis using nude mice. Cancer Metastasis Rev 8:285-297. doi:10.1007/BF00052605

46. Frojdo S, Cozzone D, Vidal H, Pirola L (2007) Resveratrol is a class IA phosphoinositide 3-kinase inhibitor. Biochem J 406:511518. doi:10.1042/BJ20070236

47. Koh SH, Kim SH, Kwon H, Park Y, Kim KS, Song CW, Kim J, Kim MH, Yu HJ, Henkel JS, Jung HK (2003) Epigallocatechin gallate protects nerve growth factor differentiated PC12 cells from oxidative-radical-stress-induced apoptosis through its effect on phosphoinositide 3-kinase/Akt and glycogen synthase kinase3. Brain Res Mol Brain Res 118:72-81. doi:10.1016/j. molbrainres.2003.07.003

48. Cantley LC (2004) The role of phosphoinositide 3-kinase in human disease. Harvey Lect 100:103-122

49. Su JL, Yang CY, Zhao M, Kuo ML, Yen ML (2007) Forkhead proteins are critical for bone morphogenetic protein-2 regulation and anti-tumor activity of resveratrol. J Biol Chem 282:1938519398. doi:10.1074/jbc.M702452200

50. Terra X, Valls J, Vitrac X, Merrillon JM, Arola L, Ardevol A, Blade C, Fernandez-Larrea J, Pujadas G, Salvado J, Blay M (2007) Grape-seed procyanidins act as antiinflammatory agents in endotoxin-stimulated RAW 264.7 macrophages by inhibiting NFkB signaling pathway. J Agric Food Chem 55:4357-4365. doi: 10.1021/jf0633185

51. Pozo-Guisado E, Merino JM, Mulero-Navarro S, LorenzoBenayas MJ, Centeno F, Alvarez-Barrientos A, Salguero PM (2005) Resveratrol-induced apoptosis in MCF-7 human breast cancer cells involves a caspase-independent mechanism with downregulation of Bcl-2 and NF-kappaB. Int J Cancer 115:74 84. doi:10.1002/ijc. 20856

52. Bhardwaj A, Sethi G, Vadhan-Raj S, Bueso-Ramos C, Takada Y, Gaur U, Nair AS, Shishodia S, Aggarwal BB (2007) Resveratrol inhibits proliferation, induces apoptosis, and overcomes chemoresistance through down-regulation of STAT3 and nuclear factorkappaB-regulated antiapoptotic and cell survival gene products in human multiple myeloma cells. Blood 109:2293-2302. doi: 10.1182/blood-2006-02-003988

53. Garcia-Mediavilla V, Crespo I, Collado PS, Esteller A, SanchezCampos S, Tunon MJ, Gonzalez-Gallego J (2007) The antiinflammatory flavones quercetin and kaempferol cause inhibition of inducible nitric oxide synthase, cyclooxygenase- 2 and reactive C-protein, and down-regulation of the nuclear factor kappaB pathway in Chang Liver cells. Eur J Pharmacol 557:221-229. doi: 10.1016/j.ejphar.2006.11.014

54. Wolska A, Lech-Marańda E, Robak T (2008) Toll-like receptors and their role in carcinogenesis and anti-tumor treatment. Cell Mol Biol Lett. doi:10.2478/s11658-008-0048-z

55. Fukao T, Koyasu S (2003) PI3K and negative regulation of TLR signaling. Trends Immunol 24:358-363. doi:10.1016/S14714906(03)00139-X

56. Martinez C, Vicente V, Yanez J, Alcaraz M, Castells MT, Canteras M, Benavente-Garcia O, Castillo J (2005) The effect of the flavonoid diosmin, grape seed extract and red wine on the pulmonary metastatic B16F10 melanoma. Histol Histopathol 20:1121-1129 
57. Singh RP, Tyagi AK, Dhanalakshmi S, Agarwal R, Agarwal C (2004) Grape seed extract inhibits advanced human prostate tumor growth and angiogenesis and upregulates insulin-like growth factor binding protein-3. Int J Cancer 108:733-740. doi: 10.1002/ijc. 11620

58. Kim H, Hall P, Smith M, Kirk M, Prasain JK, Barnes S, Grubbs C (2004) Chemoprevention by grape seed extract and genistein in carcinogen-induced mammary cancer in rats is diet dependent. $\mathbf{J}$ Nutr 134:3445S-3452S

59. Morre DM, Morre DJ (2006) Anticancer activity of grape and grape skin extracts alone and combined with green tea infusions. Cancer Lett 238:202-209. doi:10.1016/j.canlet.2005.07.011

60. Kapoor P, Suva LJ, Welch DR, Donahue HJ (2008) Osteoprotegrin and the bone homing and colonization potential of breast cancer cells. J Cell Biochem 103:30-41. doi:10.1002/jcb.21382
61. Ignatoski KM, Escara-Wilke JF, Dai JL, Lui A, Dougall W, Daignault S, Yao Z, Zhang J, Day ML, Sargent EE, Keller ET (2008) RANKL inhibition is an effective adjuvant for docetaxel in a prostate cancer bone metastases model. Prostate 68:820-829. doi:10.1002/pros.20744

62. Cicek M, Oursler MJ (2006) Breast cancer bone metastasis and current small therapeutics. Cancer Metastasis Rev 25:635-644. doi:10.1007/s10555-006-9035-x

63. Meir T, Dror R, Yu X, Qian J, Simon I, Pe'er J, Chowers I (2007) Molecular characteristics of liver metastases from uveal melanoma. Invest Ophthalmol Vis Sci 48:4890-4896. doi:10.1167/iovs.07-0215 